\title{
通过环加成反应和串联反应构建桥环化合物的研究进展
}

\author{
王乐乐 ${ }^{a} \quad$ 张子莹 $^{a} \quad$ 韩华涁 $^{a}$ 刘雄利 ${ }^{b}$ \\ 卜站伟 $a$ 王琪琳*,a \\ ( ${ }^{a}$ 河南大学化学化工学院 河南开封 475004)

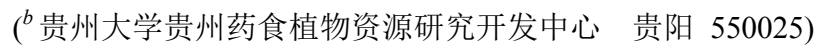

\begin{abstract}
摘要 桥环化合物广泛存在于天然产物和具有重要生理活性的分子中, 在药物化学、天然产物化学、合成化学、材料 化学及生命科学等领域具有重要的应用价值. 近年来, 经过广大化学工作者的不解努力, 已发展了系列高效构建桥环 化合物的新方法. 从环加成反应和串联反应两种策略出发, 详细介绍近五年来用于构建桥环化合物的方法及最新研究 进展，简要分析目前方法的优势及存在的问题，以期为从事有机合成及相关领域的研究者提供有益借鉴和参考.

关键词＼cjkstart桥环化合物; 环加成; 串联反应
\end{abstract}

\section{Recent Advances in the Construction of Bridged Rings through Cycloadditions and Cascade Reactions}

\author{
Wang, Lele ${ }^{a}$ \\ Zhang, Ziying ${ }^{a}$ \\ Han, Huabin ${ }^{a}$ \\ Liu, Xiongli ${ }^{b}$ \\ $\mathrm{Bu}$, Zhanwei $^{a}$ \\ Wang, Qilin*,a \\ ( ${ }^{a}$ College of Chemistry and Chemical Engineering, Henan University, Kaifeng, Henan 475004) \\ ( ${ }^{b}$ Guizhou Medicine Edible Plant Resources Research and Development Center, Guizhou University, Guiyang 550025)
}

\begin{abstract}
Bridged rings are frequently encountered in natural products and biologically active molecules, which have significant application in the field of medicinal chemistry, natural product chemistry, synthetic chemistry, material chemistry and life science. In recent years, with the unremitting efforts of a large number of chemists, a series of new methods have been developed for the efficient synthesis of bridged compounds. The detailed synthetic methods to access bridged compounds in the past five years involving cycloadditions and cascade reactions are summarized, and the advantages and problems of the current methods are briefly analyzed, which would provide useful reference for the researchers engaged in organic synthesis and related fields.

Keywords bridged ring; cycloaddition; cascade reaction
\end{abstract}

桥环化合物广泛存在于天然产物当中，同时还是合 成许多重要天然产物和药物的关键中间体, 在人类生命 活动中扮演着重要的作用, 具有抗肿瘤、抗辐射、抗氧 化、抗癌、镇痛、镇静和止咳等活性(图 1) ${ }^{[1]}$. 例如, 紫 丹参萜醚(przewalskin) ${ }^{[2]}$ 、鼠尾草酚(carnosol) ${ }^{[3]}$ 和吗啡 (morphine)等均具有桥环结构单元. $( \pm)$-lingzhiol 是从灵 芝(Ganoderma lucidum) 中分离得到的, 具有抗癌及抗病 毒活性, 可以用来保护肾脏 ${ }^{[4]}$. Actinophyllic acid 是从鸭 脚木的树叶中分离得到的, 可用作羧肽酶抑制剂 ${ }^{[5]}$.
桥环化合物通常具有合成难度大的复杂的刚性桥 环结构, 具有较大的角张力和环张力, 反应的成键效率 是合成挑战之一. 另外，桥环化合物空间结构复杂，常 含有多个手性中心, 无其是桥头手性中心，因此，立体 化学控制也是时常面临的问题. 鉴于(杂)桥环化合物具 有极其重要的药用价值, 发展高效、高选择性的合成结 构新䓉、高附加值的桥环化合物的方法对药物化学和合 成化学等均具有重要的研究意义和应用价值, 也逐渐成 为广大化学工作者研究的热门课题. 近年来, 经过广大

\footnotetext{
* Corresponding author. E-mail: wangqilin@henu.edu.cn

Received July 18, 2020; revised August 29, 2020; published online September 15, 2020.

Project supported by the National Natural Science Foundation of China (No. U1504206), the China Postdoctoral Science Foundation (No. 2020M672200) and the Henan University (Nos. SYL19060137, SYL19030204).

国家自然科学基金(No. U1504206)、中国博士后科学基金(No. 2020M672200)和河南大学(Nos. SYL19060137, SYL19030204)资助项目.
} 


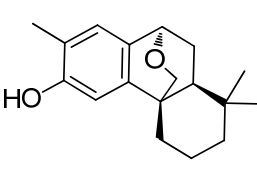

Przewalskin

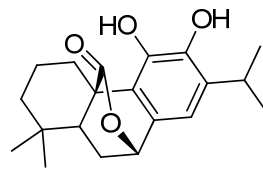

Carnosol

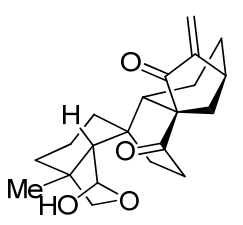

Shikodonin

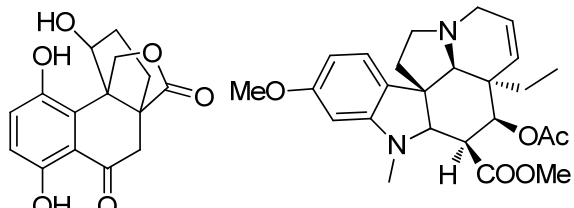

Vindoline

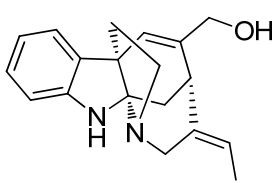

Minfiensine

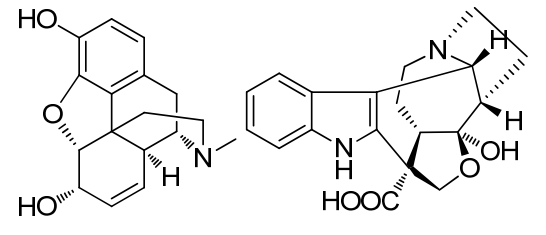

Morphine Actinophyllic acid

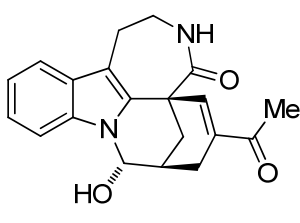

Tronocarpine

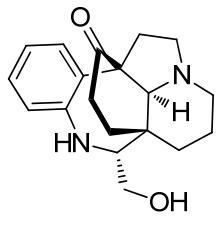

Hunterine A

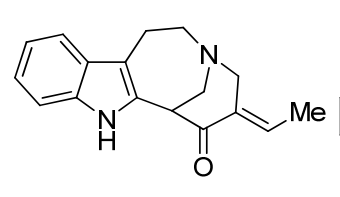

Subincanadine F

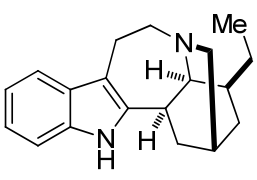

Ibogamine

图 1 几种重要的含桥环骨架的天然产物及药物

Figure 1 Some important natural products and pharmaceuticals containing bridged rings

化学工作者的不解努力, 在桥环化合物的构筑方面已取 得重要研究进展. 虽然, Bera 等 ${ }^{[6]} 2018$ 年对桥环缩酮骨 架的合成方法进行了总结; 2013 年和 2018 年贾彦兴课 题组 ${ }^{[7]}$ 分别对 3,4-桥环吲哚类生物碱的全合成进行了综 述; 李闯创课题组 ${ }^{[8]}$ 最近对环加成反应在桥环天然产物 全合成中的应用进行了介绍, 但是, 它们都集中于对特 定桥环骨架化合物的总结. 目前尚无相关有机合成方法 学方面的专题综述对其进行归纳总结. 随着最近几年桥 环化合物合成的新方法和新策略越来越多, 以及该类化 合物在生命活动中的重要应用, 因此, 很有必要对桥环 化合物的合成方法进行梳理总结, 分析目前方法的优势 及存在的问题, 以期为从事有机合成及相关领域的研究 者提供有益借鉴和参考. 本文将主要根据近五年来发展 的合成桥环化合物的反应类型, 分别对环加成([3+2]、 $[3+3] 、[4+2] 、[4+3] 、[4+4] 、[5+2] 、[5+3] 、[5+$ 4])和串联反应两种合成策略进行综述, 并分析这些反 应体系的特点和反应机理.

\section{1 环加成策略构建桥环化合物}

环加成反应是构建桥环化合物最有效、最直接的手 段之一, 可以在有效构建多个化学键的同时合成结构刚 性、立体化学复杂的桥环化合物 ${ }^{[9]}$. 近年来, 该策略受到 国内外化学家的广泛关注并得以迅速发展, 且已被成功 用于一些具有桥环结构的天然产物的全合成中. 目前发 展的构建桥环化合物的环加成模式主要有预先制备或 原位生成的亚胺叶立德作为三原子合成子发生的 $[3+n]$ 反应、电性匹配的 “双亲电” 试剂与 “双亲核” 试剂或 “亲核一亲电” 试剂与 “亲电-亲核” 试剂发生的形式 $[m+n]$ 反应以及双烯体发生的 $[4+n]$ 反应. 下面我们将 从成环大小的角度出发, 详细介绍近五年来 $[3+2] 、[3+$ $3] 、[4+2] 、[4+3] 、[4+4] 、[5+2] 、[5+3] 、[5+4]$ 等 环加成方法在构建桥环化合物方面的研究进展.

\section{$1.1[3+2]$ 环加成反应构建桥环化合物}

托品烷是很多天然产物的核心结构, 在治疗神经病 和精神病上有很好的疗效 ${ }^{[10]}$. 因此, 发展一种高效的方 法来合成该类化合物具有重要的研究意义. 2013 年, Waldmann 课题组 ${ }^{[11]}$ 以一价铜为催化剂, 开发了色氨酸 衍生的亚胺叶立德 $\mathbf{1}$ 与硝基烯 $\mathbf{2}$ 参与的不对称 $[3+2]$ 环 加成反应, 以不错的收率(up to $91 \%$ )和优秀的对映选择 性(up to 96\%)得到了手性托品烷类化合物 3 (Scheme 1). 最近, 郭海明课题组 ${ }^{[12]}$ 采用不对称去芳构化的策略, 实 现了色氨酸衍生的亚胺叶立德 1 与 2-硝基苯并呋喃 4 参 与的不对称 $[3+2]$ 环加成反应. 在 $\mathrm{Cu}(\mathrm{II}) / \mathbf{6}$ 的催化下, 以 高达 $91 \%$ 的收率和高达 $98 \%$ 的对映选择性实现了托品 烷桥环多环 5 的高效立体选择性合成(Scheme 2).
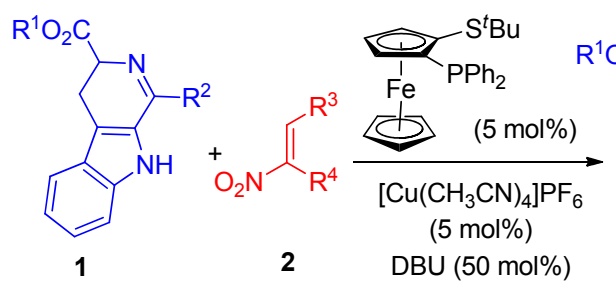

DBU $(50 \mathrm{~mol} \%)$<smiles>[R]C1[C@]2(C(=O)[O-])Cc3c([nH]c4ccccc34)[C@]([R])(N[C@@]1([R])[N+](=O)[O-])[C@H]2[R]</smiles>

23 examples up to $91 \%$ yield up to $96 \%$ ee<smiles>CCOC[C@]1(C)Cc2c([nH]c3ccccc23)[C@](C)([C@H](c2ccccc2)[C@@H](c2ccccc2)[N+](=O)[O-])N1</smiles>

$75 \%$ yield, $87 \%$ ee

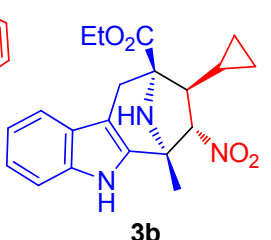

3b

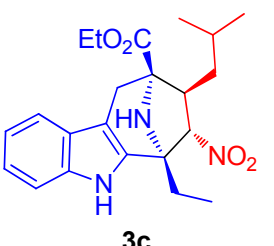

$3 c$
$86 \%$ yield, $91 \%$ ee $\quad 76 \%$ yield, $85 \%$ ee

图式 1 色氨酸衍生物与硝基烯参与的不对称 $[3+2]$ 环加成反 应

Scheme 1 Asymmetric [3+2] cycloaddition of tryptophan derivatives with nitrostyrene 


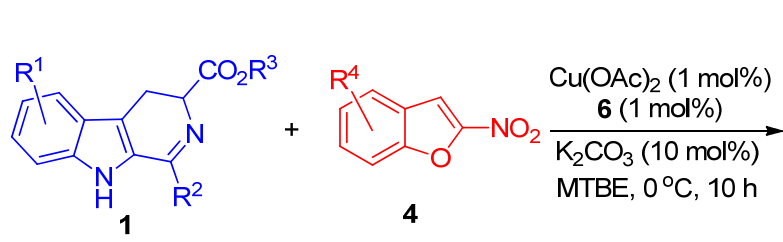

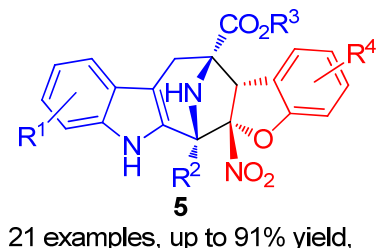

21 examples, up to $91 \%$ yield, up to $98 \%$ ee

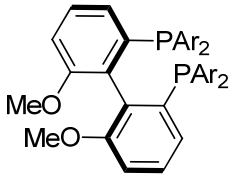

$\mathrm{Ar}=3,4,5-(\mathrm{MeO})_{3} \mathrm{C}_{6} \mathrm{H}_{2}$

6

Selected examples<smiles>CC(=O)[C@@]12Cc3c([nH]c4ccc(C)cc34)[C@](C)(N1)[C@@]1([N+](=O)[O-])Oc3ccccc3[C@H]21</smiles>

$5 \mathbf{a}$

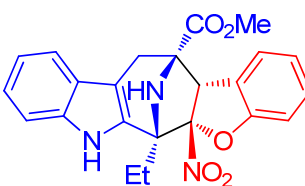

$5 b$

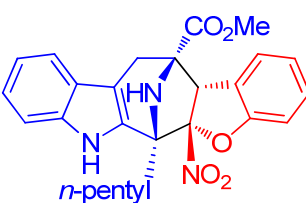

$5 c$

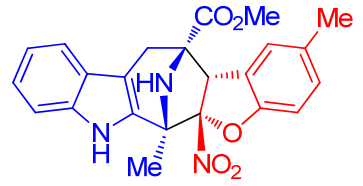

5d

$85 \%$ yield, $16: 1 d r, 95 \%$ ee

$83 \%$ yield, $14: 1 d r, 94 \%$ ee

$77 \%$ yield, $11: 1 d r, 90 \%$ ee

$83 \%$ yield, $14: 1 d r, 94 \%$ ee

图式 2 色氨酸衍生的亚胺叶立德与 2-硝基苯并呋喃参与的不对称去芳构化的 [3+2]环加成反应

Scheme 2 Asymmetric dearomative [3+2] cycloadditions of tryptophan-derived imine ylides with 2-nitrobenzofurans

2018 年, Waldmann 课题组 ${ }^{[13]}$ 通过双金属 “接力” 催化合成策略, 发展了酰基重氮 7 与 3-烯氧化吲哚 8 的
不对称 $[3+2]$ 环加成反应, 高效地构筑了具有托品烷骨 架的手性螺环桥环氧化吲哚 10 (Scheme 3). 首先, 酰基

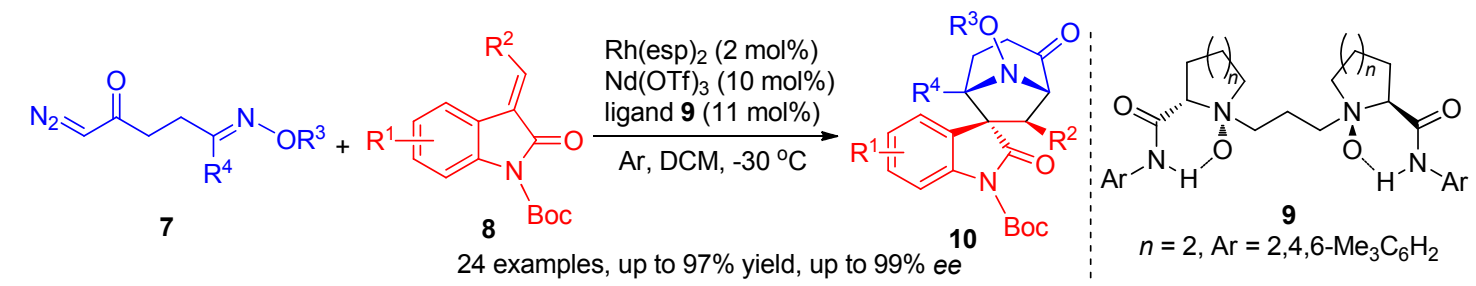

Selected examples<smiles>COC(=O)C1C(C)C2(C)CC(=O)N(C)C12C(=O)Nc1ccccc1</smiles>

$10 \mathrm{a}$<smiles>COC1C(=O)C2C(C#N)C(C)(C)N1C21C(=O)Nc2ccc(C)cc21</smiles>

Boc

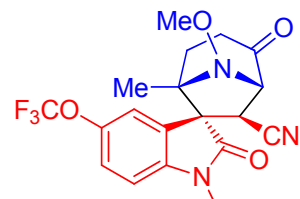

Boc

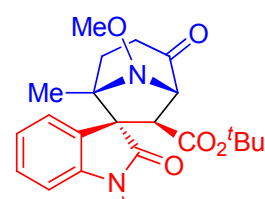

Boc

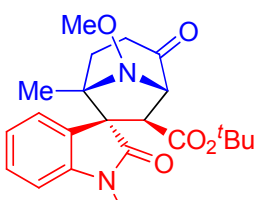

Boc

97\%, 13.1:1 dr, 97\% ee $\quad 96 \%, 14.0: 1 d r, 97 \%$ ee $\quad 89 \%, 3.2: 1 d r, 81 \%$ ee $\quad 96 \%, 4.2: 1 d r, 87 \%$ ee $\quad 54 \%,>20: 1 d r, 77 \%$ ee

Postulated mechanism

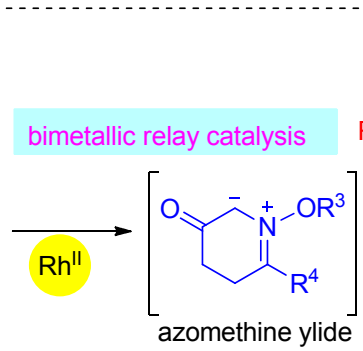

11

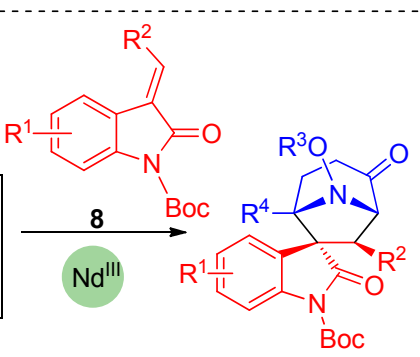

Unsuccessful substrates<smiles>CCOC(=O)C(=O)CC/C=N/OC</smiles><smiles>CON=C(C)C(C)(C)C(=O)C=N</smiles><smiles>CN=CCCCC(=O)CCC(C)=NC</smiles><smiles>CON(C)c1ccccc1C(=O)C=N</smiles><smiles>O=C(C=CC=[V])n1ccoc1=O</smiles><smiles>COC(=O)c1cc2ccccc2oc1=O</smiles><smiles>CC1C=CC(=O)N1C</smiles>
$\mathrm{Ph} \curvearrowright \mathrm{NO}_{2}$

图式 3 双金属 “接力” 催化构建螺托品烷骨架氧化吲哚

Scheme 3 Bimetallic relay catalysis for the construction of spirotropanyl oxindoles 
重氮 7 在金属铑的作用下, 原位形成亚胺叶立德 11, 随 后与 3-烯氧化吲哚 8 在手性路易斯酸催化下发生 1,3偶极环加成反应, 得到目标产物 10. 该反应 “一锅” 双金属接力催化, 操作简便, 并且有较高的对映选择 性(upto 99\%)和优秀的收率(up to 97\%). 值得说明的 是，该反应仅限于形成六元环状的亚胺叶立德前体， 而形成五元环和七元环亚胺叶立德的重氮化合物不 能参与反应. 另外, 亲偶极子的范围也较为受限, 马 来酰亚胺及硝基烯等均不能参与该反应. 2019 年, Suga 课题组 ${ }^{[14]}$ 采用相同的合成策略, 通过原位生成的 亚胺叶立德 13 与 Michael 受体 14 发生不对称 $[3+2]$ 环 加成反应, 高效地合成了系列 8-氮杂双环 [3.2.1]辛烷 15 (Scheme 4).

2017 年, 胡文浩课题组 ${ }^{[15]}$ 开发了重氮化合物 18、 芳胺 19 和喹啉盐 20 的三组分反应. 在钯的催化下, 重 氮化合物 18 和芳胺 19 形成具有双亲核性质的金属铵盐 叶立德, 随后与 $N$-烷基活化的喹啉盐 20 发生 $[3+2]$ 环加 成反应, 以不错的收率得到系列桥环四氢喹啉 21 (Scheme 5). 美中不足的是, 该反应的非对映选择性较 差. 且芳环上无取代的喹啉盐不能参与该反应, 作者认 为可能是由于无取代喹啉盐在二氯甲烷中溶解性较差 导致的. 此外, 作者通过在喹啉盐 C-3 位引入酯基吸电 子基, 得到了 C-4 位单功能化的产物 22. 根据控制实验, 作者提出了三组分反应的机理. 首先, 重氮化合物在过 渡金属 $\mathrm{Pd}$ 作用下形成金属卡宾 $\mathbf{A}$, 金属卡宾被伯胺亲 核进攻得到氮杂金属叶立德 $(\mathbf{B}$ 和 $\mathbf{C})$, 该叶立德具有双 亲核特性, 通过与喹啉盐发生加成反应, 得到 C-4 位功 能化的 1,4-二氢喹啉 22 . 当 22 的 C-3 位无取代基时, 可
进一步发生环化串联反应得到桥环产物 21. 由于 1,4-二 氢喹啉 22 的 C-3 位存在酯基，可稳定烯胺结构，导致后 续的分子内环化不能进行(Scheme 5).

2020 年, Dixon 课题组 ${ }^{[16]}$ 开发了可见光催化的亚胺 23 与喹啉 24 的[3+2]环加成反应，以 $40 \% \sim 94 \%$ 的收率 合成了系列 $N, N$-缩酮类桥环四氢喹啉 25 (Scheme 6). 在 该反应中，亚胺 23 首先与汉斯酯反应生成 $\alpha$-氨基烷基 自由基, 随后和喹啉 24 发生[3+2]环加成反应, 得到含 氮桥环化合物 25. 该反应并不仅仅局限于喹啉, $N$-苄基 活化的喹啉盐也能高效地参与该反应，以 $51 \%$ 的收率和 1：1 的非对映选择性得到 $\mathbf{2 5 b}$. 此外, 芳香醛也可以参 与该反应. 需要强调的是, 当以醛 $26 \mathrm{a}$ 作为底物时, 2 equiv. 的 4-甲基喹啉(24a)参与了反应，生成了更复杂的 双桥环化合物 $27 \mathbf{a}$, 进一步拓宽了该合成方法的应用范 围.

活化的异喹啉也可经过自由基环化反应用于构建 含氮桥环化合物. 2019 年, 江智勇课题组 ${ }^{[17]}$ 利用自主研 发的双氰基吡嗪衍生的发色团(DPZ)光催化剂, 在蓝光 的照射下，实现了 $N$-芳基- $\alpha$-氨基酸 28 与异喹啉氮氧化 物 29 的[3+2]环加成反应(Scheme 7). 该反应经历自由 基过程，无需过渡金属催化，并且首次在有机合成中将 $N$-芳基- $\alpha$-氨基酸 28 作为 1,2-合成子. 作者通过 Stern-Volmer 控制实验，提出了反应可能的机理：首先， $N$-芳基- $\alpha$-氨基酸 28 经单电子氧化脱羧, 生成烷基自由 基 $\mathbf{A}$; 随后 $\mathbf{A}$ 与异喹啉氮氧化物 29 发生自由基加成反 应，得到烯胺中间体 $\mathbf{B}$ ，再经电子转移及分子内 Mannich 反应，最终以较高的收率(up to $95 \%$ )得到桥环 产物 30.

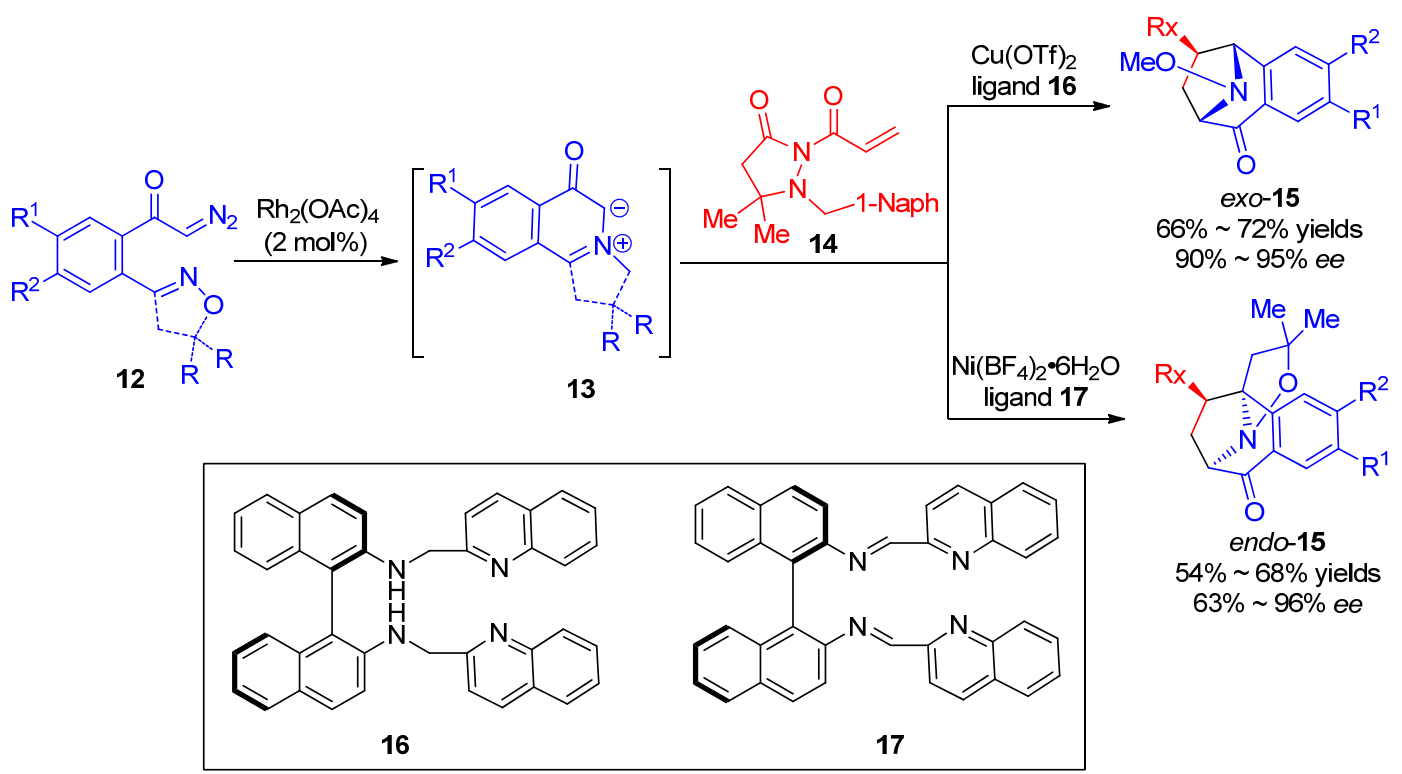

图式 4 环状亚胺叶立德的不对称 [3+2]环加成反应构建氮杂双环 [3.2.1]辛烷

Scheme 4 Asymmetric 1,3-dipolar cycloadditions of cyclic azomethine ylides for the synthesis of chiral 8-azabicyclo[3.2.1] octanes 


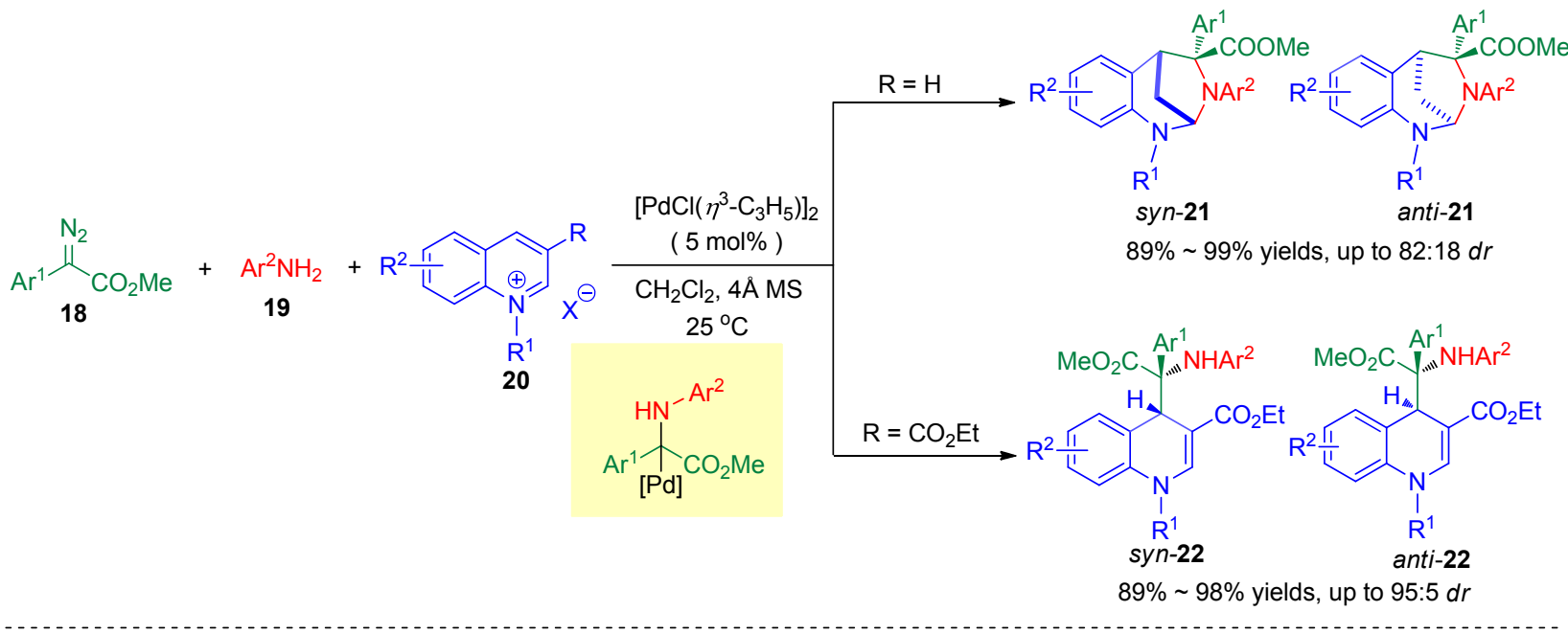

Selected examples<smiles>COc1ccc2c(c1)C1CC(C(C(=O)Oc3ccccc3)C1c1ccccc1)N2c1ccccc1</smiles>

21a, $97 \%$ yield, $82: 18 d r$<smiles>COc1ccc(N2C3CC(c4cc(Br)ccc4N3Cc3ccccc3)C2(C(=O)Oc2ccccc2)c2ccccc2)cc1</smiles>

21d, $97 \%$ yield, $60: 40 d r$<smiles>COc1ccc2c(c1)C1CC(N2c2ccccc2)N(c2ccc(Br)cc2)C1c1ccccc1</smiles>

21b, $96 \%$ yield, $70: 30 d r$<smiles>COc1ccc2c(c1)C1CC(N(C(=O)c3ccccc3)C1)N2c1ccc(C)cc1</smiles>

Bn<smiles>COC(=O)C1C2CC(Nc3cc(Br)ccc32)N1c1ccc(Br)cc1</smiles>

$\mathrm{Bn}$

21c, $93 \%$ yield, $81: 19 d r$<smiles>COC(c1ccccc1)C1C2CC(N3CC2c2ccccc23)N1c1ccc(Br)cc1</smiles>

$\mathrm{Bn}$

21e, $92 \%$ yield, $66: 34 d r$

21f, $98 \%$ yield, $56: 44 d r$

Plausible mechanism

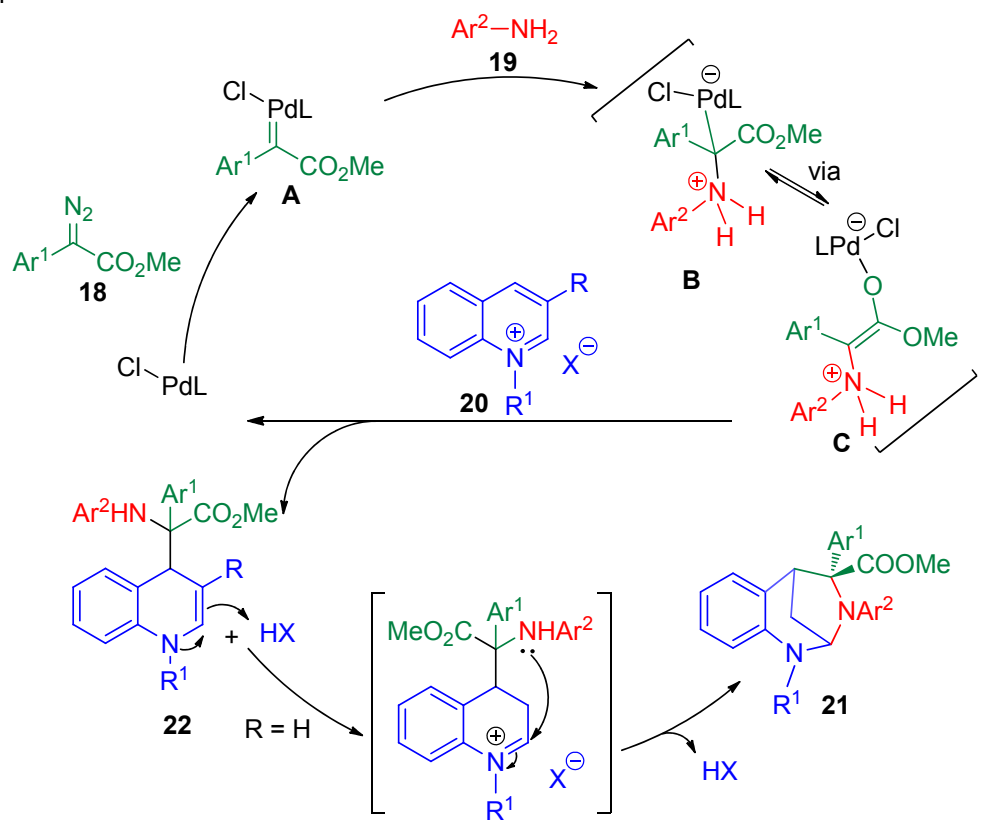

D

图式 5 三组分反应合成多取代的桥环四氢喹啉和二氢喹啉衍生物

Scheme 5 Three-component reactions of $N$-alkylquinolinium salts for the synthesis of multisubstituted bridged tetrahydroquinolines and dihydroquinoline derivatives 
<smiles>[R]N=C([R])[NH2+][R]</smiles>

Quinolinium salt as substrate<smiles>COc1ccc(/N=C/c2ccc(F)cc2)cc1</smiles>

23a

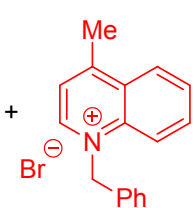

24b
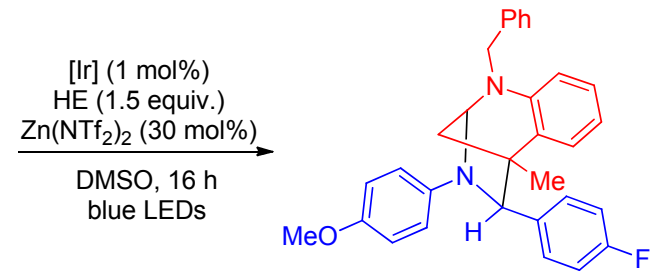

Aldehyde as substrate<smiles>O=Cc1ccc(F)cc1</smiles>

26a<smiles>[124OH]</smiles>

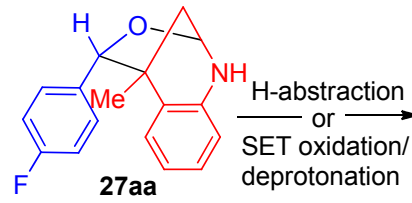
unstable, not isolated<smiles>Cc1ccnc2ccccc12</smiles>

24a

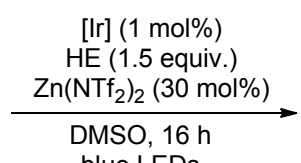

blue LEDs

$25 \%$ yield

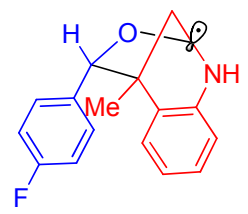

25b, $51 \%, 1.0: 1 d r$

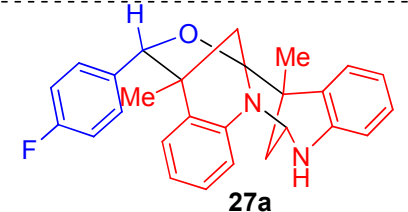

24a

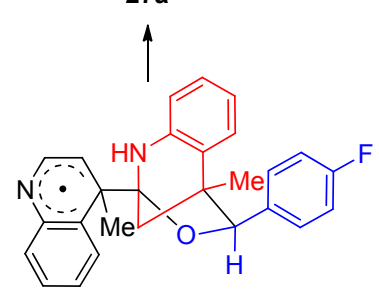

图式 6 光催化亚胺与喹啉的 $[3+2]$ 环加成反应

Scheme 6 Photocatalytic [3+2] cycloadditions of imines with quinolones

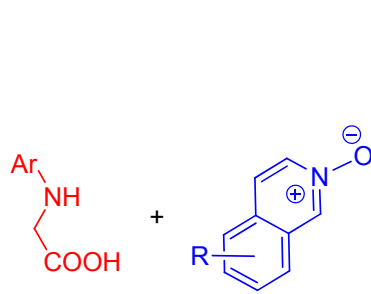

28

$$
29
$$

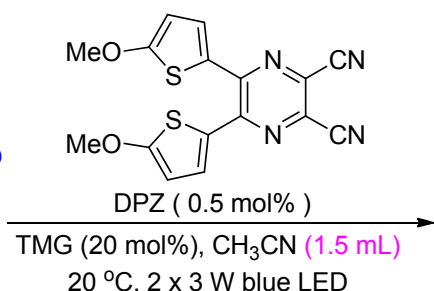

政

under argon, $8 \mathrm{~h}$

15 examples, $60 \% \sim 95 \%$ yields

Proposed mechanism<smiles>ON1c2nnnc(n2)-c2ccccc21</smiles><smiles></smiles>
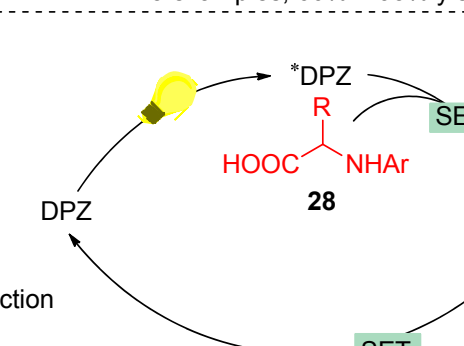<smiles></smiles>

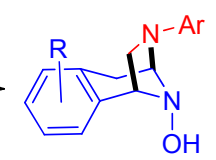

30

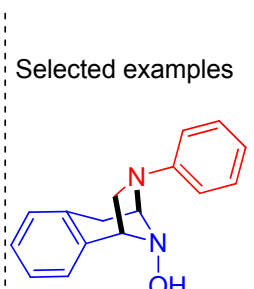

30 a, $84 \%$ yield

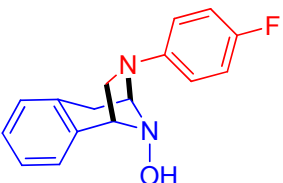

30b, $92 \%$ yield

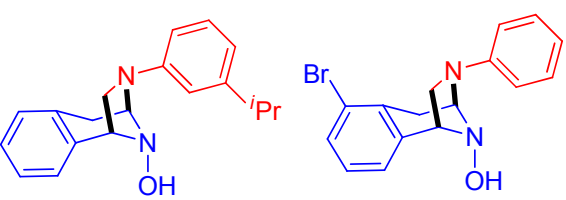

30 c, $87 \%$ yield

30 d, $85 \%$ yield

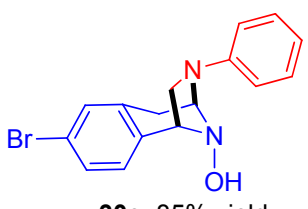

30 e, $85 \%$ yield

图式 7 光催化 $N$-芳基- $\alpha$-氨基酸与异喹啉氮氧化物参与的 $[3+2]$ 环加成反应

Scheme 7 Photoredox-catalysed formal [3+2] cycloaddition involving $N$-aryl $\alpha$-amino acids with isoquinoline $N$-oxides 
邻着基查尔酮是一类很好的双亲电试剂, 可以和双 亲核试剂发生环加成反应, 用于构建结构多样的桥环色 满类化合物 ${ }^{[18]} .2017$ 年, 我们课题组 ${ }^{[19]}$ 利用邻羟基查尔 酮 31 的双亲电特性, 在三氟甲磺酸的作用下, 通过与双 亲核的 3-羟基氧化吲哚 32 发生 Michael 加成/缩酮化串 联环化反应, 实现了具有螺环氧化吲哚骨架的桥环缩酮 35 的高效非对映选择性合成(Scheme 8). 随后, 我们 ${ }^{[20]}$ 又将 3-着基氧化吲哚拓展到反应活性稍低的 3-氨基氧
化吲哚 33, 也能得到不错的反应结果. 该反应不但为具 有生理活性桥环结构 $O, O-/ N, O$-缩酮的合成提供了新的 思路和方法, 同时也丰富了为数不多的合成螺环桥环氧 化吲哚的例子. 异吲哚啉酮 $\mathbf{3 4}^{[21]}$ 也能作为很好的双亲 核试剂参与到该反应体系中，在对甲苯磺酸的催化下， 以高达 99\%的收率得到含有异吲哚啉酮多环骨架的桥 环 $N, O$-缩酮 37. 尽管产物中含有三个立体手性中心, 仅 仅产生一个非对映异构体(Scheme 8).

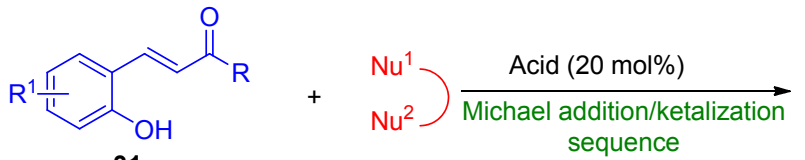

31

$32 \sim 34$

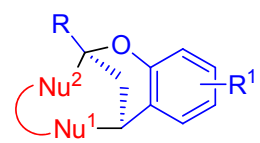

$35 \sim 37$

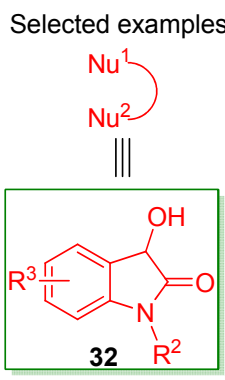<smiles>CN1C(=O)[C@@]2(Cc3ccccc3OC(c3ccccc3)O2)c2ccccc21</smiles>

$35 a, 96 \%$ yield

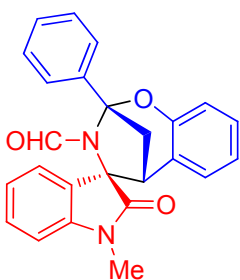

36a, $97 \%$ yield

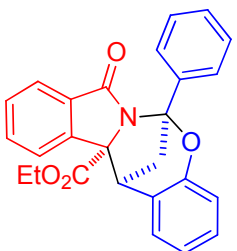

37 a, $97 \%$ yield<smiles>CN1C(=O)[C@@]2(Cc3ccccc3O[C@H](c3ccccc3)O2)c2cc(Cl)ccc21</smiles>

$35 \mathrm{~b}, 80 \%$ yield

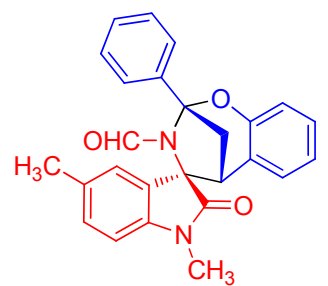

36b, $78 \%$ yield

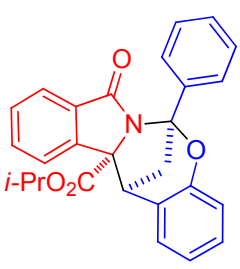

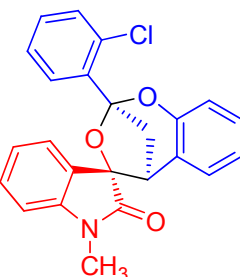

$35 \mathrm{c}, 98 \%$ yield<smiles>Fc1ccccc1</smiles><smiles>CCCC12Cc3ccccc3OC1(CCC)N(C)C(=O)N2C</smiles>

$\mathrm{CH}_{3}$ 36c, $93 \%$ yield

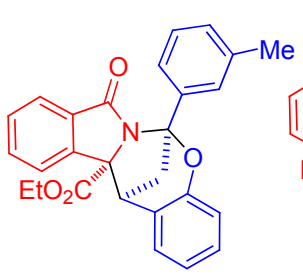<smiles>COc1cccc2c1O[C@@]1(C[C@H]3C(=O)N(C)c4ccccc43)OC2c2ccccc21</smiles>

$35 d, 86 \%$ yield<smiles>CN1C(=O)[C@]23CC[C@]1(Oc1ccccc1O2)c1ccccc13</smiles>

36d, $49 \%$ yield

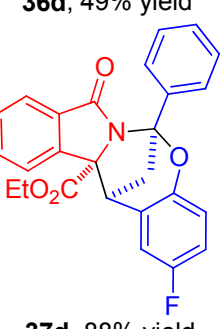

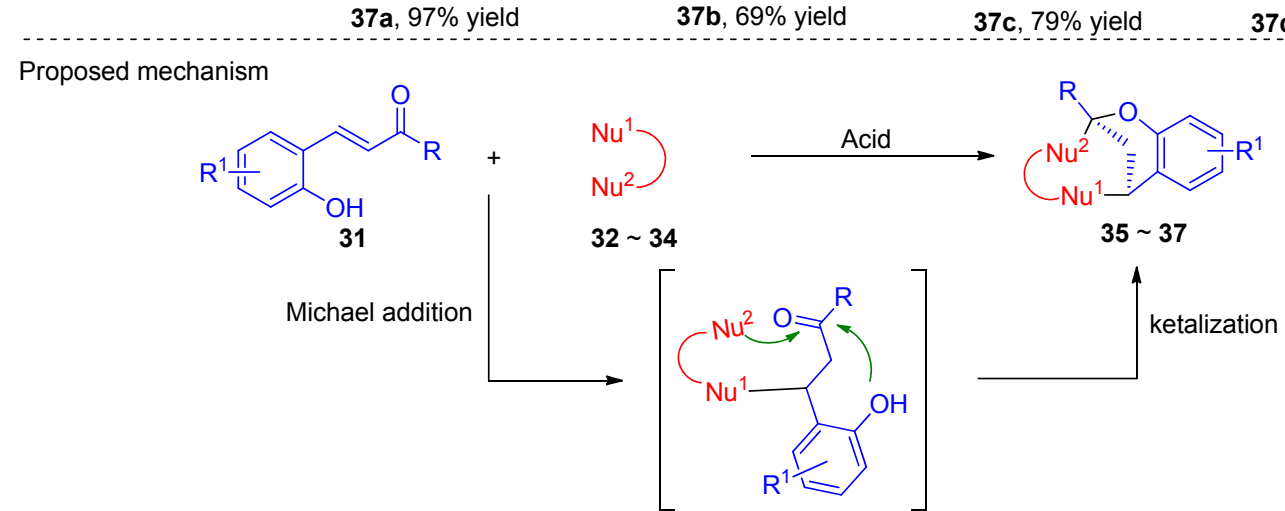

图式 8 Michael 加成诱导的串联环化构建桥环 $O, O-/ N, O$-缩酮

Scheme 8 Michael addition-inspired cascade annulations for the construction of bridged $O, O-/ N, O$-ketals 
在我们工作之后, Pan 课题组 ${ }^{[22]}$ 以脯氨醇硅醚 39 为 催化剂, 实现了邻着基肉桂醛 38 与 3-羟基氧化吲哚 32 的不对称 Michael 加成/缩醛化串联反应(Scheme 9). 该 反应经历 “一锅、两步” 过程, 即脯氨醇硅醚催化的 Michael 加成和三氟醋酸催化的缩醛化, 最终以 $22 \%$ $80 \%$ 的收率和 $85 \%$ \% $99 \%$ 的对映选择性得到具有桥环 $O, O$-缩醛骨架的手性螺环氧化吲哚 35. 同时, 他们 ${ }^{[23]}$ 还
实现了金鸡纳碱伯胺 40 催化的邻羟基查尔酮 31 与 3差弪基氧化吲哚 32 参与的类似反应，也能得到不错的立 体控制结果( $>20 ： 1 d r, 74 \% \sim 97 \% e e)$ (Scheme 9).

2017 年, Ramachary 课题组 ${ }^{[24]}$ 实现了指甲花醌 41 与 $\alpha, \beta$-不饱和酮 42 参与的不对称 [3+2]环加成反应 (Scheme 10). 在双功能催化剂手性奎宁硫嫝 44 的作用

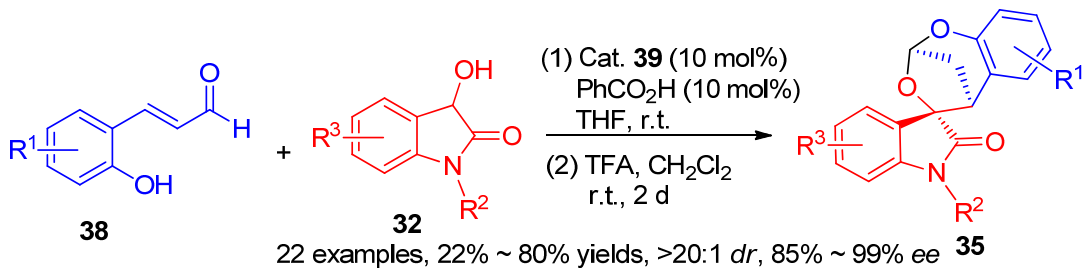

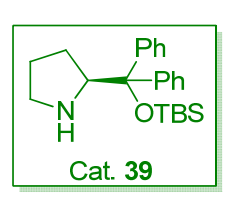
22 examples, $22 \% \sim 80 \%$ yields, $>20: 1 d r, 85 \% \sim 99 \%$ ee 35<smiles>[R11]c1ccc(O)c(/C=C/C(C)=O)c1</smiles>

31
(1) Cat. 40 (10 mol\%) $\mathrm{PhCO}_{2} \mathrm{H}(10 \mathrm{~mol} \%)$ THF, r.t.

(2) $\mathrm{TFA}, \mathrm{CH}_{2} \mathrm{Cl}_{2}$ r.t., 2 d<smiles>[R]c1ccccc1O[C@@]1(C)C[C@@H]2C[C@]1(C)O[C@@]21C(=O)Nc2ccccc21</smiles>

$35 \stackrel{\prime}{R^{2}}$

25 examples, $30 \% \sim 81 \%$ yields, $>20: 1 d r, 74 \% \sim 97 \%$ ee

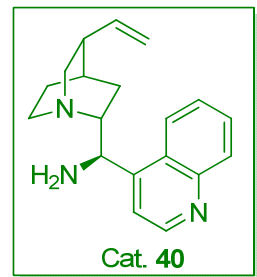

图式 9 有机催化不对称合成具有螺环氧化吲哚骨架的桥环缩酮

Scheme 9 Organocatalytic asymmetric synthesis of bridged acetals with spirooxindole skeletons<smiles>[R][Al]CC1=C(O)C(=O)c2ccccc2C1=O</smiles>

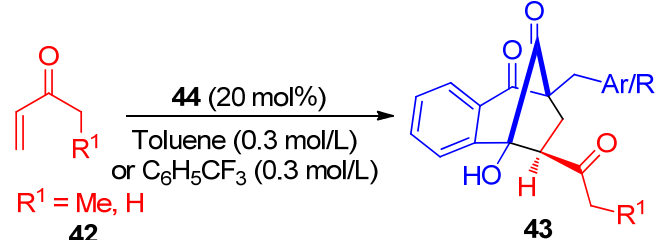

42

43

39 examples, up to $99 \%$ yield, up to $>20: 1 d r$, up to $99 \%$ ee

Selected examples<smiles>CC(=O)[C@H]1C[C@]2(Cc3ccc(F)cc3)Oc3ccccc3C(=O)[C@@H]1C2=O</smiles>

$80 \%$ yield, $20: 1 d r, 95 \%$ ee

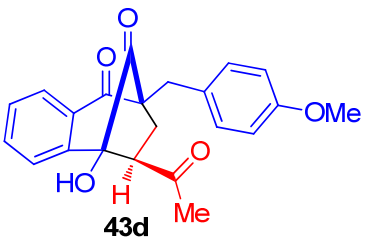

95\% yield, $23: 1 d r, 92 \%$ ee<smiles>CCC(=O)[C@H]1CC2(Cc3ccc(C)cc3)C(=O)C[C@]1(O)c1ccccc1C2=O</smiles>

$65 \%$ yield, $16: 1 d r, 74 \%$ ee<smiles>CC(=O)[C@H]1C[C@@]2(Cc3ccc(Cl)cc3)COC(=O)[C@]1(O)c1ccccc1C2=O</smiles>

$90 \%$ yield, $20: 1 d r, 95 \%$ ee

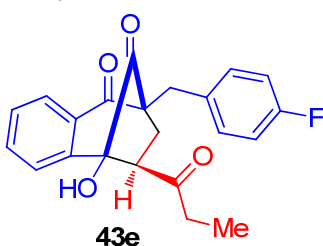

$65 \%$ yield, $90: 1 d r, 97 \%$ ee

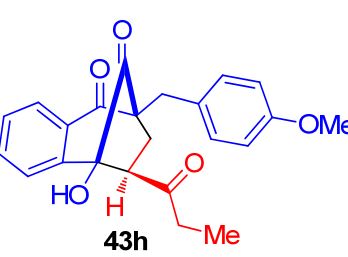

$80 \%$ yield, $84: 1 d r, 87 \%$ ee

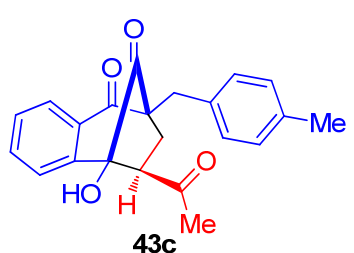

$88 \%$ yield, $22: 1 d r, 99 \%$ ee

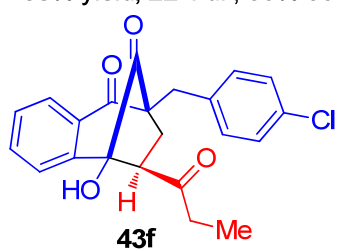

$75 \%$ yield, $90: 1 d r, 73 \%$ ee

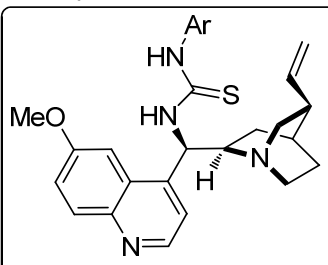

$\mathrm{Ar}=3,5-\left(\mathrm{CF}_{3}\right)_{2} \mathrm{C}_{6} \mathrm{H}_{3}$

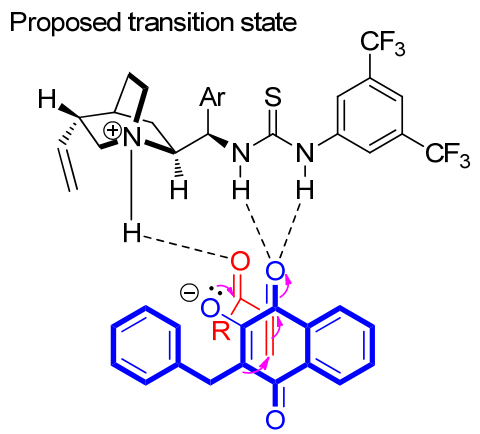

TS-1 [favorable TS]

Synergistic activation in Pre-TS [Re-Si-face Approach]

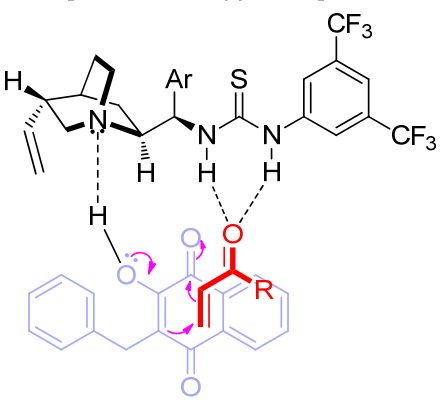

TS-2 [unfavorable TS] Non-synergistic activation in Pre-TS [Si-Si-face Approach]

图式 10 指甲花酮与烷基乙烯基酮参与的不对称 $[3+2]$ 环加成反应

Scheme 10 Asymmetric formal [3+2] cycloaddition of lawsones with alkyl vinyl ketones 
下，该反应得以顺利进行，以 $65 \% \sim 99 \%$ 的收率、 $2: 1 \sim$ $>20 ： 1$ 的非对映选择性以及高达 $99 \%$ 的对映选择性合 成了高度官能化的双环[3.2.1]辛烷骨架桥环化合物 43 . 相较于甲基乙烯基酮, 乙基乙烯基酮反应活性较低, 收 率和对映选择性略有降低. 随后, 作者通过高分辨质谱 检测到关键中间体的分子离子峰, 表明该反应可能经历 逐步机理过程. 并根据实验结果, 作者阐述了反应可能 经历的中间过渡态(Scheme 10).

2020 年, 陈海军课题组 ${ }^{[25]}$ 采用氧化偶联环化策略 发展了四氢咔唑或四氢咔啉 45 与芳胺参与的 $[3+2]$ 环 加成反应, 用于桥环双吲哚啉 47 的高效非对映选择性 合成(Scheme 11). 该反应经历三步, 首先四氢咔唑或四 氢咔啉与叔丁氧氯反应, 生成双亲电的 3-氯代假吲哚中
间体 $\mathbf{I}$; 随后，中间体 $\mathbf{I}$ 在酸的作用下，经碳正离子中间 体 II 与芳胺反应，生成吲哚 C-3 胺化的产物 III; 最后, 再发生分子内的环化反应即可得桥环双吲哚啉 47. 当 采用大位阻的芳胺或者缺电子的芳胺为原料时, 仅仅得 到 C-3 胺化的产物, 后续的分子内环化反应无法进行. 在此条件下，采用酚类化合物为反应底物时，也无后续 的关环产物产生, 但是, 作者可以通过改变酸的种类实 现后续的分子内环化过程. 如将硫酸换为三氯化铝, $47 \mathbf{i}$ 以 $74 \%$ 的收率转化为苯并呋喃类化合物 $\mathbf{4 7} \mathbf{j}$.

2020 年, Moshkin 课题组 ${ }^{[26]}$ 报道了芳香醛 48 和不稳 定的亚胺叶立德 49 参与的环化串联反应，以高达 $85 \%$ 的收率合成了系列桥环四氢异喹啉 51. 根据实验结果, 作者提出了两种可能的反应路径. 如 Scheme 12 路径 A
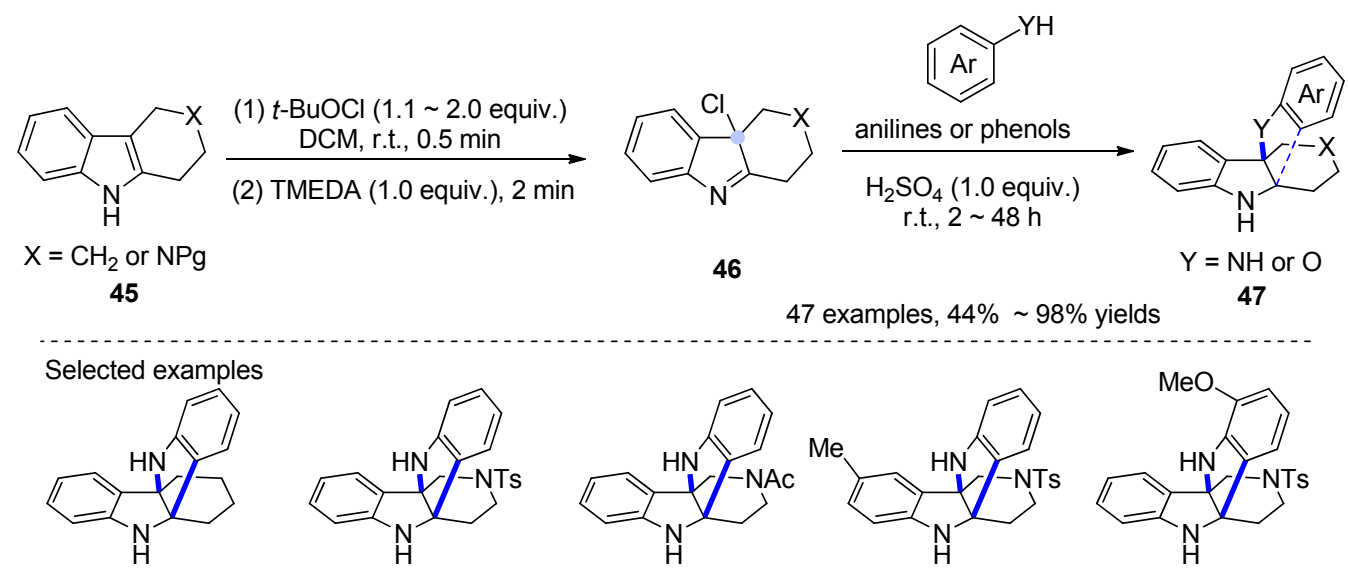

$47 a, 84 \%$ yield
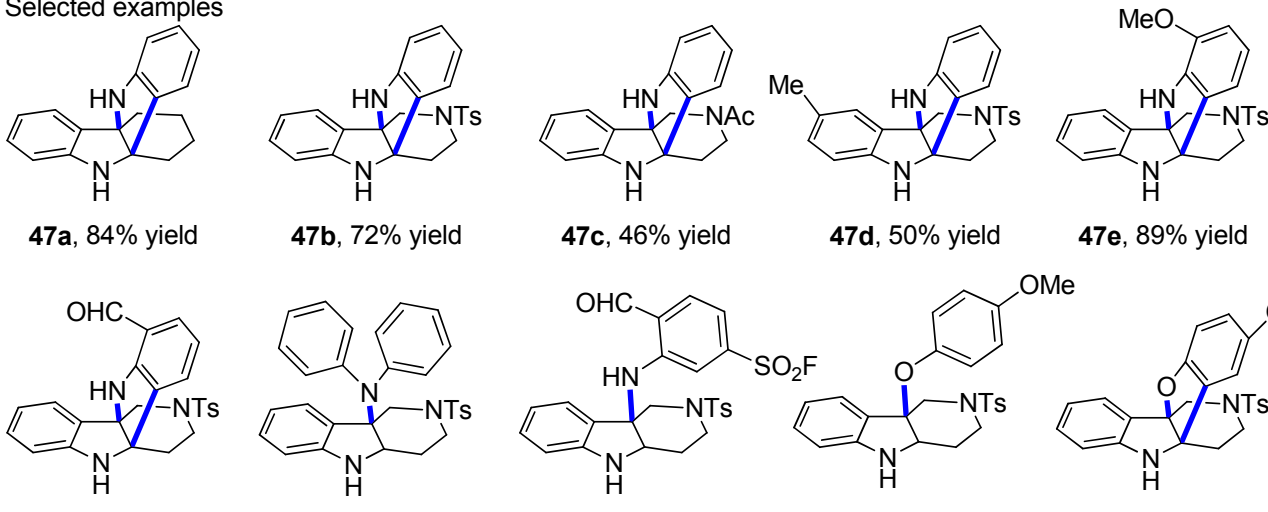

47b, $72 \%$ yield

47c, $46 \%$ yield

47d, $50 \%$ yield

$47 e, 89 \%$ yield

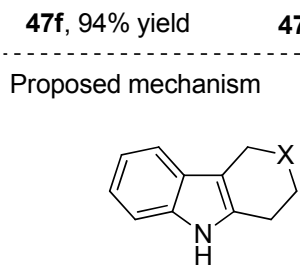

45

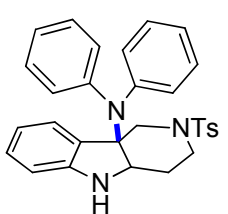<smiles>CC=CCCC1Nc2ccccc2C1(CN1CCCCC1)Nc1cc(S(=O)(=O)F)ccc1C=O</smiles><smiles>COc1ccc(OC2(CN3CC[N+]4([S-])CCCCC34)Nc3ccccc32)cc1</smiles><smiles></smiles>

47h, $91 \%$ yield

$47 i, 82 \%$ yield

47j, 74\% yield

$\underset{\text { (2) TMEDA }}{\stackrel{\text { (1) } t-\mathrm{BuOCl}}{\longrightarrow}}$

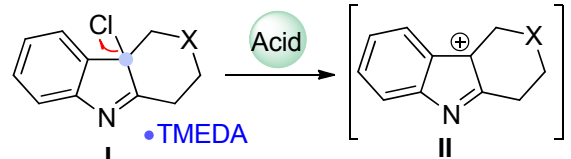

Stable
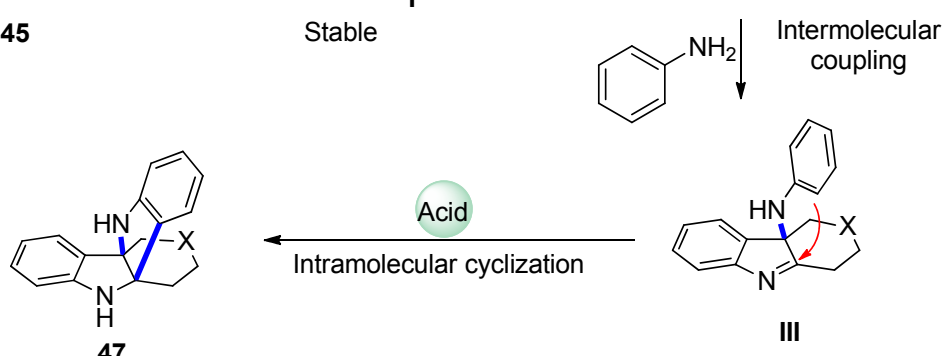

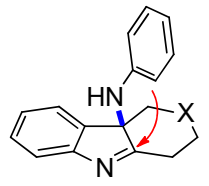

III

图式 11 通过氧化偶联环化反应构建桥环双吲哚啉

Scheme 11 Construction of bridged bisindolines via oxidative coupling cyclization 


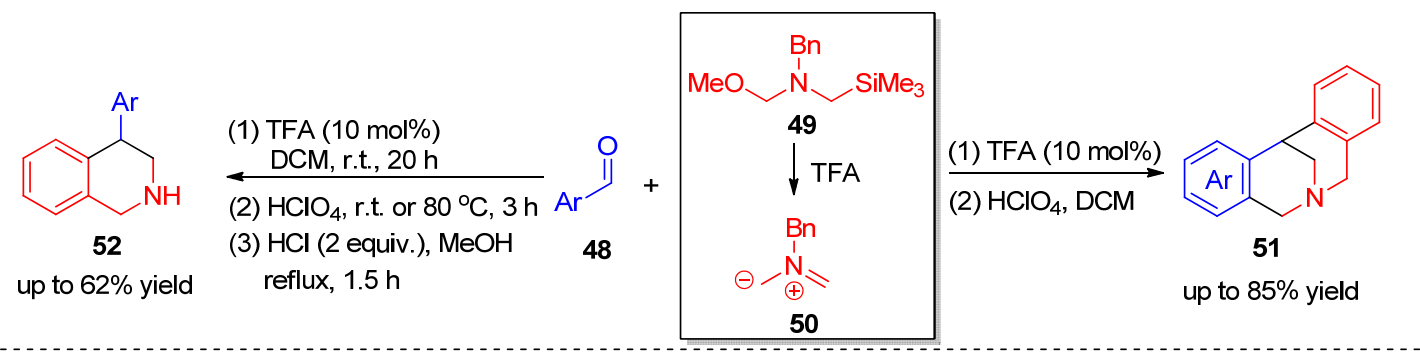<smiles>CC(C)=O</smiles>

51a, $85 \%$<smiles>Cc1ccc2c(c1)CN1CC2CC2CC1c1ccccc12</smiles>

51b, 59\%<smiles></smiles>

51c, $50 \%$

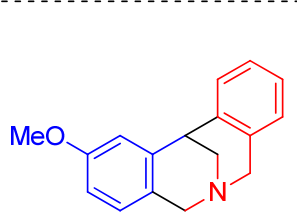

51d, $62 \%$<smiles>COc1ccc(C2CNCc3ccccc32)cc1</smiles>

52a, $45 \%$

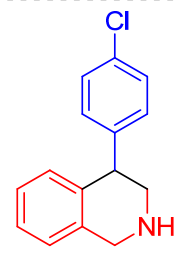

52b, $49 \%$

Proposed mechanism<smiles>COCN(Cc1ccccc1)CC(C)C(C)C(C)C(C)C(C)C</smiles>

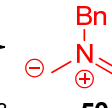

$\operatorname{Ar}>\mathrm{O}$
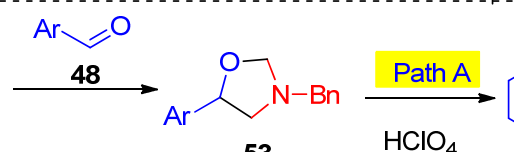

$\mathrm{OH}$

53

$\mathrm{HClO}_{4}$

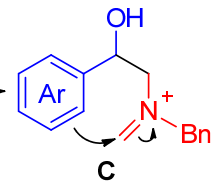<smiles>CCN1Cc2ccccc2C(Br)C1</smiles>

52<smiles>OC1C[N+]2(Cc3ccccc3C1Br)Cc1ccccc12</smiles>

G<smiles>C=CO</smiles>

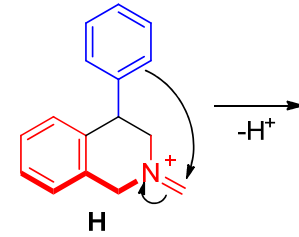<smiles>[TeH][TeH]</smiles>
$\mathrm{Ar}$<smiles>O</smiles><smiles>C1CCCC1</smiles><smiles>C1=CCCCC1</smiles>

Path $\mathrm{B} \quad \mathrm{HClO}_{4}$

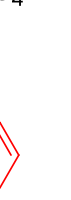

F
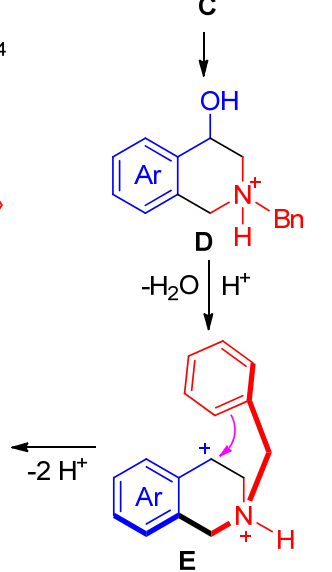

图式 12 芳香醛和亚胺叶立德参与的串联环化反应

Scheme 12 Cascade annulations of aromatic aldehydes and azomethine ylides

所示, 亚胺叶立德前体 49 首先与三氟醋酸反应, 生成亚 胺叶立德 50, 随后与芳香醛 48 发生[3+2]环加成反应, 生成啞唑中间体 53. 在高氯酸的作用下, 53 发生分子内 的 Pictet-Spengler 环化后得到异喹啉骨架 D. 通过失水 及后续的分子内 Friedel-Crafts 烷基化反应, 最终得到四 氢异喹啉桥环化合物 51. 该反应也可能采用路径 B 进 行，质子化的啞唑中间体 $\mathbf{F}$ 发生分子内的 Friedel-Crafts 烷基化反应, 构建异喹啉中间体 $\mathbf{G}$, 随后中间体 $\mathbf{G}$ 发生 失水及分子内 Friedel-Crafts 烷基化反应得到目标产物 51. 需要说明的是, 当反应结束后, 往反应体系里添加 2 equiv. 盐酸, 得到了 4-芳基取代的四氢异喹啉 52. 作者 认为可能是中间体 $\mathbf{G}$ 在酸性条件下脱去了一分子甲醛 而导致的.

\section{$1.2[3+3]$ 环加成反应构建桥环化合物}

2017 年, 王兴旺课题组 ${ }^{[27]}$ 发展了邻羟基 $\alpha, \beta$-不饱和 酮酸酯 54 与 3-吡咯取代氧化吲哚 55 的不对称 Michael
加成/半缩酮化/氧杂-Pictet-Spengler 串联反应(Scheme 13). 在 Takemoto 催化剂 57 的作用下, 大部分例子均能 以中等及以上的收率(up to $82 \%$ yield)、优秀的立体选择 性( $>20 ： 1 d r$, up to $99 \% e e$ )得到一系列具有光学活性 的螺环桥环氧化吲哚 56. 初步的生理活性评价表明所 合成的螺环桥环氧化吲哚 56 具有明显的抑制癌细胞增 长的作用. 进一步机理研究表明, 反应先通过 Michael 加成/半缩酮化生成半缩酮中间体 $\mathbf{I}$, 随后在酸的作用下, 吡咯环再与 $\mathbf{I}$ 发生分子内的 Pictet-Spengler 反应，最终得 到目标产物 56 (Scheme 13).

2018 年, 我们课题组 ${ }^{[28]}$ 以邻羟基查尔酮 31 与 3-吲 哚取代氧化吲哚 58 为起始原料, 在三氟甲磺酸的催化 下，实现了它们的 Michael 加成/缩合/Friedel-Crafts 烷基 化串联反应，以 $42 \% \sim 90 \%$ 的收率得到吲哚桥连色满骨 架的螺环氧化吲哚 59 (Scheme 14). 反应的非对映选择 性非常好，尽管产物有多个手性中心，且含有刚性的桥 


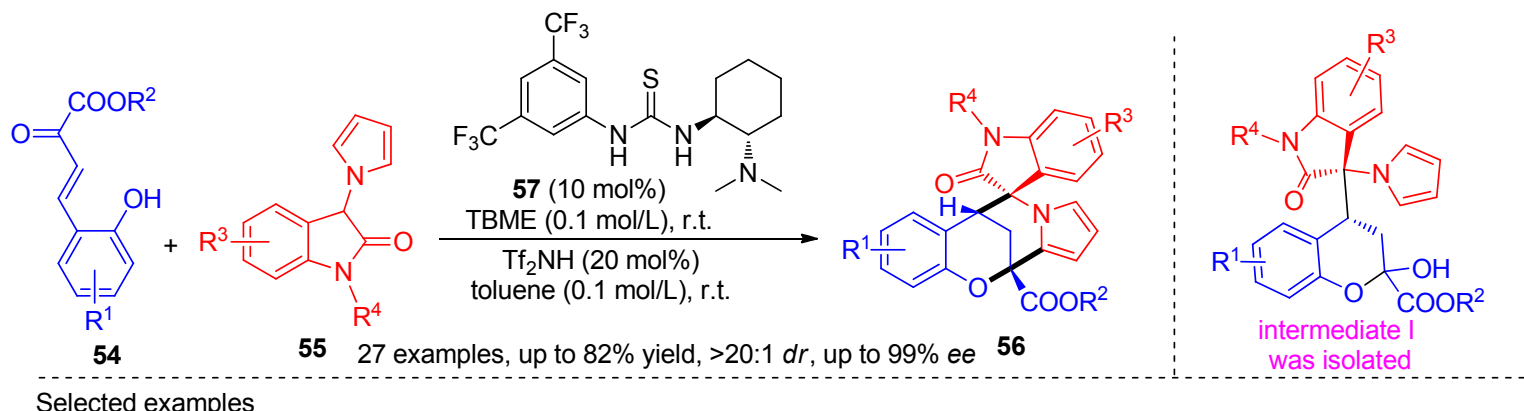

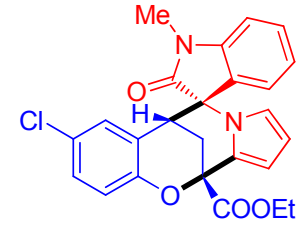

56a, $65 \%,>20: 1 d r, 97 \%$ ee

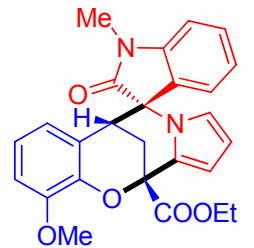

56b, $67 \%,>20: 1 d r, 82 \%$ ee<smiles>CCOC(=O)C1(C)C[C@]2(C(=O)N1C)c1cc(Cl)ccc1OC21CCCC1</smiles>

56c, $62 \%,>20: 1 d r, 93 \%$ ee

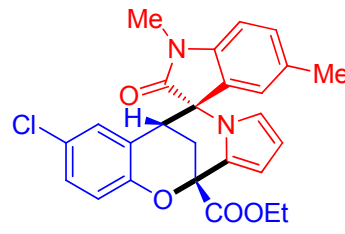

56d, $64 \%,>20: 1 d r, 88 \%$ ee

图式 13 不对称 Michael 加成/半缩酮化/氧杂-Pictet-Spengler 串联反应构建螺环桥环氧化吲哚

Scheme 13 Asymmetric Michael addition/hemiketalization/oxa-Pictet-Spengler cascade for the synthesis of bridged spirooxindoles

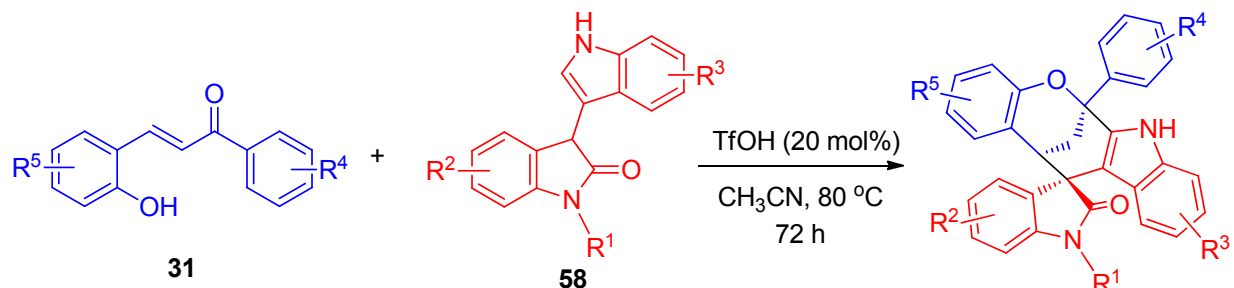

33 examples, $42 \% \sim 90 \%$ yields, $>20: 1 d r$ for all cases

59<smiles>CC(C)=O</smiles>

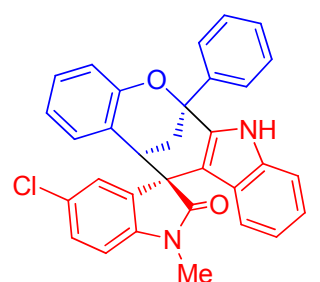

$59 b, 80 \%$ yield

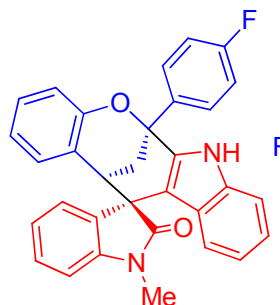

59c, $72 \%$ yield

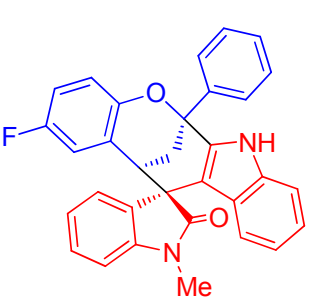

59d, $70 \%$ yield

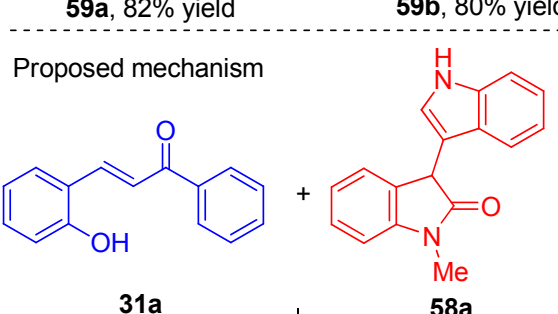

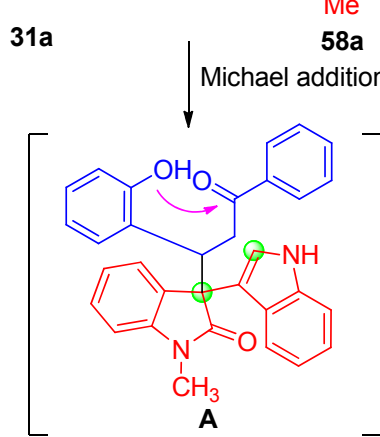

Michael addition-inspired triple cascade<smiles>O=C1Nc2ccccc2[C@]12C[C@@](C[C@H]1Oc3ccccc31)(c1ccccc1)c1[nH]c3ccccc3c12</smiles>

Me

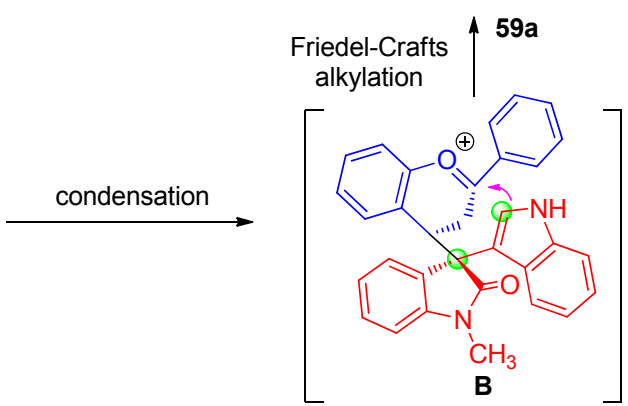

图式 $14 \mathrm{TfOH}$ 催化的 Michael 加成 “诱导” 的串联环化反应构建螺环桥环氧化吲哚

Scheme 14 A TfOH-catalyzed Michael addition-inspired cascade annulation for the construction of bridged spirooxindoles 
环结构, 但我们仅仅得到一个非对映异构体. 这也是 3吲哚取代氧化吲哚作为双亲核试剂的第一个例子. 几乎 同时, 刘延凯课题组 ${ }^{[29]}$ 以邻羟基肉桂醛 38 为原料, 实 现了该反应的不对称版本. 在脯氨醇硅醚的催化下, 38 与 3-吲哚取代氧化吲哚 $\mathbf{5 8}$ 发生 Michael 加成/半缩醛化 反应，随后在三氟化嗍乙醚的作用下，发生分子内的 Friedel-Crafts 烷基化反应, 最终合成了系列手性吲哚桥
连色满骨架的螺环氧化吲哚 59 和 59'. 尽管该反应的非 对映选择性不高, 但是均能以不错的对映选择性得到目 标产物(Scheme 15).

谭海波课题组 ${ }^{[30]}$ 利用邻羟基肉桂醛的双亲电性, 在构建桥环化合物方面也做了一些工作. 2018 年，他们 开发了一种乙二胺二乙酸(EDDA)催化的串联反应选择 性构建桥环黄酮类化合物 62 的方法(Scheme 16). 从邻

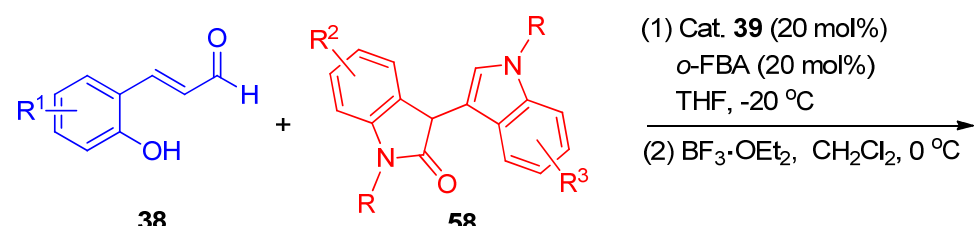

38

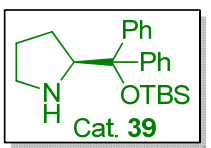

58

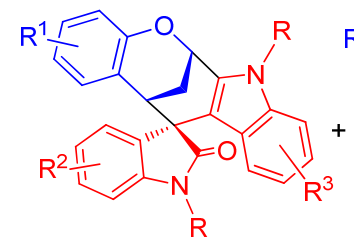

59

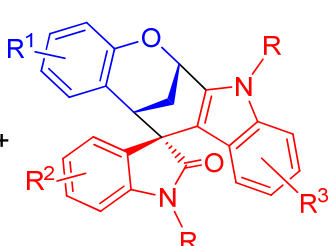

59

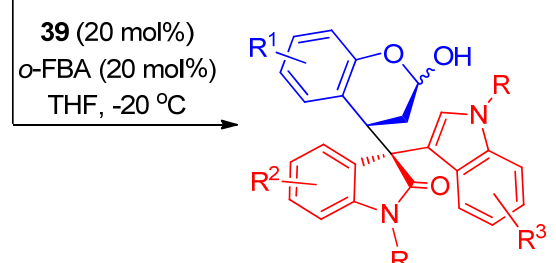

60

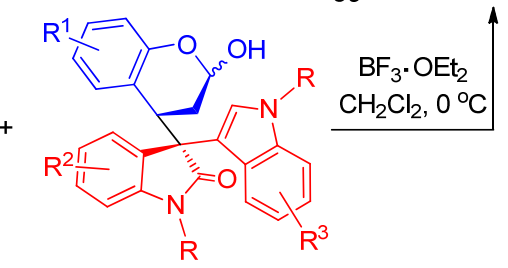

$60^{\prime}$

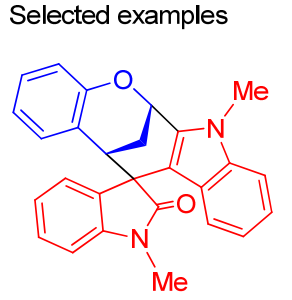

59a, 22\% yield $59 a^{\prime}, 61 \%$ yield, $>99 \%$ ee $59 b^{\prime}, 54 \%$ yield, $>99 \%$ ee

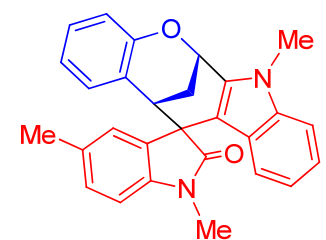

$\mathrm{Me}$

59c $30 \%$ yield $>99 \%$ 59d $23 \%$ yield, $98 \%$ $59 c^{\prime}, 62 \%$ yield, $>99 \%$ ee $\mathbf{5 9 d}$ ', $47 \%$ yield, $>99 \%$

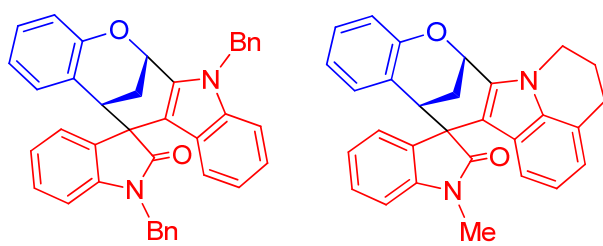

59 e, $25 \%$ yield, $99 \%$ ee $59 e^{\prime}, 49 \%$ yield, $>99 \%$ ee

图式 15 邻着基肉桂醛与 3-吲哚取代氧化吲哚参与的不对称 Michael 加成/半缩醛化/Friedel-Crafts 烷基化串联反应

Scheme 15 Asymmetric Michael addition/hemiacetalization/Friedel-Crafts alkylation sequence of 2-hydroxy cinnamaldehydes and 3-indolyl oxindoles

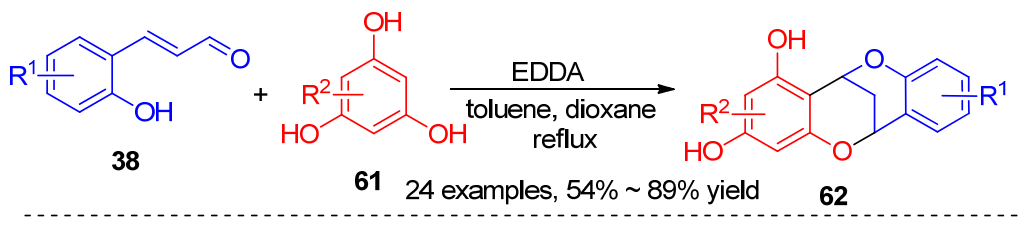

\section{Selected examples}<smiles>CCCC(=O)c1c(O)cc(O)c2c1OC1CC2Oc2ccccc21</smiles>

62a, $58 \%$ yield<smiles>C=CCC(=O)c1c(O)cc(O)c2c1OC1CC2Oc2ccccc21</smiles>

$\mathbf{6 2 b}, 65 \%$ yield<smiles>Oc1cc(O)c2c(c1)OC1CC2Oc2ccccc21</smiles>

62c, $75 \%$ yield<smiles>COc1cc(OC)c2c(c1)OC1CC2Oc2c(C(=O)O)c(O)cc(O)c2C1Oc1ccccc1</smiles>

Proposed mechanism

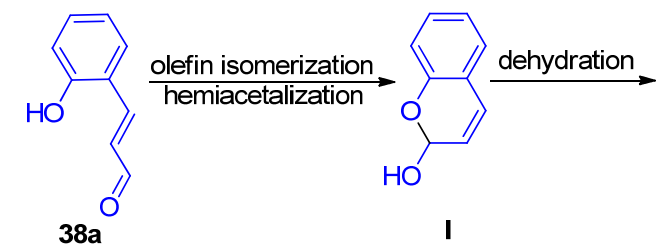

$38 \mathrm{a}$

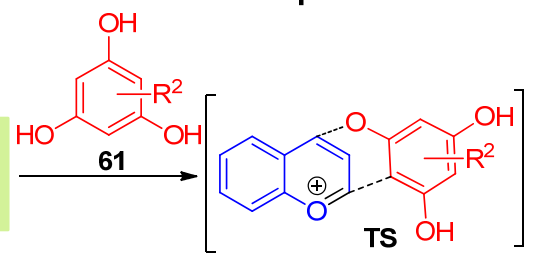

图式 $16[3+3]$ 环加成反应合成桥环黄酮类化合物

Scheme 16 Synthesis of bridged flavonoid derivatives via [3+3] cycloaddition 
羟基肉桂醛 38 与间苯三酚 61 出发, 通过双键异构化/ 半缩醛化/失水/[3+3]环加成串联反应，以 $54 \% \sim 89 \%$ 的 收率得到一系列含有黄酮骨架的桥环化合物 62. 通过 控制实验，作者认为，在酸的作用下，邻羟基肉桂醛 38 发生分子内的环化反应生成氧鎓离子中间体 II 是反应 的关键步骤 ${ }^{[31]}$, 随后再与间苯三酚 61 发生 [3+3]环加成 反应，最终得到桥环产物 62. 2020 年, 该课题组 ${ }^{[32]}$ 以同 样方法在还实现了天然产物 Sanctis A 和 Sanctis B 的仿 生全合成(Scheme 17).

2018 年, 邓卫平课题组 ${ }^{[33]}$ 开发了一种 $\mathrm{Cu}(\mathrm{II})$ 催化的
2-乙烯基吲哚 63 和环状亚胺酯 64 的不对称 $[3+3]$ 环加 成反应，用于高效构筑吲哚桥连托品烷骨架的杂环桥环 化合物 65 (Scheme 18). 该反应经历 “一锅、两步” 过 程, 即铜催化的 Michael 加成及后续的路易斯酸催化的 氮杂-Friedel-Crafts 烷基化串联反应.

\section{$1.3[4+2]$ 环加成反应构建桥环化合物}

2016 年, 游书力课题组 ${ }^{[34]}$ 以 2,3-环状双取代的吲哚 67 和烯丙基碳酸酯 68 为原料，在金属 $\mathrm{Pd}$ 的作用下，以 三(2-呋喃基)膦 70 为配体，实现了二者的[4+2]环加成<smiles>[R6]c1cc(C)c(C(=O)OC)c(O)c1/C=C/C(C)=O</smiles>

图式 17 Sanctis A 和 Sanctis B 的仿生全合成

Scheme 17 Biomimetic total syntheses of sanctis A and sanctis B
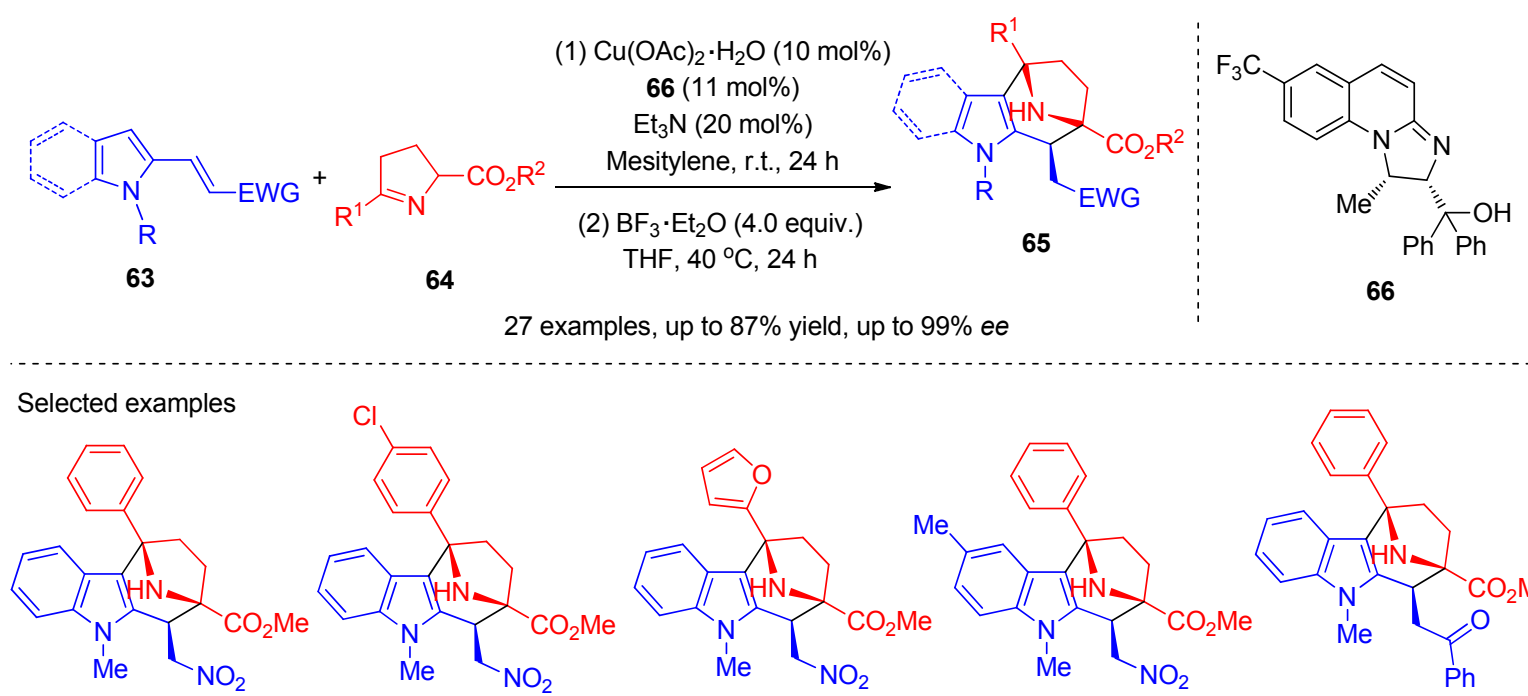

65a, $66 \%, 98 \%$ ee

65b, $83 \%, 95 \%$ ee

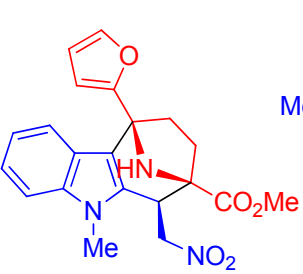

$65 \mathrm{c}, 63 \%, 89 \%$ ee

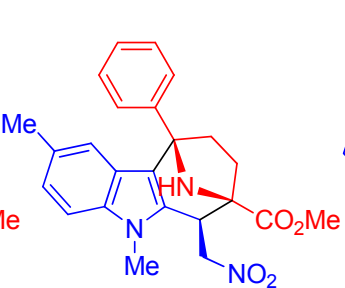

65d, $71 \%, 98 \%$ ee

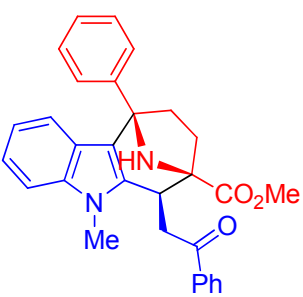

65e, $72 \%, 84 \%$ ee

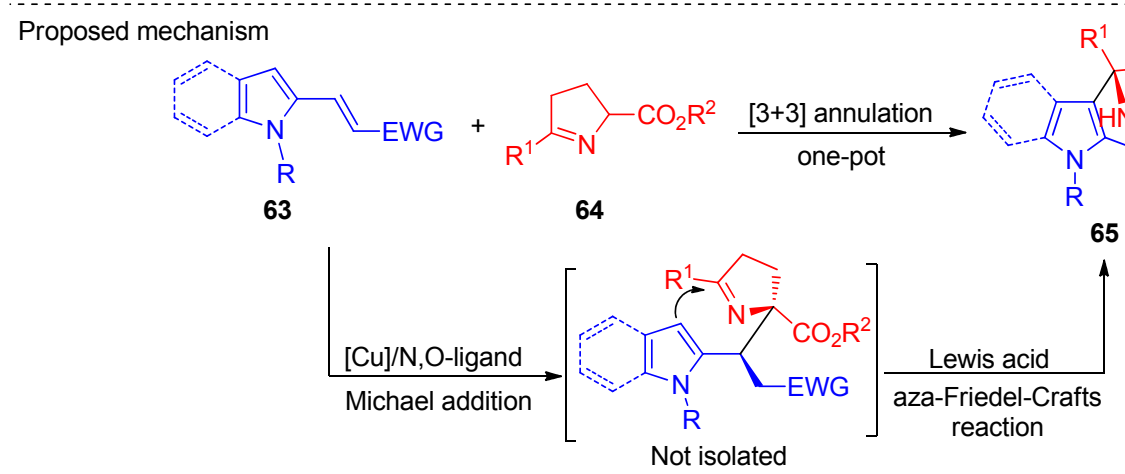

图式 18 2-乙烯基吲哚与环状亚胺叶立德参与的不对称 [3+3]环加成反应

Scheme 18 Asymmetric [3+3] annulation of 2-vinylindoles with cyclic azomethine ylides 
反应, 以 $49 \%$ \%9\%的收率得到桥环吲哚啉 69 (Scheme 19). 随后作者还尝试了该反应的不对称版本，通过选 择合适的亚磷酰胺配体, 可以实现优秀的立体控制.
2016 年, 魏万国课题组 ${ }^{[35]}$ 报道了三氟甲磺酸铟催 化的 2,3-环状双取代的吲哚 72 和邻氨基茮醇 73 的 [4+ 2]环加成反应(Scheme 20). 在三氟甲磺酸铟的作用下,
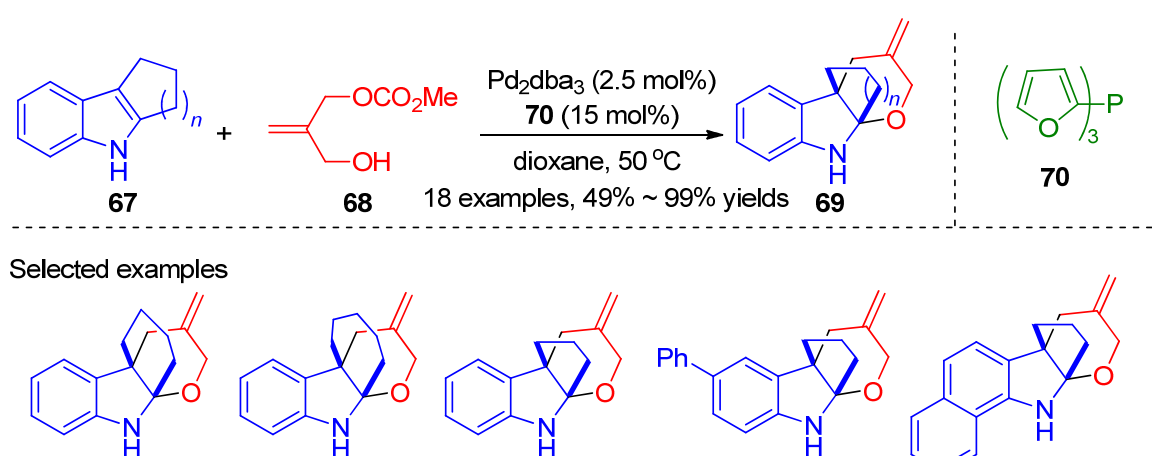

$69 a, 74 \%$

$69 \mathrm{~b}, 63 \%$<smiles>C=C1COC2(CC3CCC32COC)Nc2ccccc21</smiles><smiles>C=C1COC2(C1)CC1CCC12Nc1ccc(-c2ccccc2)cc1</smiles>

69d, $60 \%$<smiles>C=C1COC2(CC3CCC2(C)N3)c2ccc3ccccc3c2N1</smiles>

Asymmetric version<smiles>C=C1CO[C@]2(C1)CC1CCC2(C)c2ccccc2N1</smiles>

- $-69 a, 61 \%$ $94 \%$ ee from $71 b$<smiles>C=C1COC23CCCC2(C1)c1ccccc1N3</smiles>

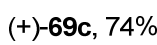

$+)-69 \mathrm{c}, 74 \%$ from $71 c$

69c, $95 \%$

$69 \mathrm{e}, 67 \%$
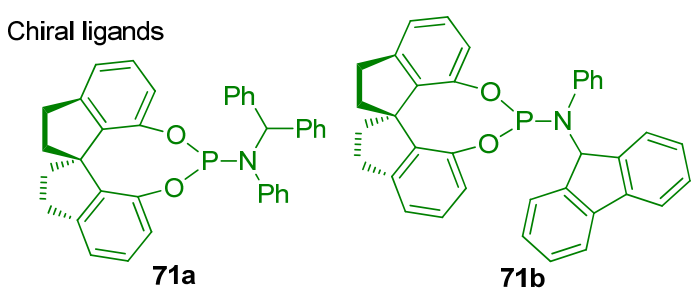

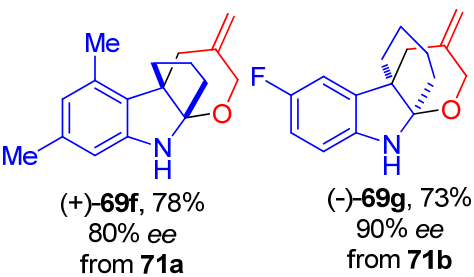

图式 192,3 -双取代的吲哚与烯丙基碳酸酯参与的[4+2]环加成反应

Scheme 19 Formal [4+2] cycloaddition of 2,3-disubstituted indoles with functionalized allylic carbonates

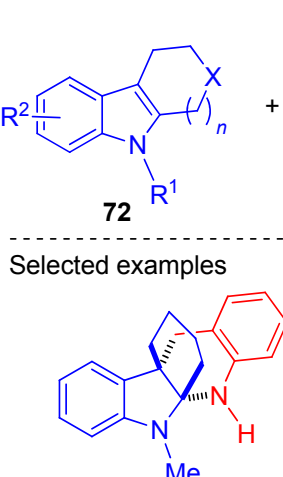

$74 a, 78 \%$

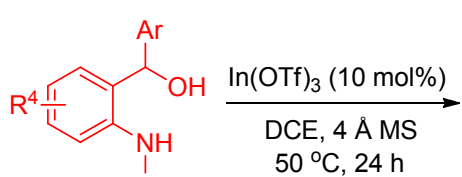

73 28 examples, $49 \% \sim 97 \%$ yields

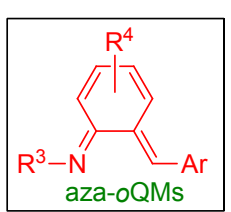

74

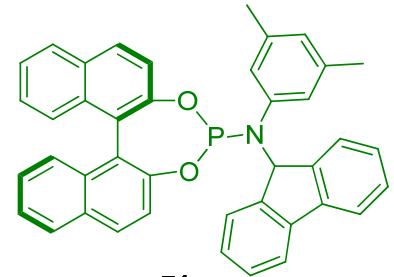

71c

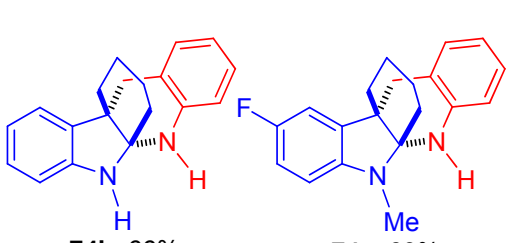

74b, $66 \%$<smiles>CCOC(=O)N1CC2(CCCC2)Nc2ccccc2N1C</smiles>

74d, $85 \%$<smiles>CCCCN(c1ccccc1C)[C@@]12CCCC1c1ccccc1N2C</smiles>

74e, $96 \%$

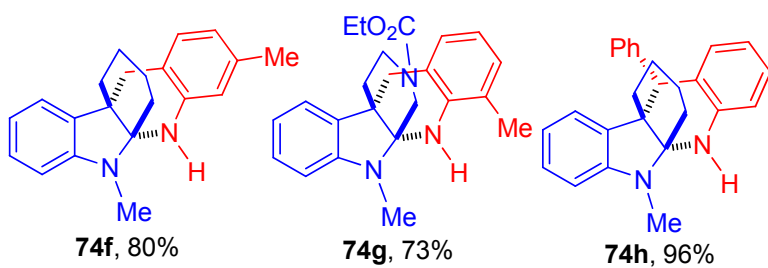

图式 202,3 -双取代吲哚与邻氨基苠醇参与的 $[4+2]$ 环加成反应

Scheme $20[4+2]$ cycloaddition of 2,3-disubstituted indoles with $o$-aminobenzyl alcohols 
邻氨基苠醇 73 原位转化为高反应活性的氮杂邻亚甲基 醌中间体, 随后与取代吲哚发生 $[4+2]$ 环加成反应, 以 49\% 97\% 的收率得到四氢喹啉并桥环吲哚啉 74 (Scheme 20). 该反应的底物范围比较广, 芳基取代的邻 氨基仲醇也能顺利参与反应，尽管产生 3 个手性中心, 但是仅仅得到一个非对映异构体(74h, 96\%).

2018 年, 我们课题组 ${ }^{[36]}$ 报道了 $\mathrm{FeCl}_{3}$ 催化的吲哚和 2 equiv. 邻羟基查尔酮参与的三组分串联环化反应，以 $41 \% \sim 85 \%$ 的收率得到了结构复杂的具有色满桥联吲哚
结构的化合物 76, 同时还伴随有双吲哚甲烷的副产物 77 生成(Scheme 21). 通过控制实验和高分辨质谱分析, 发现邻羟基查尔酮 31a 在 $\mathrm{FeCl}_{3}$ 的作用下，发生逆 Aldol 反应，生成水杨醛和苯乙酮，水杨醛和吲哚 $75 \mathrm{~b}$ 反应生 成副产物 77b. 而苯乙酮和吲哚 75b 发生 Friedel-Crafts 烷基化反应，生成 3-烯基吲哚中间体 $\mathbf{A}$; 中间体 $\mathbf{A}$ 和另 一分子邻羟基查尔酮 31a 发生分子间的[4+2]环加成反 应，生成中间体 $\mathbf{B}$; 随后， $\mathbf{B}$ 发生氧化及分子内的 1,4-加 成反应，最终得到色满桥连吲哚结构的化合物 76b.

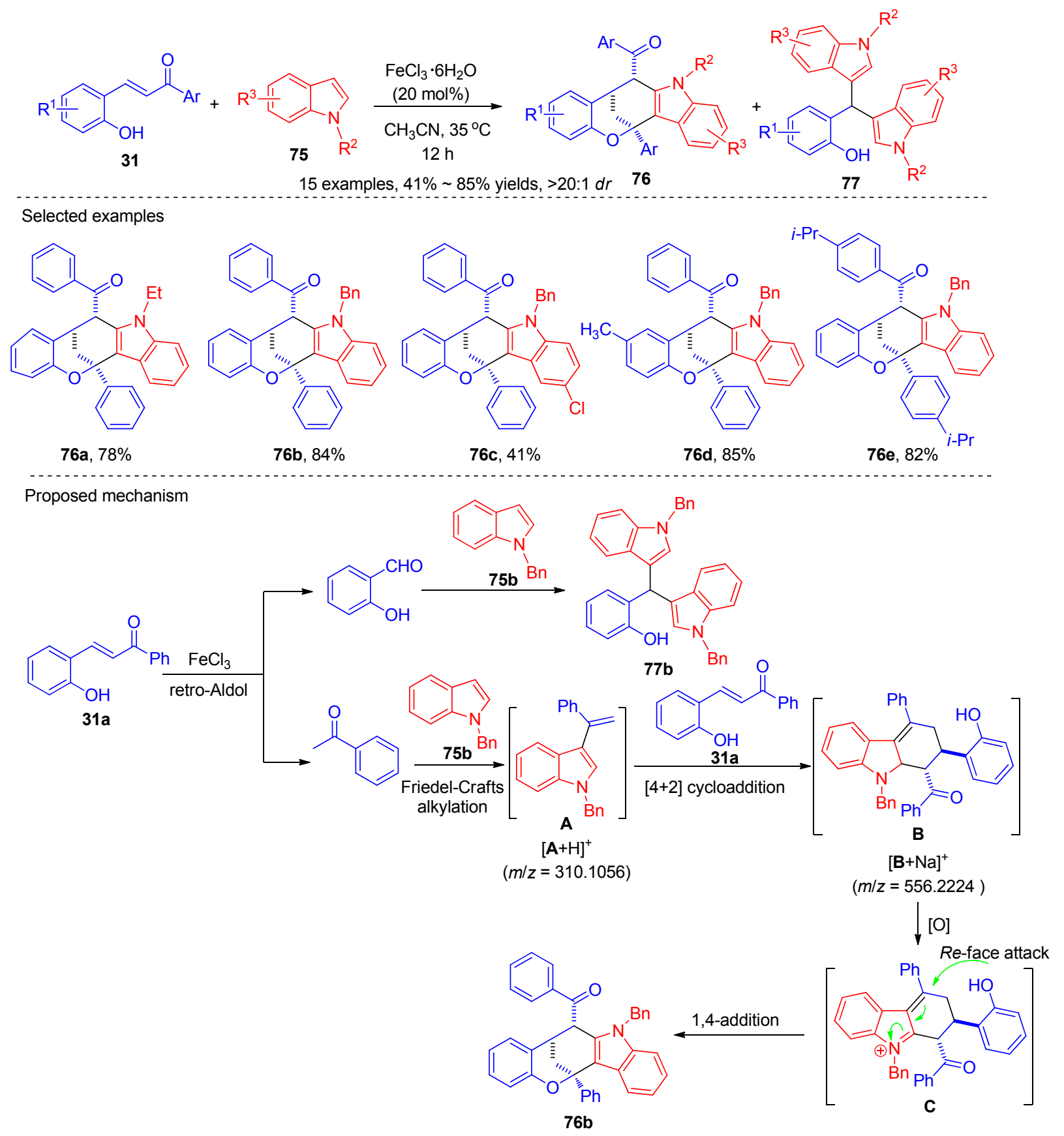

图式 21 吲哚和邻羟基查尔酮参与的多组分串联环化反应

Scheme 21 A multicomponent cascade reaction of indoles and ortho-hydroxychalcones 
2-吡喃酮是一类很好的 $4 \mathrm{C}$ 合成子, 可以作为双烯 体与 Michael 受体如 $\alpha, \beta$-不饱和酮、 $\alpha, \beta$-不饱和硝基烯烃 以及马来酰亚胺等发生 $[4+2]$ 环加成反应 $^{[37]}$. 但是, 其 缺电子的结构特点, 导致反应活性较低, 因此发展高效 的反应体系和催化体系具有一定的挑战. 2017 年, 王春 江课题组 ${ }^{[38]}$ 开发了 3-羟基-2-吡喃酮 78 与 “潜手性” 环 戊烯二酮 79 参与的去对称化的不对称 Diels-Alder 反应,
在金鸡纳碱衍生的多氢键叔胺硫脲 81 作用下，以 $43 \% \sim 91 \%$ 的收率和优秀的立体控制 $(>20: 1 d r$, $80 \% \sim 96 \% e e$ ) 得到含有五个手性中心的桥环多环产物 80 (Scheme 22).

2020 年, Snyder 等 ${ }^{[39]}$ 报道了脯氨醇硅醚 84 催化的 2-吡喃酮 78 和 $\alpha, \beta$-不饱和醛 82 参与的不对称 [4+2]环 加成反应(Scheme 23, a). 该反应过程操作简单, 对空气

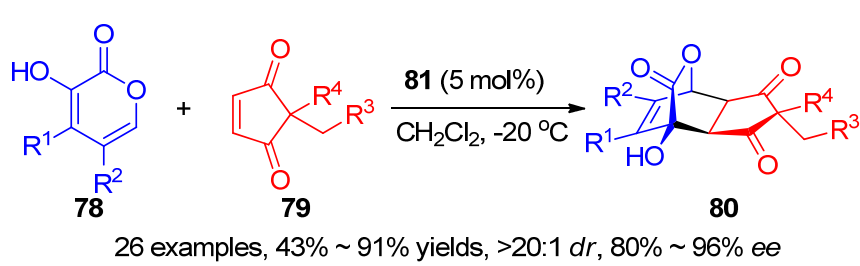<smiles>C=CC1CN2CCC1C2C(NC(=S)NC(c1ccccc1)c1ccccc1)c1ccnc2ccccc12</smiles>

For selected examples

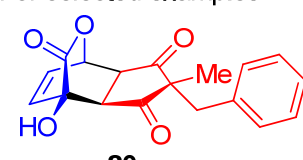

80a

$85 \%$ yield, $94 \%$ ee

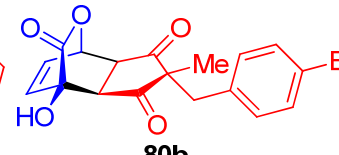

80b

$86 \%$ yield, $92 \%$ ee

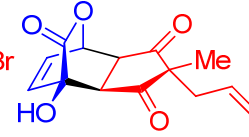

80c $67 \%$ yield, $93 \%$ ee

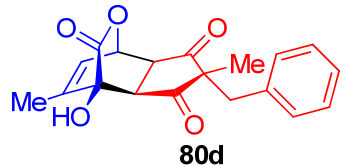

$85 \%$ yield, $94 \%$ ee

图式 223 -差基吡喃酮与环戊烯二酮参与的不对称 Diels-Alder 反应

Scheme 22 Asymmetric Diels-Alder reaction of 3-hydroxypyrones with cyclopentendiones

(a) Snyder's work<smiles>[X]c1cc(C([R])(C)O)coc1=O</smiles>

78<smiles>[R]C/C([R])=C/C=O</smiles>

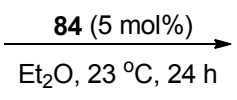

$\mathrm{Et}_{2} \mathrm{O}, 23^{\circ} \mathrm{C}, 24 \mathrm{~h}$

mples, $46 \% \sim 96 \%$ yields p to $99 \%$ ee, $>20: 1 d r$

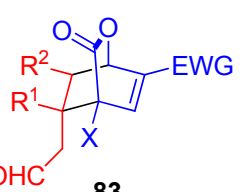

83

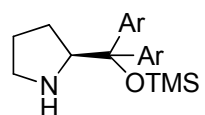

84

Selected examples

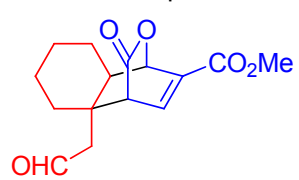

83a, $50 \%$ 3.1:1 dr, 94\% ee

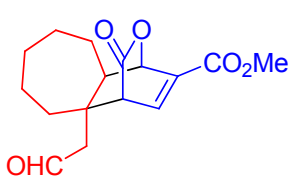

$83 b, 76 \%$ $8.7: 1 d r, 97 \%$

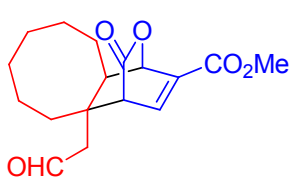

$83 c, 75 \%$

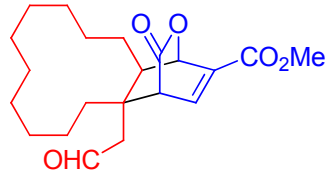

$83 d, 47 \%$ $>20: 1 d r, 21 \%$ ee

\section{(b) Albrecht's work}<smiles></smiles>

78

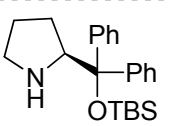

$39(20 \mathrm{~mol} \%)$ $24 \sim 72 \mathrm{~h}$ 2.3:1 dr, 59\% ee

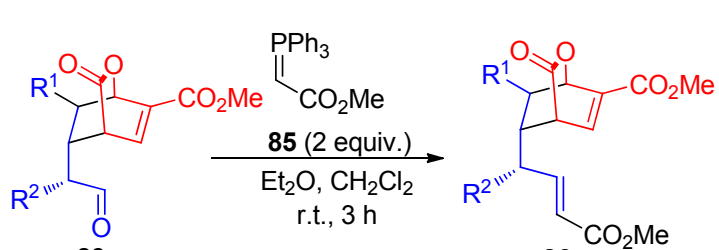

83

86

Selected examples

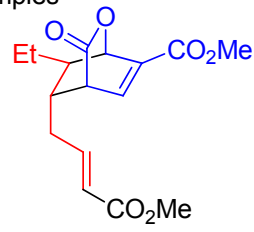

86a, $92 \%$ 20:3:1.5:1 dr, 88\% ee

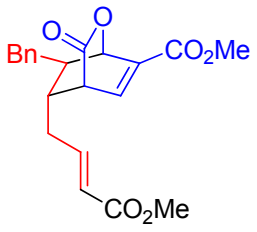

86b, $85 \%$

13:1.1:1 dr, $84 \%$ ee

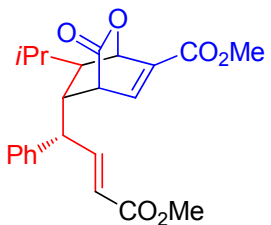

86c, $83 \%$

4:1:0:0 dr, 99\% ee

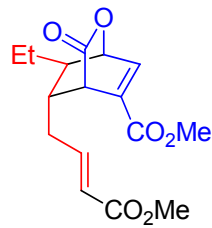

86d, $85 \%$

$2: 1 d r, 14 \% / 20 \%$ ee

图式 23 吡喃酮和 $\alpha, \beta$-不饱和醛参与的不对称的 $[4+2]$ 环加成反应

Scheme 23 Asymmetric [4+2] cycloadditions of pyrones and $\alpha, \beta$-unsaturated aldehydes 
或水分并不敏感, 不需要酸添加剂, 仅需要 $5 \mathrm{~mol} \%$ 的催 化剂在室温条件下即可顺利进行, 以不错的结果得到手 性[2.2.2]二环内酯 83. 反应底物耐受性比较好, $\alpha, \beta$-不饱 和醛 82, 无论是链状的, 还是环状的, 甚至是大环状的, 均可参与反应. 同年, Albrecht 课题组 ${ }^{[40]}$ 也报道了类似 的 2-吡喃酮 78 和链状 $\alpha, \beta$-不饱和醛 82 参与的不对称的 $[4+2]$ 环加成反应, 经后续的 Wittig 反应, 也能以不错 的结果得到手性[2.2.2]二环内酯 86 (Scheme 23, b).

2018 年, Reddy 课题组 ${ }^{[41]}$ 利用手性双官能硫脲 90 催化 3-吲哚酮-2-羧酸酯 87 与环己烯酮 88 的 Robinson 环化反应, 高效地合成了具有四个连续的手性中心的手 性桥连咔唑衍生物 89 (Scheme 24). 该反应经历 Michael 加成/分子内 Aldol 串联过程, 具有优秀的非对映选择性 和良好至优秀的对映选择性(>20：1 $d r, 74 \% \sim 98 \%$ $e e$ ). 很遗憾的是, 该反应仅限于环已烯酮 $\mathbf{8 8}$, 当采用环 戊烯酮或链状的甲基乙烯基酮作为底物时, 仅得到 Michael 加成的产物, 后续的 Aldol 反应无法进行. 另外, 吲哚酮 87 的结构对产物也有影响, 如 3-吲哚酮的苯环 被噻吩取代时，也仅仅得到 Michael 加成产物 89e.

\section{$1.4[4+3]$ 环加成反应构建桥环化合物}

烯丙基阳离子与二烯烃的 $[4+3]$ 环加成反应是制备 七元环的有效方法 ${ }^{[42]}$. 2017 年, Harmata 课题组 ${ }^{[43]}$ 报道 了 $N$-烷基 5-着基烟酸甲酯 91 与共轭二烯 92 的 $[4+3]$ 环加成反应，以 $46 \% \sim 99 \%$ 的收率合成了系列 7-氮杂双 环[4.3.1]癸烷(Scheme 25). 对于 1-取代和 1,2-双取代的 1,3-丁二烯，反应可以区域专一地生成 93. 对于 2-取代 的 1,3-丁二烯，反应面临区域选择性低的缺点. 此外, 该反应还可以在吡定盐的 $N$-保护基上引入双烯体, 发 生分子内的 $[4+3]$ 环加成反应(Scheme 25). 密度泛函 (DFT)理论计算表明，环加成反应经历协同机理.

2017 年, Vicario 课题组 ${ }^{[44]}$ 以联烯酰胺 96 和呋喃 97 为起始原料，在手性 Brønsted 酸 99 和二甲基过氧化酮 (DMDO)的作用下，实现了二者的不对称氧化/[4+3]环 加成串联反应(Scheme 26). 该合成策略适用于各种取 代联烯和呋喃，具有较好的底物耐受性，以 $45 \% \sim 87 \%$ 的收率和 $72 \% \sim>99 \%$ 的对映选择性得到 8-氧杂双环 [3.2.1]辛烷 98. 如 Scheme 26 所示, 联烯酰胺 96 和二甲 基过氧化酮发生氧化/开环生成氧杂烯丙基碳正离子 III<smiles>[R1]c1ccc2c(c1)C(=O)C(C(C)=O)N2[R]</smiles>

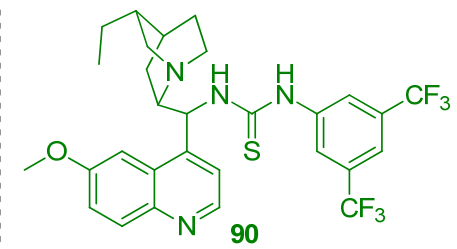

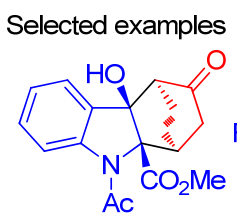

$89 a, 75 \%, 96 \%$ ee

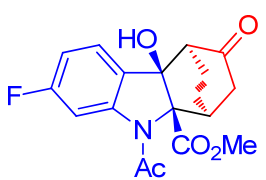

89b, $72 \%, 91 \%$ ee

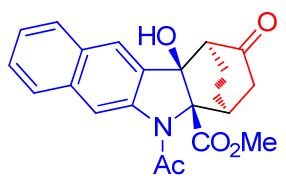

$89 c, 80 \%, 95 \%$ ee

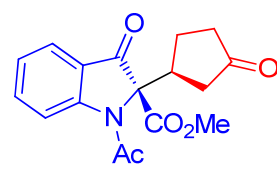

89d, 91\%, 64\% ee

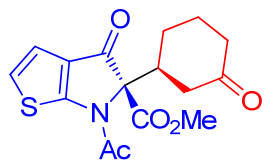

89 e, $90 \%, 63 \%$ ee

图式 24 不对称 Robinson 环化反应制备手性桥连咔唑衍生物

Scheme 24 Asymmetric Robinson annulation for the construction of chiral bridged tricyclic hydrocarbazoles

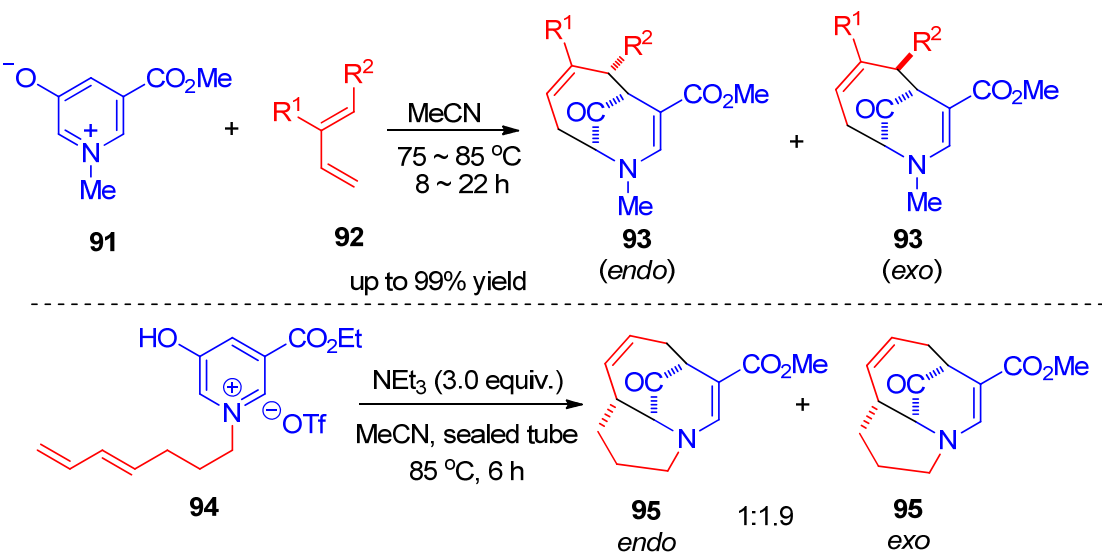

图式 $25 N$-烷基氧化吡啶盐与共轭二烯的 $[4+3]$ 环加成反应

Scheme $25[4+3]$ cycloaddition of $N$-alkyl oxidopyridinium ions with conjugated dienes 
是反应的核心，随后 III 与呋喃 97 发生[4+3]环加成反 应得到 8-氧杂双环[3.2.1]辛烷 98. 在反应过程中, 手性 磷酰亚胺催化剂 99 通过分子间氢键和离子对相互作用 来活化氧杂烯丙基碳正离子 III, 从而实现手性转移.
2018 年, Lautens 课题组 ${ }^{[45]}$ 报道了樟脑磺酸催化的 重氮酰亚胺 100 与原位生成的邻亚甲基醌 101 参与的 $[4+3]$ 环加成反应，以 $30 \% \sim 81 \%$ 的收率实现了氧杂桥 环噁唑嗪 102 的非对映选择性合成(Scheme 27). 该反应<smiles>[R]C=C=CN([R])[R]</smiles>

25 examples, $45 \% \sim 87 \%$ yields, $72 \% \sim>99 \%$ ee
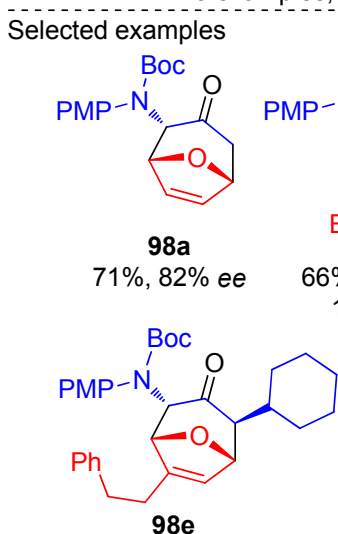

$70 \%, 96 \%$ ee

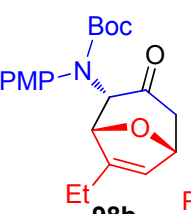

$\mathbf{9 8 b}$ $10: 1$ r.r.
10.

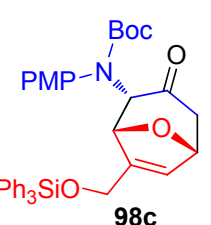

$68 \%, 90 \%$ ee

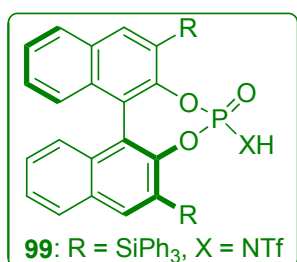

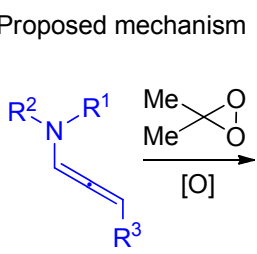

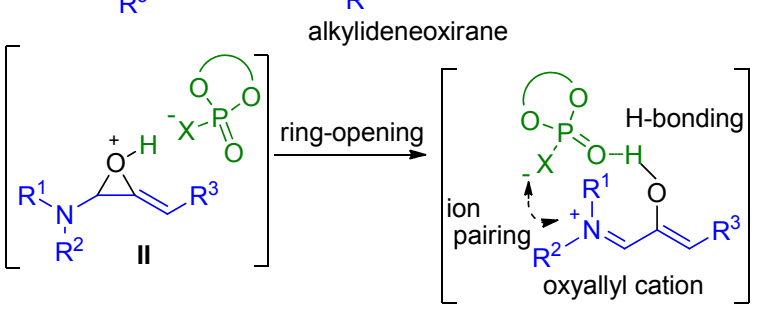

$4 \%, 90 \%$ ee

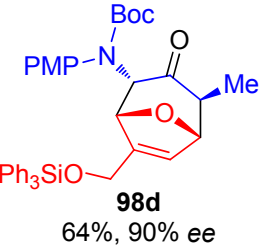

$\mathrm{R}^{2} \mathrm{~N}^{-\mathrm{R}^{1}}$

III

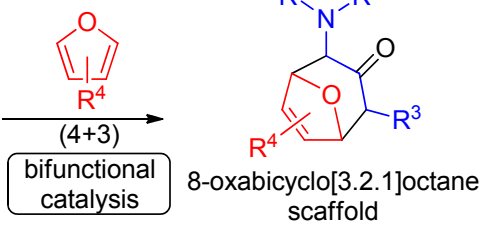

图式 26 丙二烯酰胺和呋喃参与的不对称氧化/[4+3]环加成反应

Scheme 26 Asymmetric oxidative $[4+3]$ cycloadditions between allenamides and furans<smiles>CC(=O)C(=N)C(=O)N1CCCCC1=O</smiles>

100<smiles>Oc1ccc2c3c1CCCC23</smiles>

101

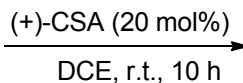

20 examples, $30 \% \sim 81 \%$ yields

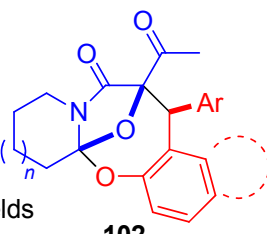

102

single diastereomer
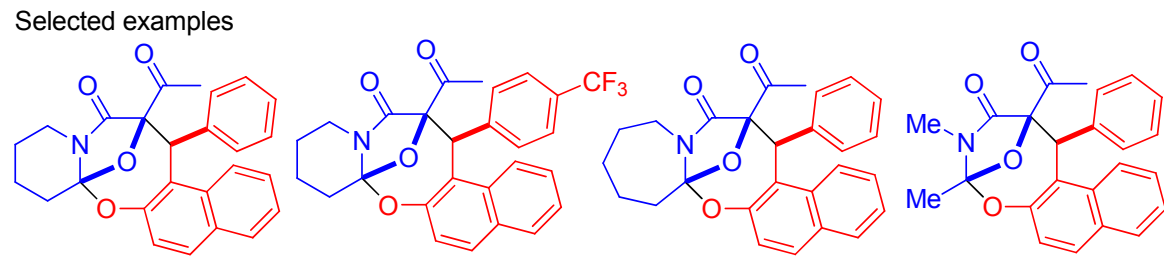

102a, $78 \%$ yield

102b, $49 \%$ yield

102c, $81 \%$ yield

102d, $56 \%$ yield<smiles>CC(=O)C(=N)C(=O)N1CCCCC1=O</smiles>

100<smiles>Oc1ccc2c3c1CCC2C3</smiles>

101
$\underset{\mathrm{DCE}, \text { r.t., } 10 \mathrm{~h}}{\stackrel{(+)-C S A}{\longrightarrow}}$

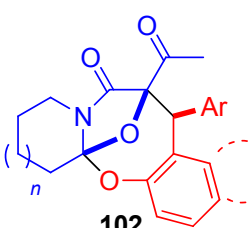

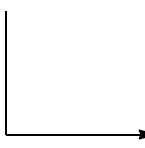

A

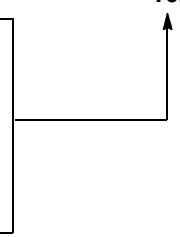

图式 27 邻亚甲基醌参与的无金属催化 [4+3]环加成反应

Scheme 27 Metal-free [4+3] cycloaddition of ortho-quinone methides 
无需使用贵金属, 在酸的作用下, 重氮酰亚胺 100 发生 分子内的环化反应生成 1,3-偶极子中间体 $\mathbf{A}$, 而 $\mathbf{1 0 1}$ 生 成活性邻亚甲基醌 $\mathbf{B}$, 随后发生分子间的 [4+3]环加成 反应，高非对映选择性地合成氧杂桥环噁唑嗪 102 .

2019 年, 冯小明课题组 ${ }^{[46]}$ 利用双金属接力催化策 略, 实现了重氮酰亚胺 103 与 $\alpha, \beta$-不饱和酮酸酯 104 的 不对称 $[4+3]$ 环加成反应, 以 $51 \% \sim 90 \%$ 的收率和 $85 \% \sim 99 \%$ 的对映选择性构建了系列具有三个手性中心 的氧杂桥环噁唑嗪 105. 如 Scheme 28 所示, 在金属铑的 作用下，重氮酰亚胺 103 原位生成 1,3-偶极子 isomünchnones, $\mathrm{Zn}(\mathrm{OTf})_{2}$ 作为路易斯酸活化 $\alpha, \beta$-不饱和 酮酸 104, 从而促进 $[4+3]$ 环加成反应的进行. 在该催化 体系中, 配体不但控制反应的立体化学, 同时还起到加 速反应的作用. 随后, Schneider 课题组 ${ }^{[47]}$ 报道了铑和手 性磷酸协同催化的 $[4+3]$ 环化反应. 该反应经历金属铑 催化原位生成的羰基叶立德和手性磷酸催化原位制备
的邻亚甲基醌参与的不对称 $[4+3]$ 环加成过程，以高达 96\%的收率和良好的立体选择性(up to $94 \%$ ee, up to $>$ 20:1 $1 d r$ )合成了系列复杂桥环化合物 109 (Scheme 29).

2019 年, Reddy 课题组 ${ }^{[48]}$ 开发了铑(III)催化 2-芳基 咪唑[1,2- $a$ 吡啶 111 与环已烯酮 88 的串联环化反应 (Scheme 30). 该反应底物普适性比较广，2-芳基咪唑 [1,2- $a$ ]吡啶 111 的 2-位是取代苯环、芸环和噻吩环时, 反 应均能顺利发生, 并以高收率、高立体选择性和高区域 选择性合成了系列桥连咪唑吡啶衍生物 112. 但是, 当 2-芳基咪唑[1,2- $a$ 吡啶 111 的 2-位为苯并呋喃取代时, 仅仅得到 1,4-加成的产物 112f. 基于实验结果, 作者提 出了可能的反应途径. 如 Scheme 30 所示, 首先, 反应 经历铑(III)催化的芳基邻位 $\mathrm{C}-\mathrm{H}$ 键与环己烯酮 88 参与 的 1,4-加成, 生成中间体 D, 随后发生分子内的 FriedelCrafts 烷基化反应，最终得到 112a.
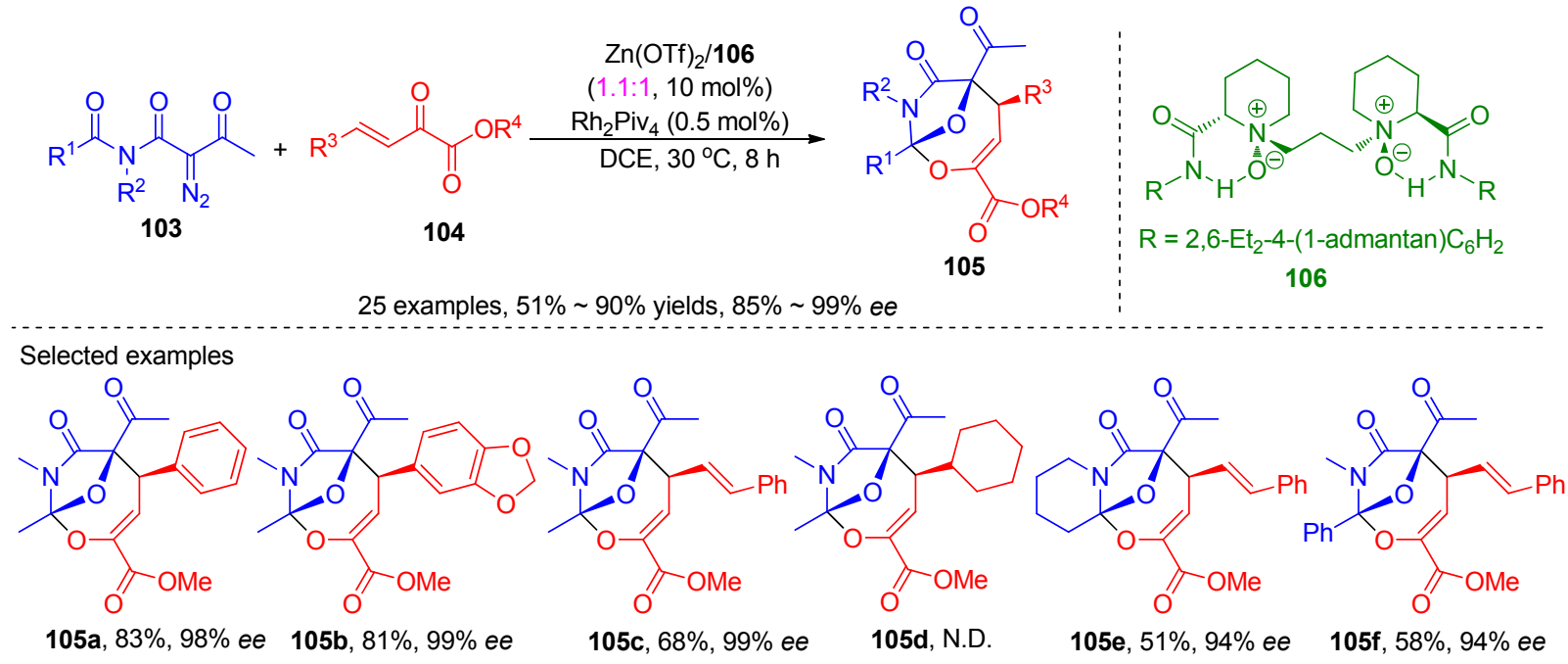

Proposed mechanism

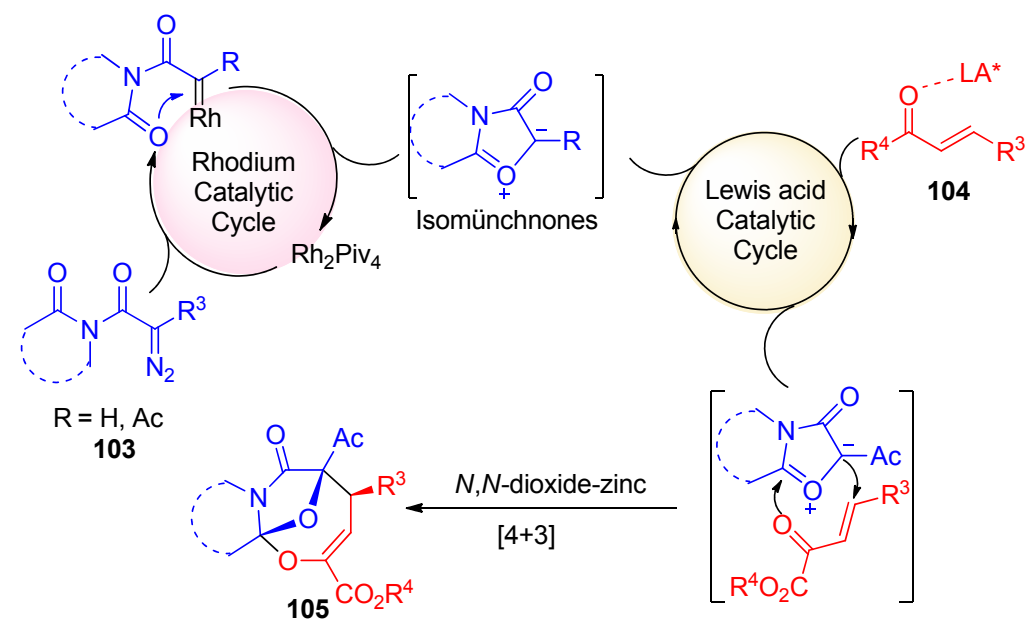

图式 28 双金属 “接力” 催化[4+3]环加成反应构建手性氧杂噁唑嗪桥环化合物

Scheme 28 Asymmetric synthesis of oxa-bridged oxazocines through a bimetallic relay [4+3] cycloaddition reaction 


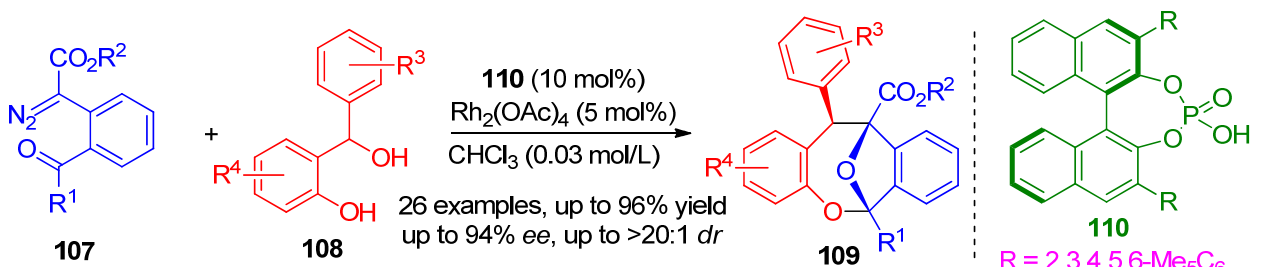

Selected examples

$\mathrm{MeO}$
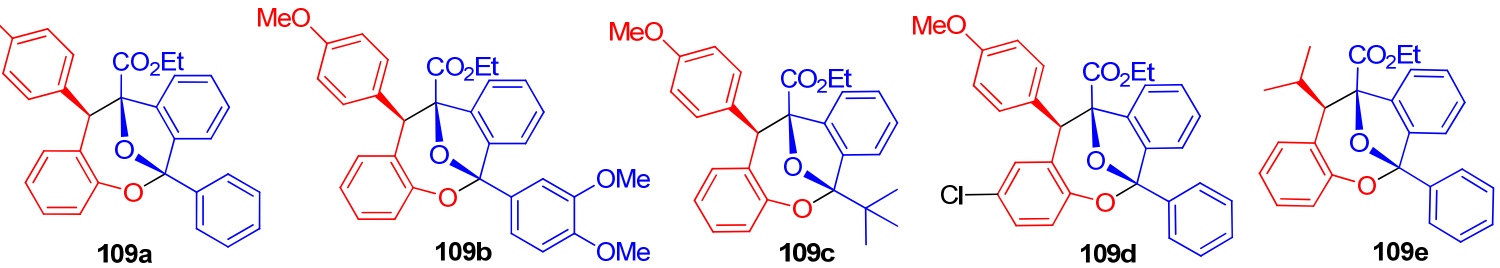

$96 \%, 20: 1 d r, 92 \%$ ee $92 \%,>20: 1 d r, 94 \%$ ee $83 \%, 6: 1 d r, 82 \%$ ee $85 \%, 10: 1 d r, 82 \%$ $<5 \%, \mathrm{ND}$ Proposed mechanism
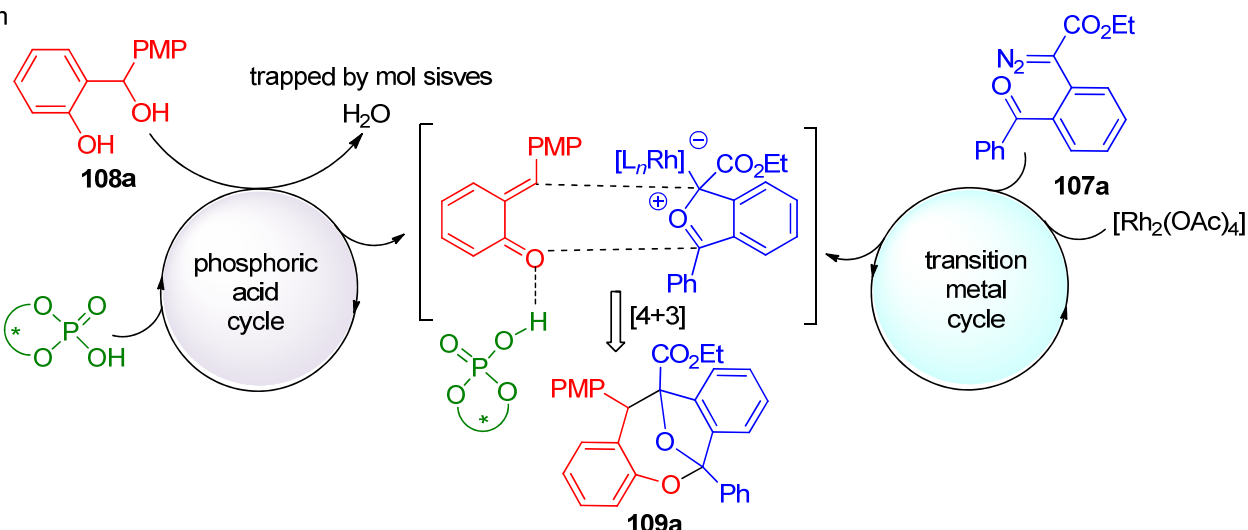

图式 29 羰基叶立德与邻亚甲基醌的不对称 $[4+3]$ 环加成反应

Scheme 29 Asymmetric [4+3] cycloaddition of carbonyl ylides with ortho-quinone methides

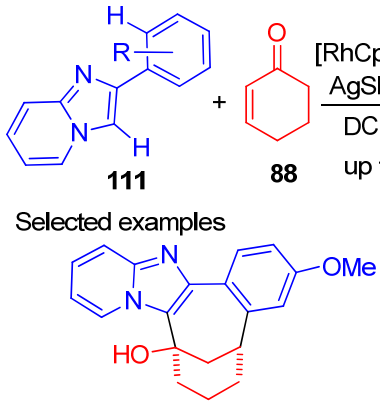

$112 a, 92 \%$ yield

Me<smiles></smiles>

112c, $92 \%$ yield

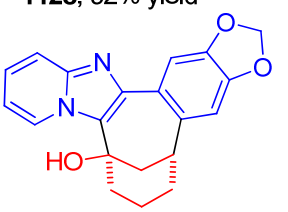

112 e, $94 \%$ yield

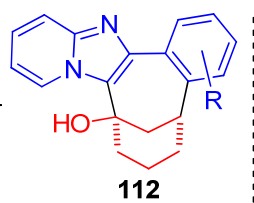

112

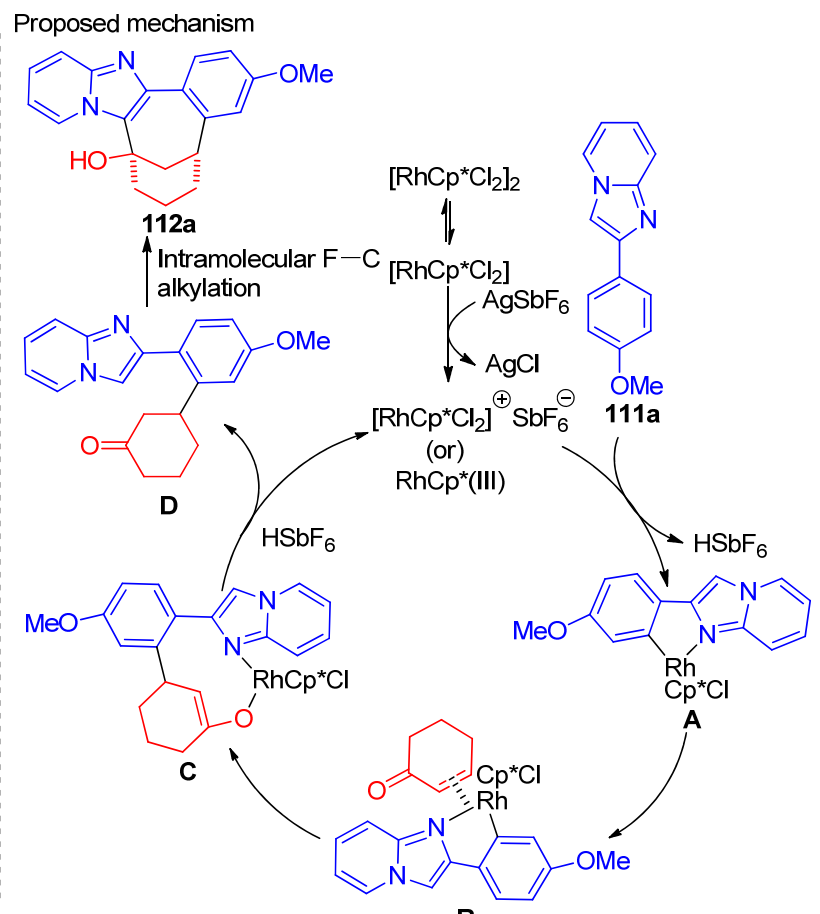

图式 30 铑(III)催化 2-芳基咪唑[1,2-a]吡啶与环己烯酮的串联环化反应

Scheme 30 Rh(III)-Catalyzed tandem bicyclization of 2-arylimidazo[1,2-a]pyridines with cyclohexanone 
2019 年, 赵明课题组 ${ }^{[49]}$ 采用 $\alpha$-溴代异羟肟酸 113 与 氨茴内酐 114 为起始原料, 在碱的作用下, 113 先失去一 分子溴化氢生成氮杂烯丙基碳正离子, 随后与氨茴内酤 114 发生 $[4+3]$ 环加成反应，最终以 $30 \%$ ～99\%的收率合 成了系列多取代苯二氮草类化合物 115 (Scheme 31). 该 方法无需金属催化, 具有条件温和及反应效率高等特 点. 但该反应原料仅限于 $\alpha$-溴代异羟肟酸, 当采用 $\alpha$-溴 代酰胺时, 反应无法进行, 可能是由于产生的氮杂烯丙 基碳正离子稳定性差导致的 ${ }^{[50]}$.

2020 年, Rossi 课题组 ${ }^{[51]}$ 报道了 2-乙烯基吲哚或 $4 H$ 呋喃[3,2-b]吲哚 116 与 $\alpha$-卤代酮 117 发生的[4+3]环加 成反应, 合成了环庚烷 $[b]$ 吲哚 118、118' 和 119、119' (Scheme 32). $\alpha$-卤代酮 117 在碱的作用下, 生成氧杂烯 丙基碳正离子, 随后与 116 发生 $[4+3]$ 环加成得到目标
产物.

\section{$1.5[4+4]$ 环加成反应构建桥环化合物}

2020 年, 李靖课题组 ${ }^{[52]}$ 报道了邻乙炔基茮醇 120 与 环状 $\alpha, \beta$-不饱和酮酰胺 121 参与的环化串联反应 (Scheme 33). 有意思的是, 可以通过调节共催化剂的种 类，选择性实现螺环 $O, O$-缩酮 122 和桥环 $O, O$-缩酮 123 的高效多样性合成. 通过分析反应过程, 作者认为: 首 先，在金的作用下，邻乙炔基茮醇 120 发生分子内环化 生成中间体 $\mathbf{A}$, 在路易斯酸 $\mathrm{Ni}(\mathrm{OTf})_{2}$ 的作用下, $\mathbf{A}$ 作为亲 双烯体与 $\alpha, \beta$-不饱和酮酰胺 121 发生反电子需求的 $[4+$ 2]环加成反应，用于构建螺环缩酮 122. 而在 Brønsted 酸的作用下, $\mathbf{A}$ 还可以异构为双烯体 $\mathbf{B}$, 随后与 121 发生 [4+4]环加成反应，用于构建桥环缩酮 123.
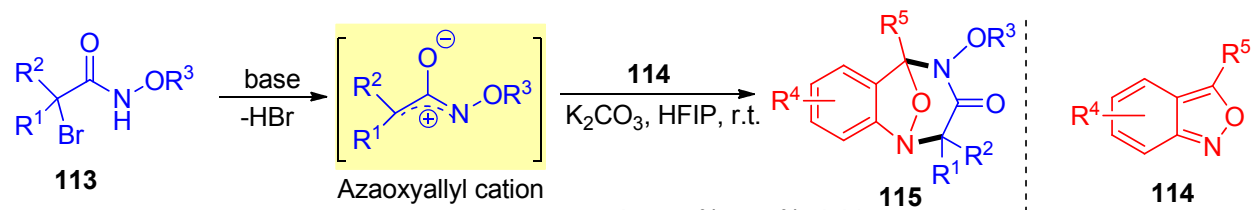

24 examples, $30 \% \sim 99 \%$ yields

114

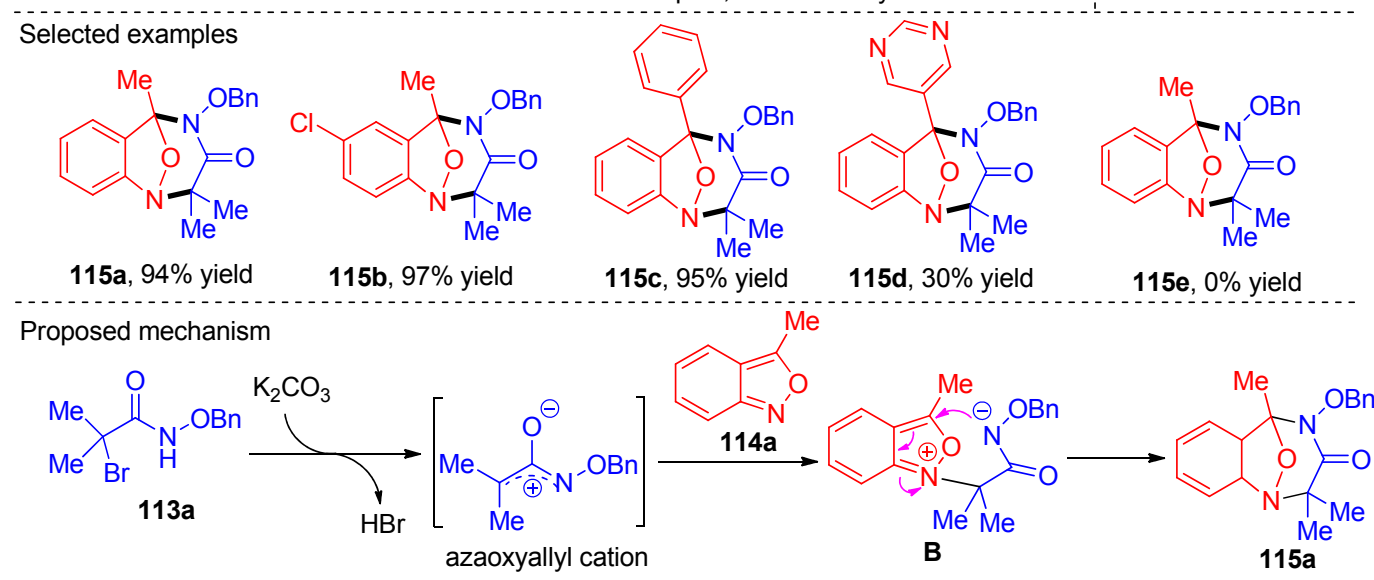

图式 $31 \alpha$-溴代异羟弜酸与氨茴内酐参与的 $[4+3]$ 环加成反应

Scheme $31[4+3]$ cycloaddition of $\alpha$-bromohydroxamates with anthranils

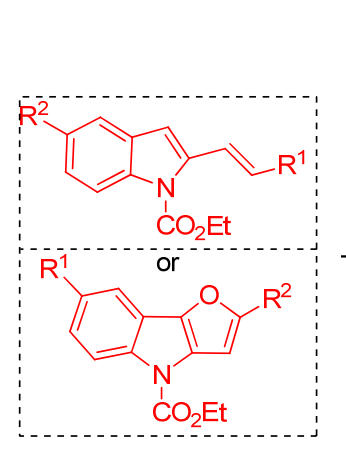

116

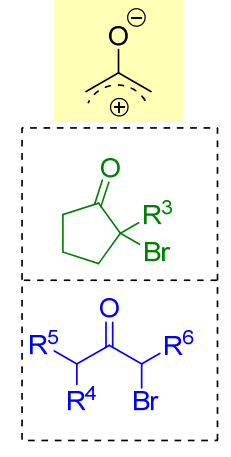

117

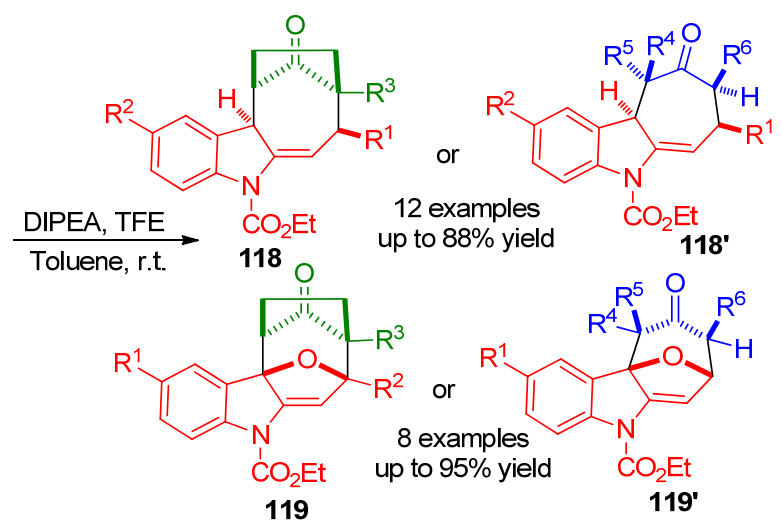

119

119'

图式 $32[4+3]$ 环加成反应合成环庚烷 $[b]$ 哚

Scheme 32 Construction of cyclohepta[b]indoles through $[4+3]$ cycloadditions 

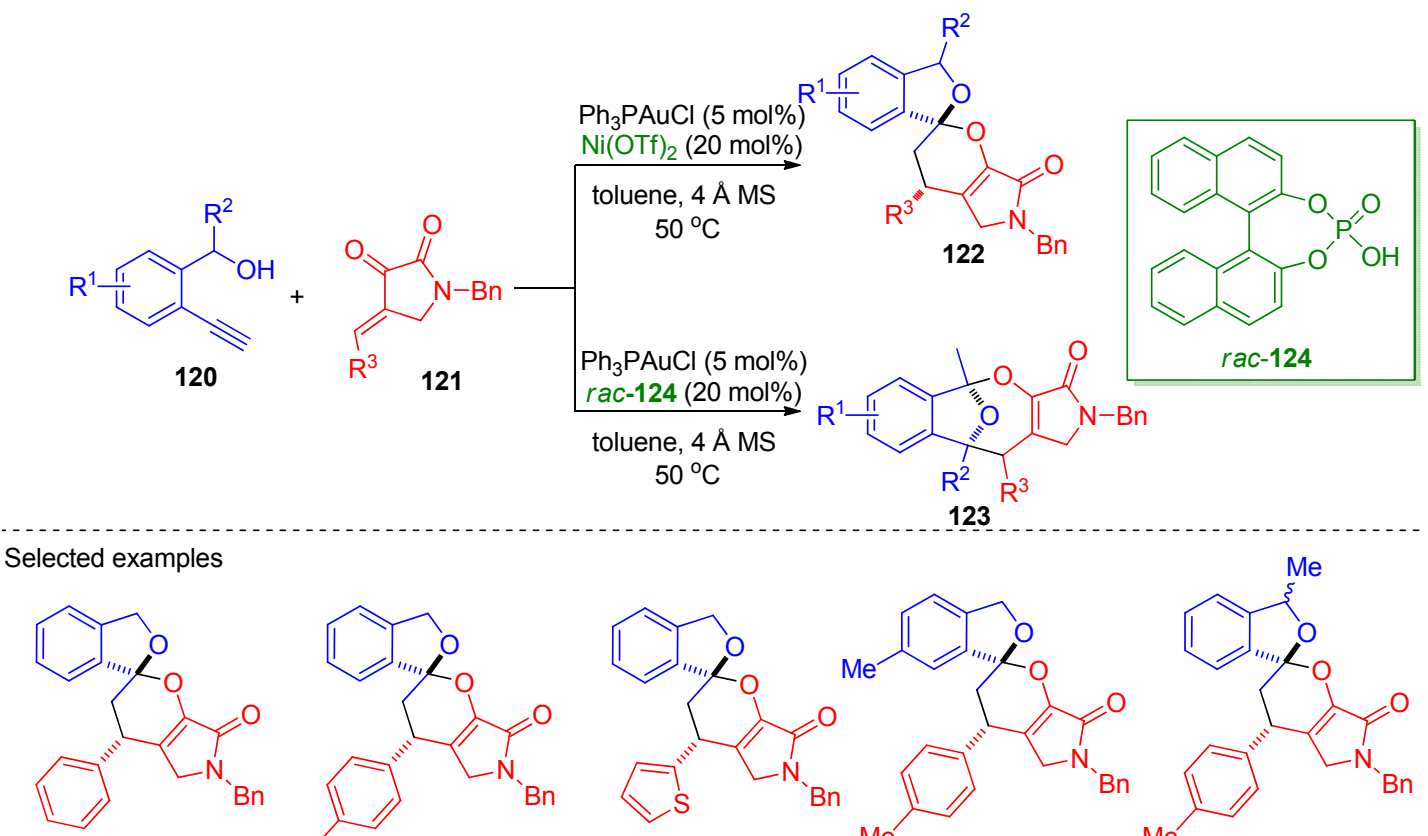

122a

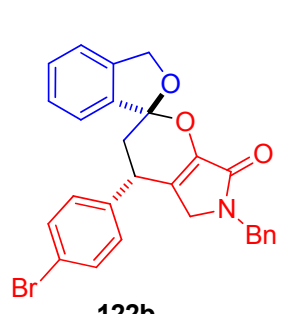

$122 b$<smiles>O=C1C2=C(CN1Br)[C@@H](c1cccs1)C[C@@]1(OCc3ccccc31)O2</smiles><smiles>Cc1ccc(C2CC3(OCc4ccc(C)cc43)OC2=C2CN(Br)CC2=O)cc1</smiles>

122d

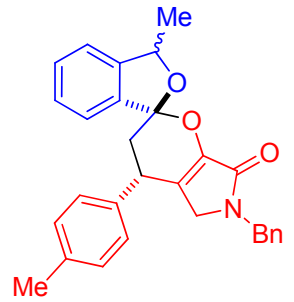

$122 \mathrm{e}$

88\% yield, $14: 1 d r \quad$ 76\% yield, $12: 1 d r \quad$ 43\% yield, >20:1 $d r \quad$ 71\% yield, 11:1 $d r \quad$ 91\% yield, $11: 6.3: 1 d r$<smiles>CC12OC3=C(CN(Cc4ccccc4)C3=O)C(c3ccccc3)[C@H]1c1ccccc12</smiles><smiles>C[C@@]1(c2ccccc2)O[C@@H]2C(c3ccc(Br)cc3)C3=C(O[C@@]21C)C(=O)N(Cc1ccccc1)C3</smiles><smiles>C[C@]12OC3=C(CN(Cc4ccccc4)C3=O)[C@H](c3cccc4ccccc34)[C@H]1c1ccccc12</smiles><smiles>CC12OC3=C(CN(Cc4ccccc4)C3=O)C(c3cccs3)[C@H]1c1ccccc12</smiles>

123a, $94 \%$ yield, $10: 1 d r$

123b, $80 \%$ yield, $6: 1 d r$

123c, $64 \%$ yield, $4: 1 d r$

123d, $76 \%$ yield, $>20: 1 d r$

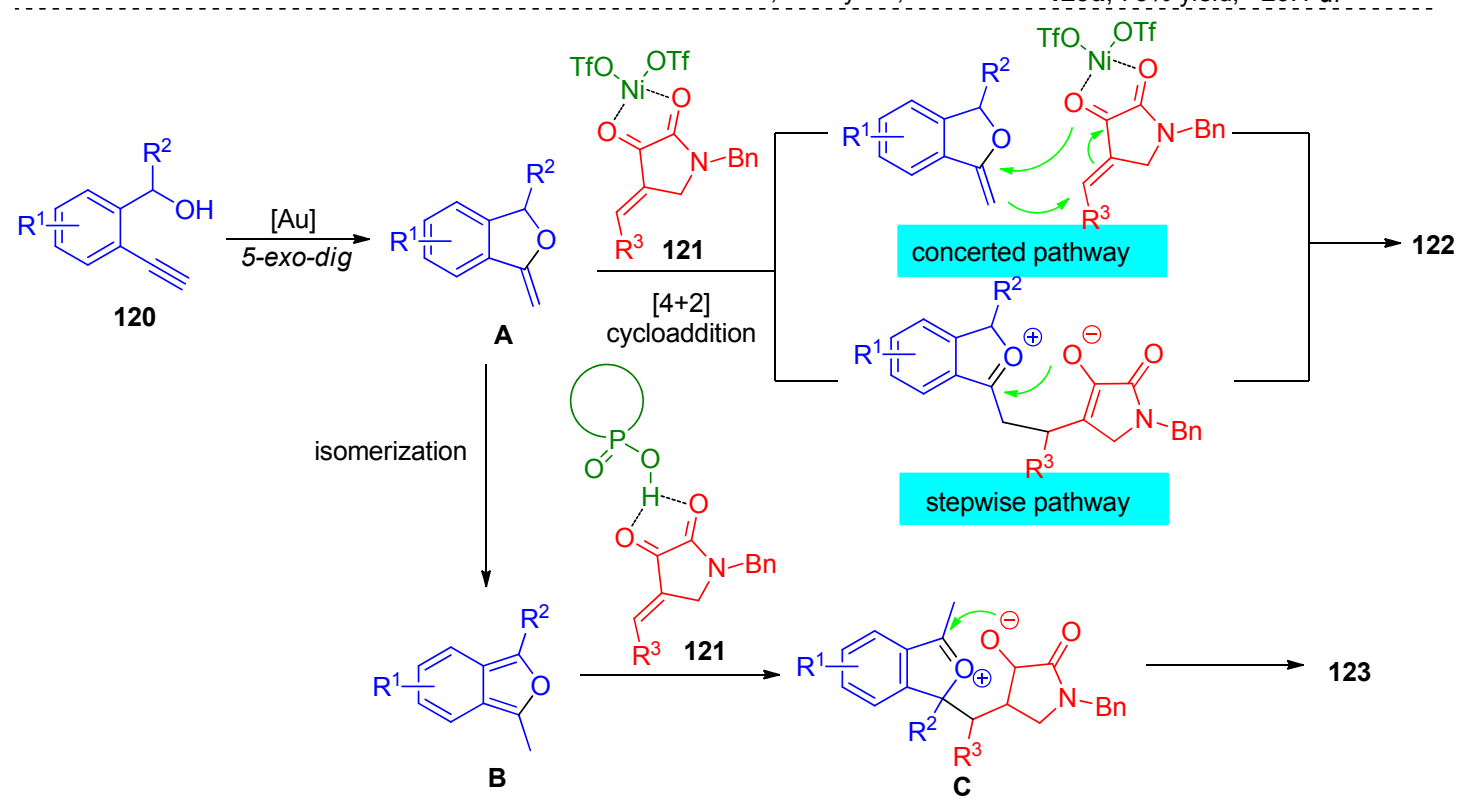

图式 33 共催化剂控制多样性合成螺环 $O, O$-缩酮和桥环 $O, O$-缩酮

Scheme 33 Cocatalyst-controlled diverse synthesis of spiro- and bridged- $O, O$-ketals

\section{$1.6[5+2]$ 环加成反应构建桥环化合物}

2010 年余志祥等 ${ }^{[53]}$ 提出了 type-II [5+2]环加成反 应的概念. 最近, 李创闯课题组 ${ }^{[8]}$ 通过 type-II 型分子内
$[5+2]$ 环加成反应，高效地合成了各种高度功能化的复 杂桥连七元环结构(Scheme 34) ${ }^{[54]}$. 该反应具有广泛的 底物范围和较高的产率，且该反应环化不依赖于 Thorpe-Ingold 效应(偕二甲基效应). 以此方法作为关键 
步骤，作者实现了天然产物 Ingenol、Cyclocitrinol ${ }^{[55]}$ 、 Cerorubenic acid-III ${ }^{[56]}$ 和 Eurifoloid $\mathrm{A}^{[57]}$ 的全合成.
2016 年, 谭斌课题组 ${ }^{[58]}$ 报道了 $\alpha, \beta$-不饱和醛与异喹 啉盐的不对称 $[5+2]$ 环加成反应(Scheme 35). 在手性氮
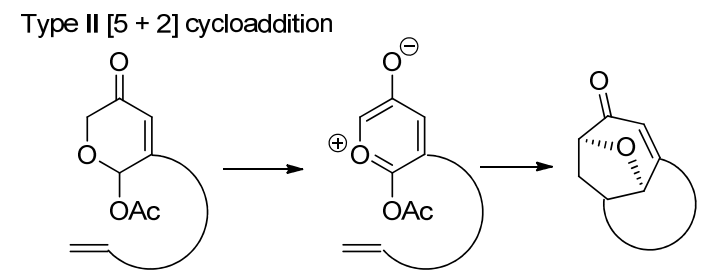<smiles>[R]CC1OC([R])C(=O)C=C1C([R])([R])CC([R])([R])C([R])=C([R])[R]</smiles>

125
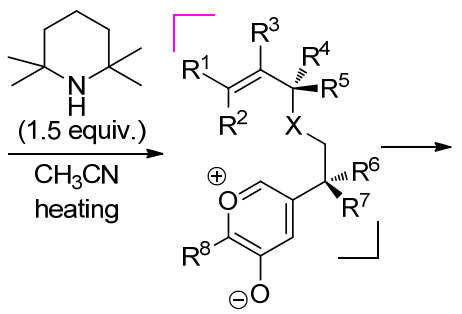

126

图式 34 Type-II 分子内 $[5+2]$ 环加成反应

Scheme 34 Type-II intramolecular [5+2] cycloadditions
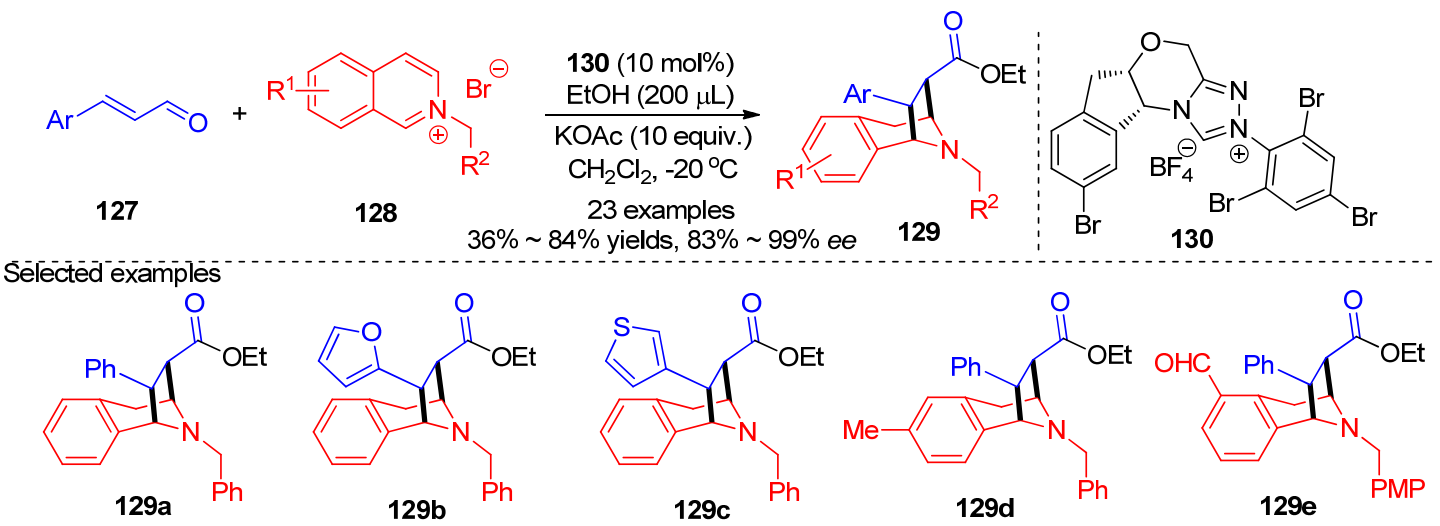

$67 \%$ yield, $93 \%$ ee $\quad 50 \%$ yield, $96 \%$ ee

$62 \%$ yield, $91 \%$ ee

$56 \%$ yield, $94 \%$ ee

$38 \%$ yield, $90 \%$ ee

$$
\text { Multi-component one-pot fashion }
$$

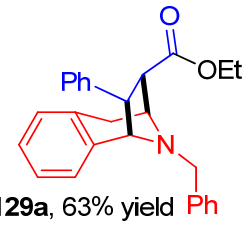

Plausible mechanism

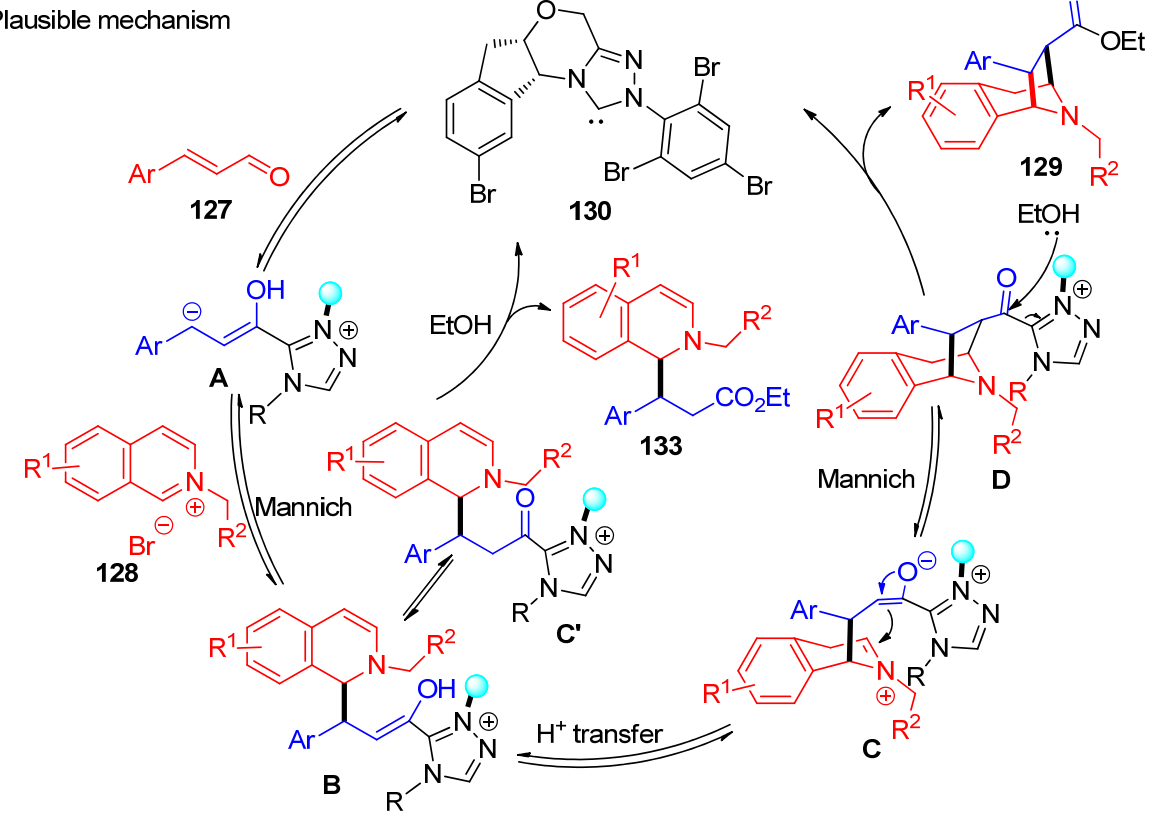

图式 35 不对称去芳构化的 $[5+2]$ 环加成反应构建托品烷衍生物

Scheme 35 Asymmetric dearomative [5+2] cycloadditions of isoquinolines to access tropane derivatives 
杂卡宾 130 的作用下, $\alpha, \beta$-不饱和醛 127 通过与异喹啉盐 128 发生双 Mannich 反应，以 $36 \%$ 84\%收率和 $83 \%$ 99\%的对映选择性合成了具有四个连续手性中心的托 品烷衍生物 129, 最终实现了异喹啉盐的不对称去芳构 化. 值得说明的是, 该反应也能通过原位活化异喹啉的 方式进行, 即 “一锅、四组分” 反应, 且反应效率和立 体控制结果基本不受影响. 基于控制实验和文献报道, 作者提出了反应可能进行的机理. 首先, $\alpha, \beta$-不饱和醛 127 在 130 作用下, 生成含有亲核位点的烯醇中间体 $\mathbf{A}$, 然后与异喹啉盐 128 的 C-1 位发生第一次 Mannich 反应 生成中间体 $\mathbf{B}, \mathbf{B}$ 通过质子转移及后续的分子内 Mannich 反应得到含托品烷骨架的中间体 $\mathbf{D}, \mathbf{D}$ 再与乙醇发生亲 核取代反应, 形成最终产物 129, 而再生的催化剂 NHC 进入下一个循环.

2020 年, 冯小明课题组 ${ }^{[59]}$ 报道了邻硝酮取代苯乙 炔 134 与 3-烯氧化吲哚 8 的不对称串联环异构化/分子 间 $[5+2]$ 环加成反应, 在温和的反应条件下, 实现了一 系列(20个例子)螺托品烷骨架螺环桥环氧化吲哚 135 的 立体选择性合成(up to $>19: 1 d r$, up to $98 \% e e$ ). 该反应 经历双金属 “接力” 催化过程, 即钯(II)催化亚胺叶立德 的原位生成及后续手性路易斯酸催化的 $[5+2]$ 环加成反
应(Scheme 36).

\section{$1.7[5+3]$ 环加成反应构建桥环化合物}

2017 年, 严胜娇课题组 ${ }^{[60]}$ 探索了 1,4-醌单缩酮 136 和杂环烯酮缩胺 137 的[5+3]加成反应, 成功发展了一 种吗啡衍生物 138 的绿色合成新方法(Scheme 37). 该合 成策略主要是基于双 Michael 加成反应进行的, 无需催 化剂和有机溶剂，在水中反应即可获得不错的收率，且 后处理简单, 仅需要简单的过滤和乙醇洗涤便可得到纯 品. 杂环烯酮缩胺 137 的环状大小对反应效率稍有影响, 当由五元环扩至六元甚至七元环时, 收率有所降低.

\section{$1.8[5+4]$ 环加成反应构建桥环化合物}

最近, 范学森课题组 ${ }^{[61]}$ 以 2-芳基吲哚 139 和 1,4-醌 单缩酮 140 为起始原料, 在金属铑的催化下, 经 $[5+4]$ 环加成反应, 构建了具有桥环结构的吲哚多环化合物 (Scheme 38). 有意思的是, 作者可以通过底物调控, 选 择性地实现 C-3 和 N-1 关环. 当采用 C-3 位无取代的 2芳基吲哚时, 反应通过 C-3 位关环实现桥环的构建; 当 采用 C-3 位取代的 2-芳基吲哚时, 反应则在 N-1 位关环. 机理研究表明该反应经历铑催化的 $\mathrm{C}-\mathrm{H}$ 烷基化及后续 的 Michael 加成串联过程.
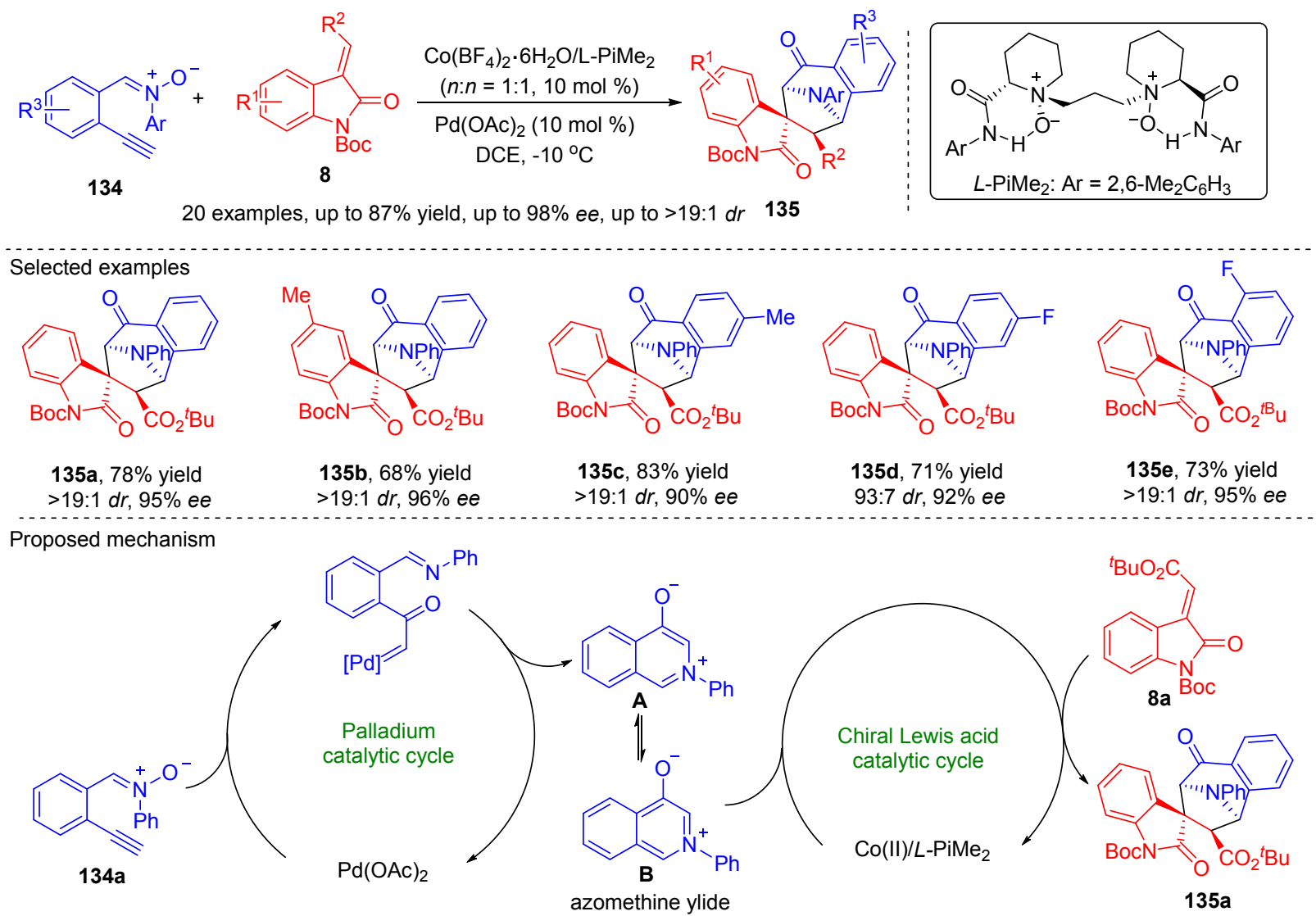

图式 36 双金属 “接力” 催化策略: [5+2]环加成反应构建螺环桥环氧化吲哚

Scheme 36 Bimetallic relay catalysis: an approach to spiro-tropanyl oxindoles through [5+2] cycloadditions 


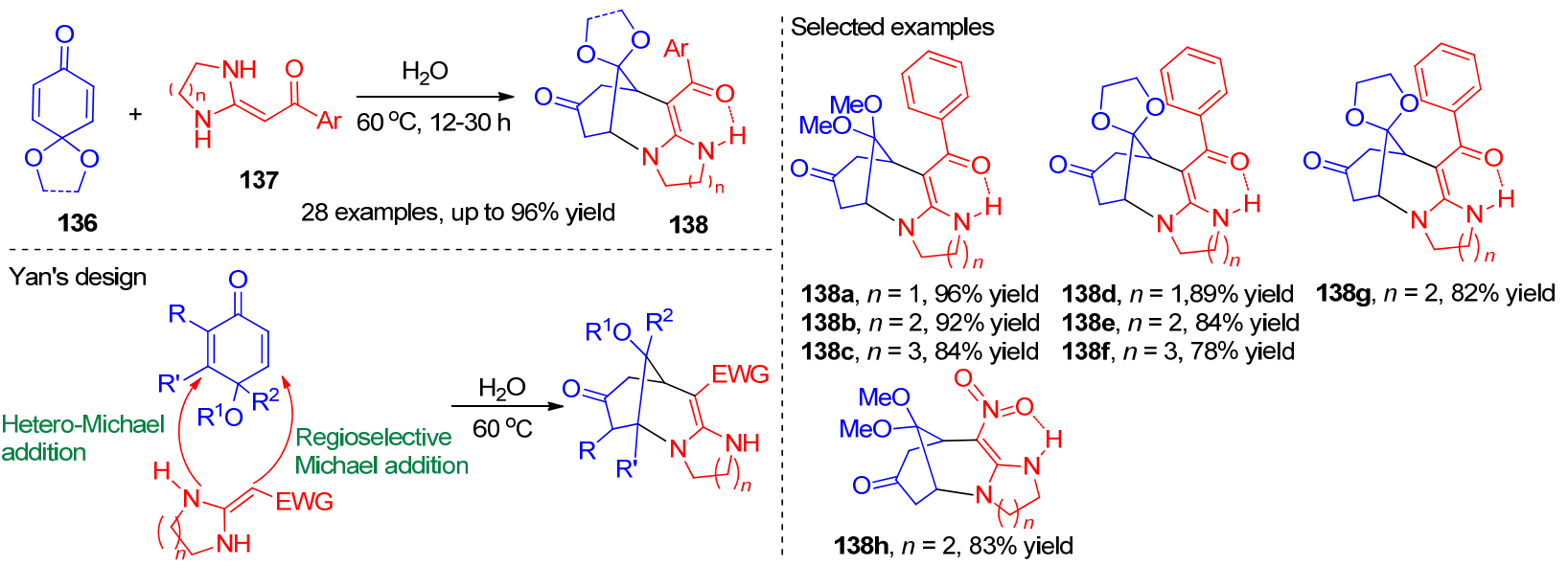

图式 37 苯醌单缩酮和杂环烯酮缩胺的 $[5+3]$ 环加成反应

Scheme 37 A [5+3] cycloaddition of quinone monoketals with heterocyclic ketene aminals
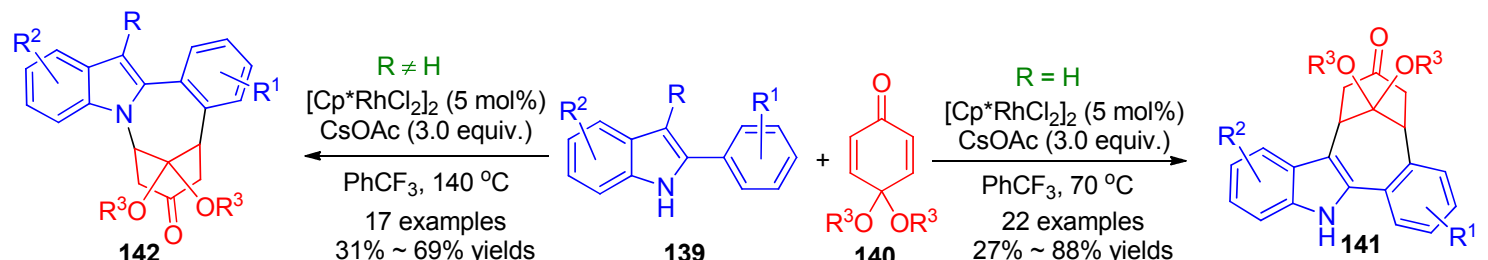

Selected examples

$31 \% \sim 69 \%$ yields

139

$140 \quad 27 \% \sim 88 \%$ yields

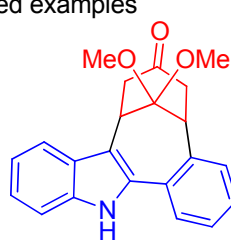

$141 \mathrm{a}, 86 \%$ yield

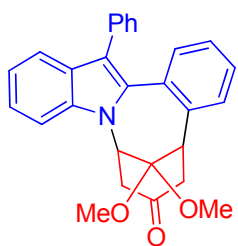

$142 a, 56 \%$ yield

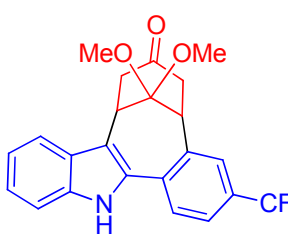

$141 \mathrm{~b}, 88 \%$ yield

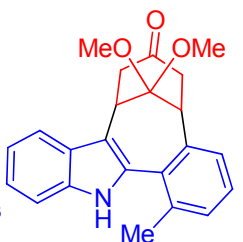

141c, $74 \%$ yield

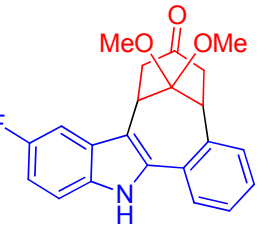

$141 \mathrm{~d}, 82 \%$ yield
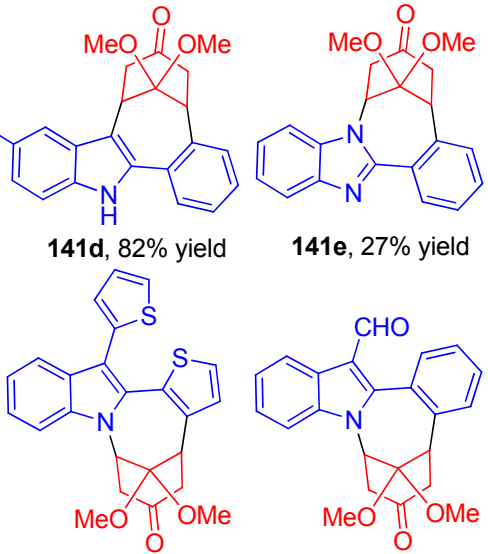

141 e, $27 \%$ yield

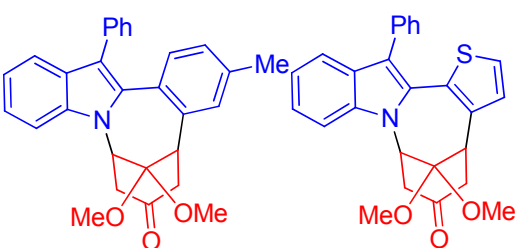

$142 \mathrm{~b}, 53 \%$ yield

142c, $44 \%$ yield

$142 d, 46 \%$ yield

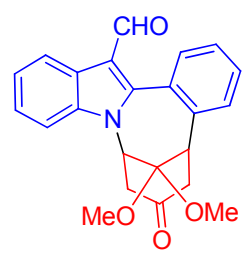

Proposed mechanism
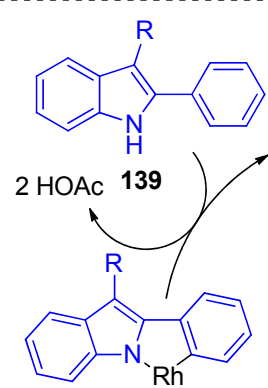

$\mathrm{Cp}{ }^{*} \mathrm{Rh}(\mathrm{OAc})_{2}$
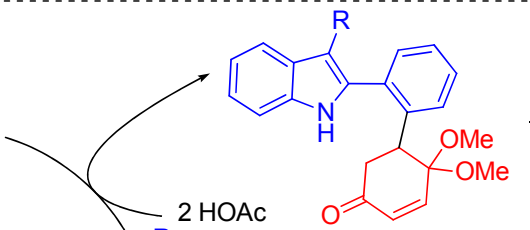

$\mathrm{R} \neq \mathrm{H}$

$\mathrm{N}(1)$ attack

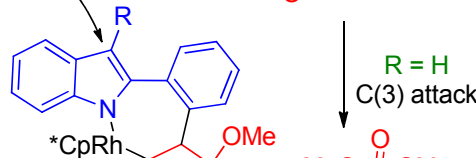

C

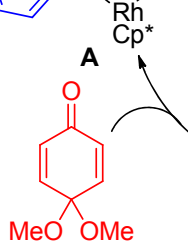

$140 \mathrm{a}$

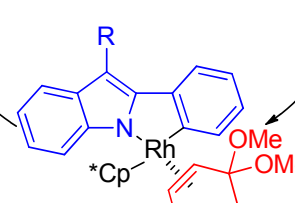

B

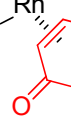

C
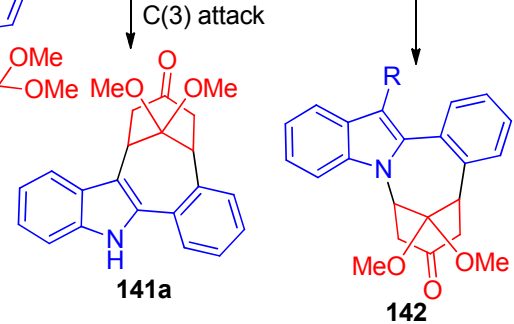

图式 38 2-芳基吲哚与苯醌单缩酮参与的 $[5+4]$ 环加成反应

Scheme 38 [5+4] cycloadditions of 2-arylindoles with quinone monoacetals 


\section{2 串联反应策略构建桥环化合物}

串联反应也是一种构建桥环化合物的重要策略, 其 具有成键效率高、立体控制好、官能团兼容性好、步骤 经济和原子经济等优点. 该策略可以通过 “一锅” 反应, 实现从简单的原料出发高选择性地构建多个化学键, 从 而合成结构复杂多样的有机化合物. 在反应过程中, 无 需对中间体进行分离纯化, 用最少的操作即可实现化学 键的最大化构建 ${ }^{[62]}$. 鉴于此, 通过串联反应来合成桥环 化合物也受到合成化学家的广泛关注, 并取得了不错的 反应结果.

2015 年, Ohno 课题组 ${ }^{[63]}$ 报道了 2-炔基 $N$-炔丙基苯 胺 143 参与的炔丙基迁移诱导的串联环化反应, 最终以 59\% 94\%的收率实现了桥环吲哚啉 144 的高效非对映 选择性合成(Scheme 39). 该串联反应具有非常高的成 环及成键效率, 通过一锅反应, 可以同时构建三个环和
四个化学键. 作者认为, 在反应的过程中, 金作为 $\pi$ 酸 活化底物 143 中碳碳参键, 促使苯胺与参键发生亲核环 化反应，形成中间体 147. 147 发生分子内炔丙基迁移反 应, 得到联烯 145 , 释放出金催化剂, 完成第一个催化 循环，这也是该反应的决速步骤. 随后，金再次作为 $\pi$ 酸活化联烯 145 , 参与到下一个催化循环, 通过成环、扩 环和亲核加成等过程, 最终得到桥环吲哚啉 144.

2016 年，梁永民课题组 ${ }^{[64]}$ 报道了三氟甲磺酸镱催 化的炔丙醇 152 与 2-乙烯基苯酚 153 或 154 的环化串联 反应，以不错的结果合成了具有四元环桥环结构的色满 类化合物(Scheme 40). 该反应条件温和, 无需任何添加 剂, 底物范围广. 基于文献报道，作者提出了可能的反 应机理: 在 $\mathrm{Yb}(\mathrm{OTf})_{3}$ 作为路易斯酸的作用下, 炔丙醇 152 形成炔丙基碳正离子中间体 $\mathbf{A}$, 它的稳定共振式为 $\mathbf{B}$; 随后 2-乙烯基苯酚 153 与 $\mathbf{B}$ 发生加成反应形成中间 $\mathrm{C}$; 再经分子内的环化, 即可获得最终产物 155.

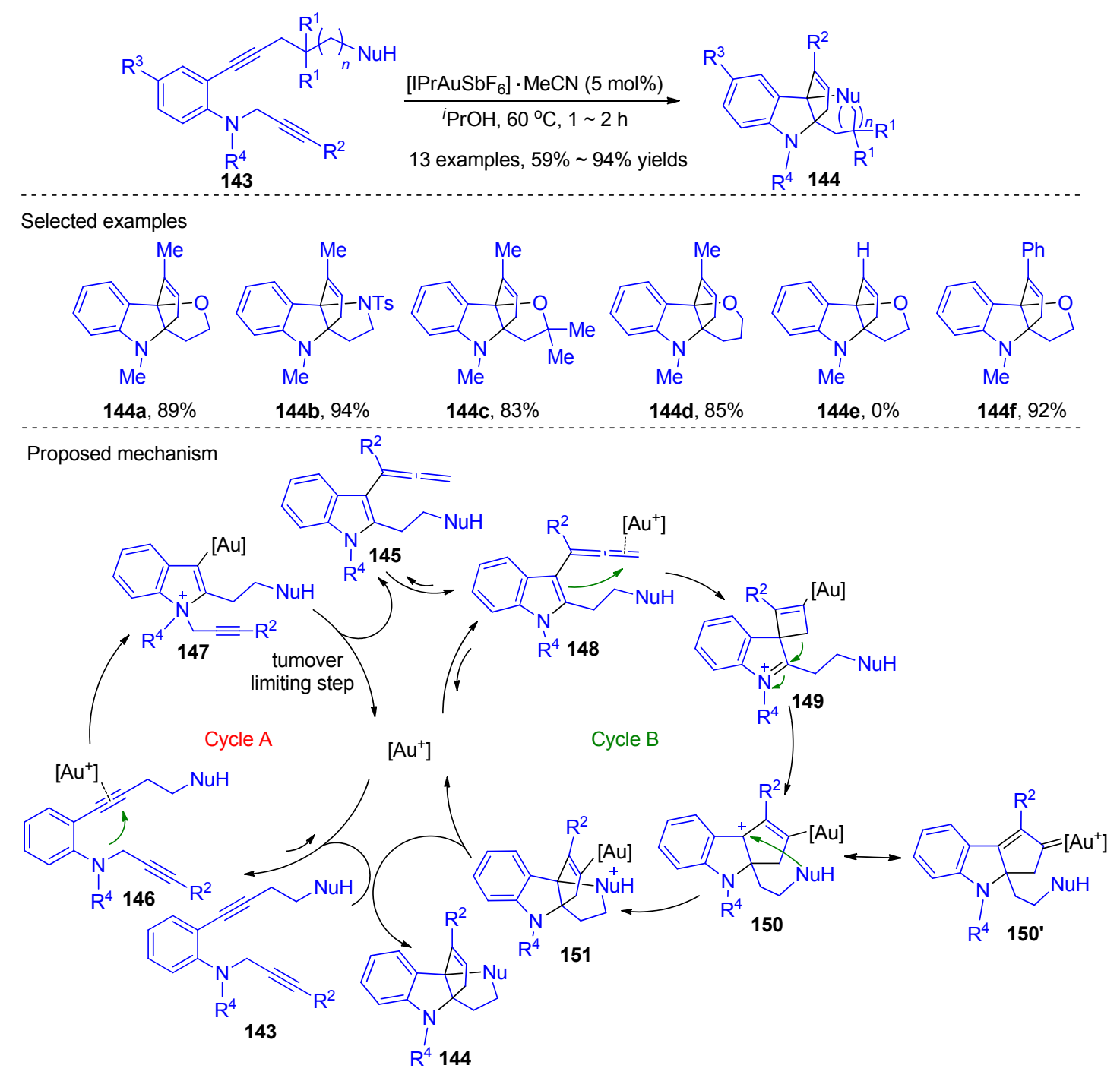

图式 392 -炔基 $N$-炔丙基苯胺参与的串联环化反应构建桥环吲哚啉

Scheme 39 Cascade reaction of 2-alkynyl- $N$-propargylanilines to access bridged indolines 

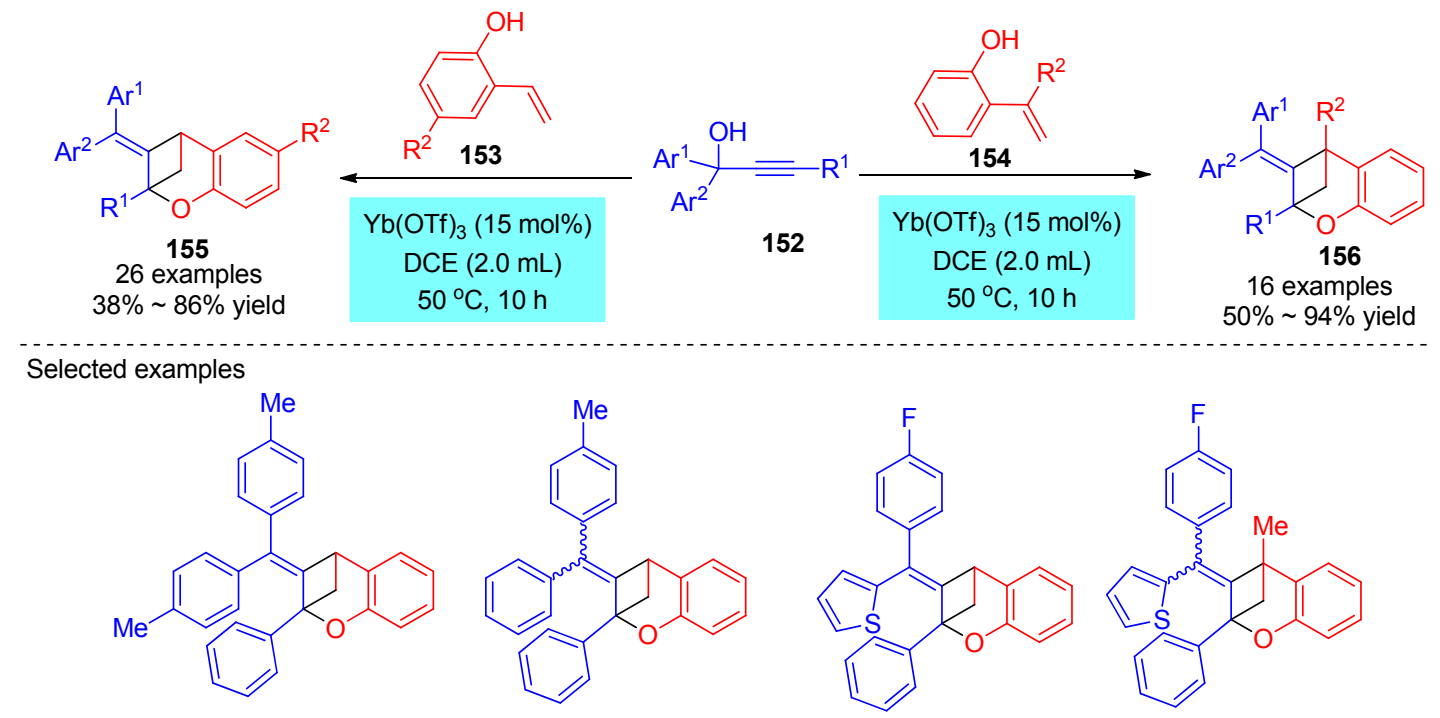

$155 a, 79 \%$ yield

$155 \mathrm{~b}, 62 \%$ yield, $Z / E=1 / 1$

155 c, $42 \%$ yield

155d, $78 \%$ yield, $Z / E=1 / 1$

Proposed mechanism
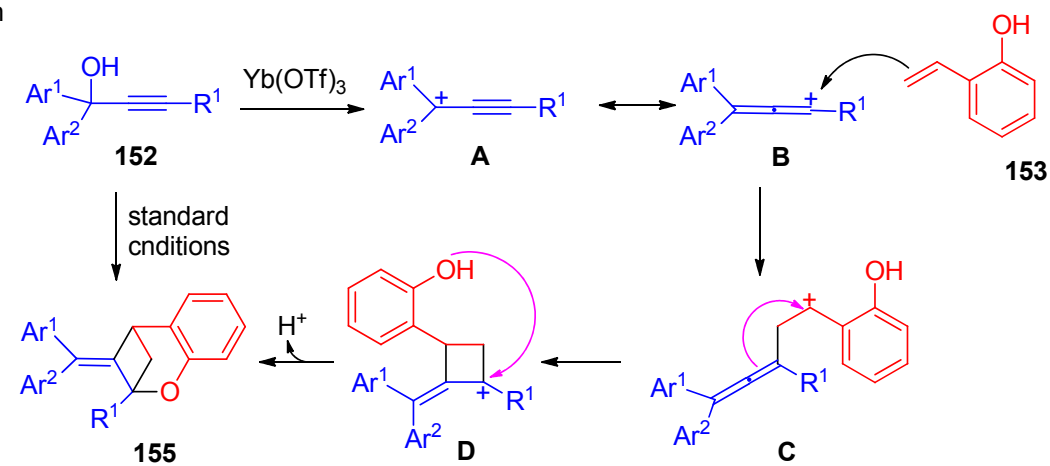

153

图式 40 炔丙醇与 2-乙烯基酚参与的串联环化反应

Scheme 40 A cascade annulation of propargylic alcohols with 2-vinylphenols

2018 年, 杜纪元课题组 ${ }^{[65]}$ 实现了 AgOTf 催化的炔 醇 157 与酚类化合物 158 的 1,4-加成/环化串联反应，高 效地构筑了系列具有潜在生物活性的氧杂双环[3.3.1]壬 烷 159 (up to 96\% yield) (Scheme 41). 在 AgOTf 的催化 下, 炔醇 157 原位生成活泼亚甲基炔基醌中间体 $o$-AQMs, 随后与苯酚 158 经历 1,4-加成/6-endo 环化/
1,3-芳基迁移/分子内 1,4-加成串联过程，最终得到目标 产物 159. 值得一提的是, 酸的种类对反应影响较大, 当采用三氟乙酸 $(T F A) 、( \pm)$-樟脑磺酸 $(\mathrm{CSA}) 、 \mathrm{BF}_{3} \cdot \mathrm{OEt}_{2}$ 、 $\mathrm{FeCl}_{3} \cdot 6 \mathrm{H}_{2} \mathrm{O}$ 时，作者仅仅得到 1,4-加成的产物 159'，而 后续的串联环化反应无法进行.

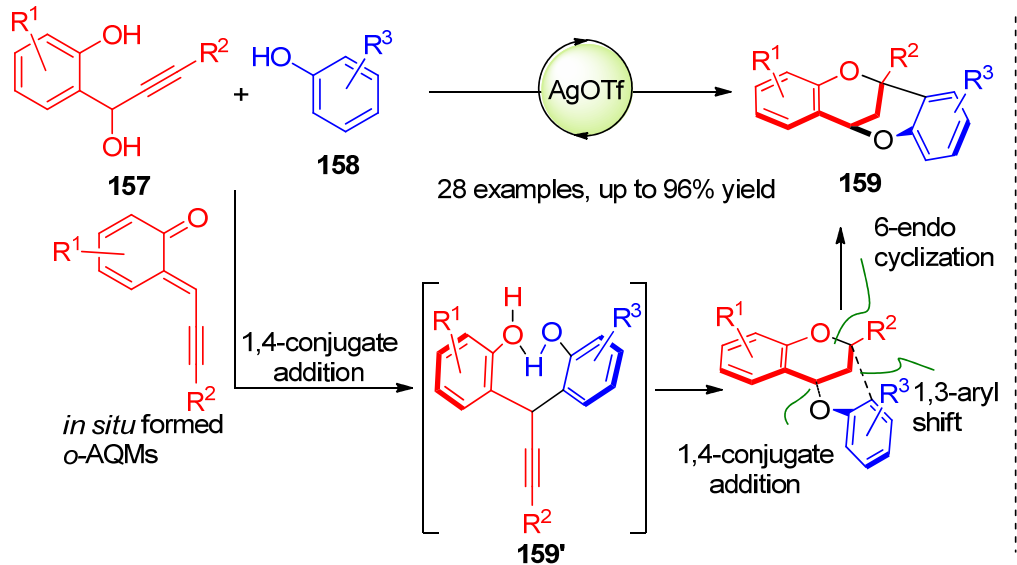

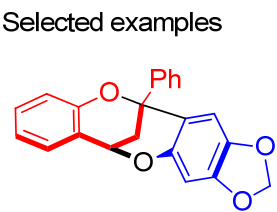

159a, $94 \%$ yield<smiles>CC(C)(C)c1cc2c(c(C(C)(C)C)c1)OC1(c3ccccc3)OC2Oc2cc3c(cc21)OCO3</smiles><smiles>CCCCC12Cc3cc4c(cc3OC1O4)OCO2</smiles>

$159 c, 78 \%$ yield 159b, $70 \%$ yield<smiles>CC(C)(C)c1cc2c(cc1OC1CC3c4ccccc4OC13)OCO2</smiles>

159d, $44 \%$ yield

图式 41 1,4-加成诱导的串联反应构建桥氧杂双环 [3.3.1]壬烷

Scheme 41 Construction of dioxabicyclo[3.3.1]nonanes through 1,4-conjugate addition-inspired cascade reaction 
功能化的 $\alpha, \beta$-不饱和羰基化合物, 具有潜在的多重 反应位点(羰基的 $\alpha$-位和 $\beta$-位及羰基), 通过巧妙的串联 反应设计, 可以将这些反应位点充分利用起来, 从而构 建结构复杂、新颖的桥环化合物. 2018 年, 孟祥太课题 组 ${ }^{[66]}$ 报道了有机膦催化的硫代橙酮衍生的 Michael 受体 160 与联烯酸酯 161 的串联反应，以 $40 \% \sim 91 \%$ 的收率 得到氧杂桥环[3.3.1]壬烷 162 (Scheme 42). 在该反应过 程中, 联烯酸酯 161 与有机膦试剂生成两性离子中间体 是引发反应进行的核心过程, 该中间体具有 “亲核” 和 “亲电”双重特性, 可以促进后续反应的进行.
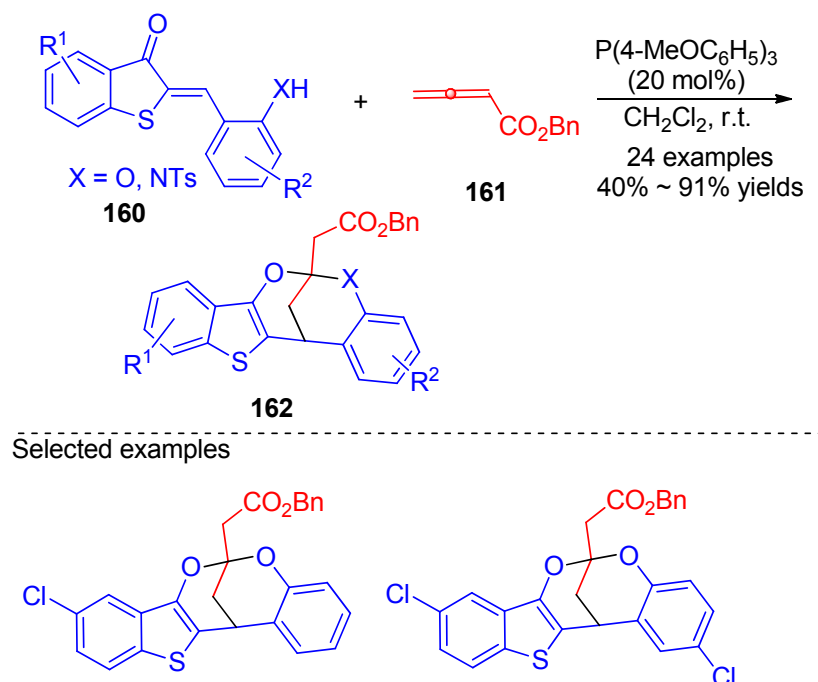

$162 \mathrm{a}, 82 \%$ yield
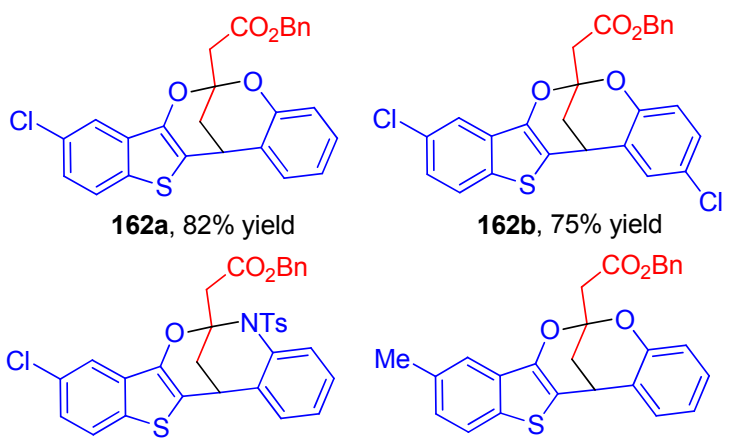

162b, $75 \%$ yield

162c, $40 \%$ yield<smiles>Cc1ccc2c(c1)C1CC(CC(=O)OCc3ccccc3)(O2)Oc2c1sc1ccc(C)cc21</smiles>

$162 e, 68 \%$ yield

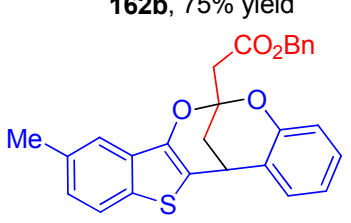

162d, $57 \%$ yield

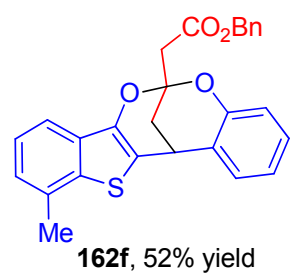

图式 42 硫杂橙酮衍生物与联烯酸酯参与的串联环化反应

Scheme 42 Cascade cyclizations of thioaurones and allenoate

同年, 陈焜铭课题组 ${ }^{[67]}$ 以三乙烯二胺 $(\mathrm{DABCO})$ 为 催化剂, 完成了水杨酰腙 163 与 2-氧代 3-丁炔酸酯 164 参与的多级串联反应, 以 $40 \% \sim 99 \%$ 的收率完成高度官 能化桥连苯并噁嗪衍生物 165 的合成(Scheme 43). 该反 应无需金属催化, 且非对映选择性非常好, 尽管产物中 有两个手性中心, 但是仅得到一个非对映异构体. 美中 不足的是, 对于底物 164, 仅限于 2-氧代-3-丁炔酸酯, 当采用 1,3-二苯基丙炔酮时, 该反应无法进行. 基于上 述实验结果, 作者提出了反应可能的机理: 首先, 在碱

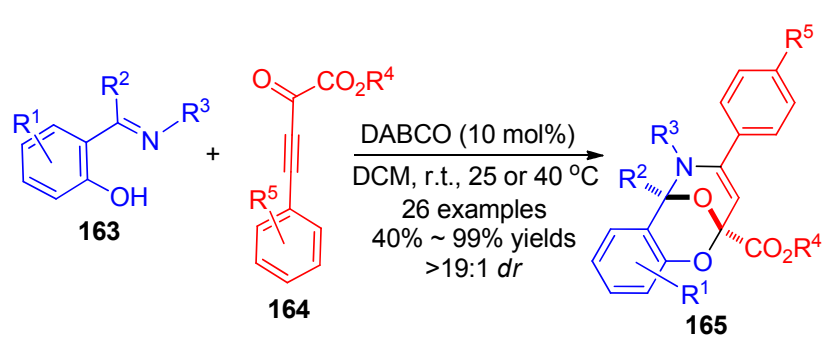

Selected examples<smiles>CCO[C@@]12C=C(c3ccccc3)N(N)[C@H](O1)c1cc(Br)ccc1O[C@H]2C(=O)c1ccccc1</smiles>

$165 a, 54 \%$ yield

165b, $74 \%$ yield

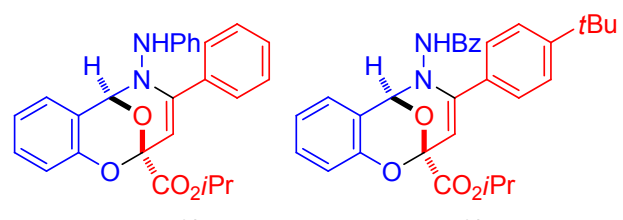

$165 \mathrm{c}, 68 \%$ yield

$165 d, 82 \%$ yield

Proposed mechanism

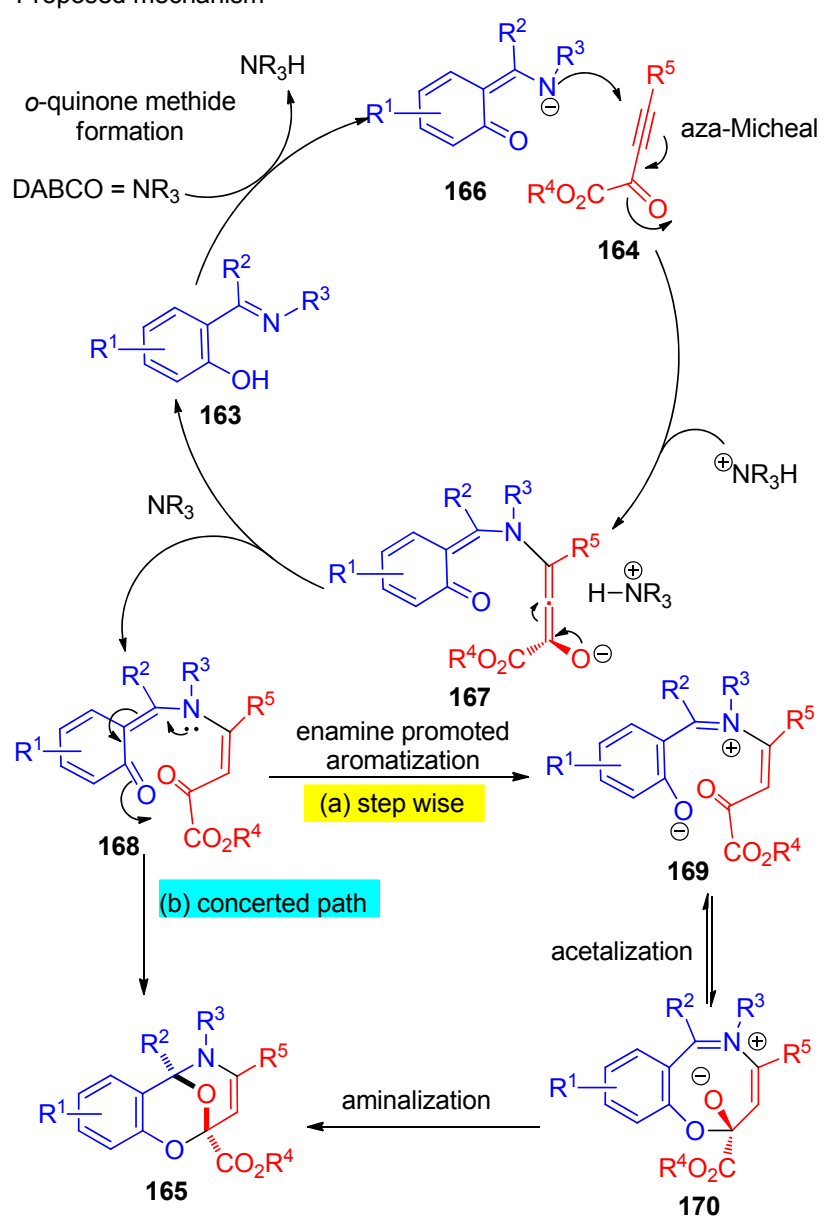

图式 $43 \mathrm{DABCO}$ 催化水杨酰腙与 2-氧代 3-丁炔酸酯的多级 串联反应

Scheme 43 DABCO-Catalyzed cascade reactions of salicylhydrazones with 2-oxo-3-butynoates 
的作用下，水杨酰腙 163 形成活泼亚甲基醌中间体 $\mathbf{1 6 6}$, 166 再与 2-氧代 3-丁炔酸酯 164 发生 Michael 加成/质子 化串联过程, 生成中间体 168; 随后 168 或经历协同过 程或经历芳构化 $/ O, O$-缩醛化 $/ O, N$-缩醛化分步串联过程, 最终得到桥连苯并噁嗪衍生物 165.

2019年, 林文偉课题组 ${ }^{[68]}$ 以奎宁衍生的硫艮 174 为 催化剂, 实现了狮酮衍生的 $\alpha, \beta$-不饱和酮 171 与 3-烯氧 化吲哚 172 参与的 “插烯” Michael 加成/缩酮化/Michael 加成/Michael 加成多级串联反应, 以高达 $92 \%$ 的收率和 98\%的对映选择性得到 $O, O$-缩酮螺环桥环氧化吲哚 173 (Scheme 44). 尽管该反应的底物普适性比较好, 但是对 一些官能团比较敏感, 如当 $\mathrm{R}^{2}$ 为甲基取代时, 收率和对 映选择性下降明显(173a vs 173b); 3-烯氧化吲哚 172 的
$N$-保护基对反应立体选择性控制影响也比较大，当 $\mathrm{R}^{4}$ 由叔丁氧羰基(Boc)换为对甲苯磺酰基( Ts)时，对映选择 性降为 $14 \%$ (173a vs 173d).

2019 年, 刘延凯课题组 ${ }^{[69]}$ 通过 “协同催化” 策略, 完成了邻羟基肉桂醛 38 与 $\beta$-氧代醛 175 的不对称串联 环化反应，高效地构建了系列具有螺环骨架的桥环色满 类化合物 177. 此外, 当采用 176 为底物时, 反应采用不 同的路径，以高达 $97 \%$ 的对映选择性得到笼状的桥环化 合物 178. 作者提出，在反应过程中，催化剂 179 和 180 分别活化两个底物, 建立 “叔胺活化、亚胺催化、负离 子键合催化” 三元催化体系, 形成 “催化剂-底物” 五元 复合物(Scheme 45).

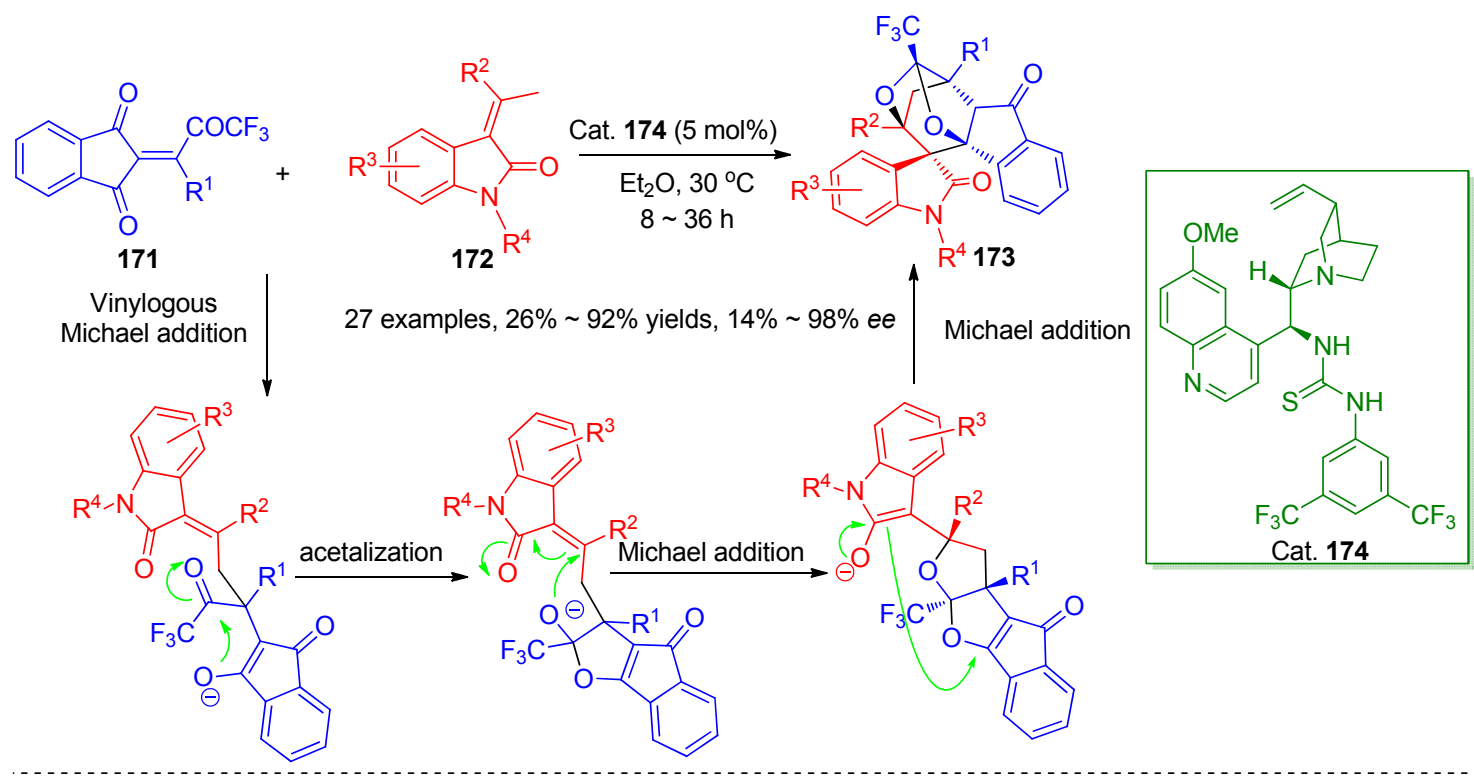

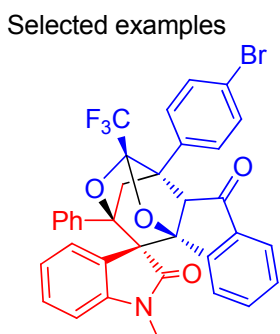

Boc

173a, $81 \%, 80 \%$ ee

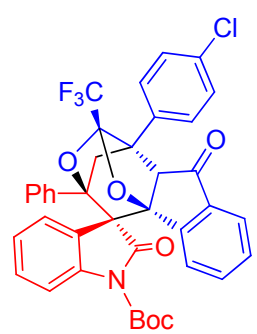

173f, $65 \%, 81 \%$ ee

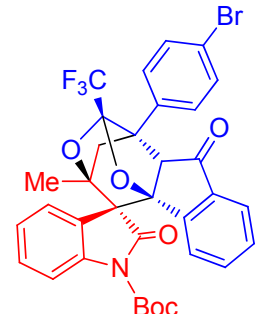

173b, $26 \%, 34 \%$ ee

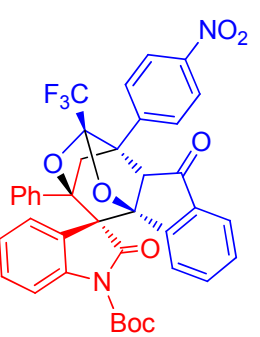

173g, $54 \%, 77 \%$ ee

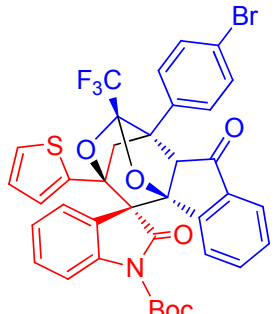

173c, $91 \%, 34 \%$ ee

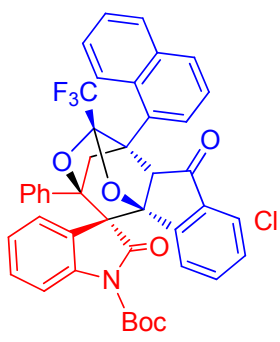

173h, $70 \%, 84 \%$ ee

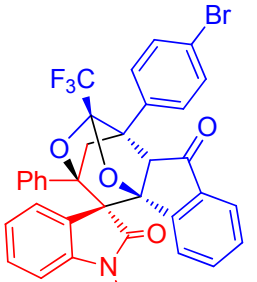

Ts

173d, $61 \%, 14 \%$ ee

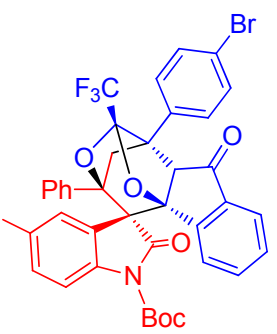

173i, $86 \%, 66 \%$ ee

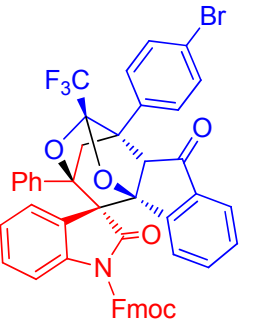

$173 \mathrm{e}, 70 \%, 75 \%$ ee

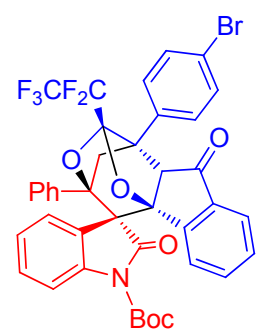

173j, 59\%, 80\% ee

图式 44 Michael 加成诱导的串联环化反应构建 $O, O$-缩酮螺环桥环氧化吲哚

Scheme 44 Michael addition-triggered cascade annulations for the assembly of bridged $O, O$-ketal spirooxindoles 


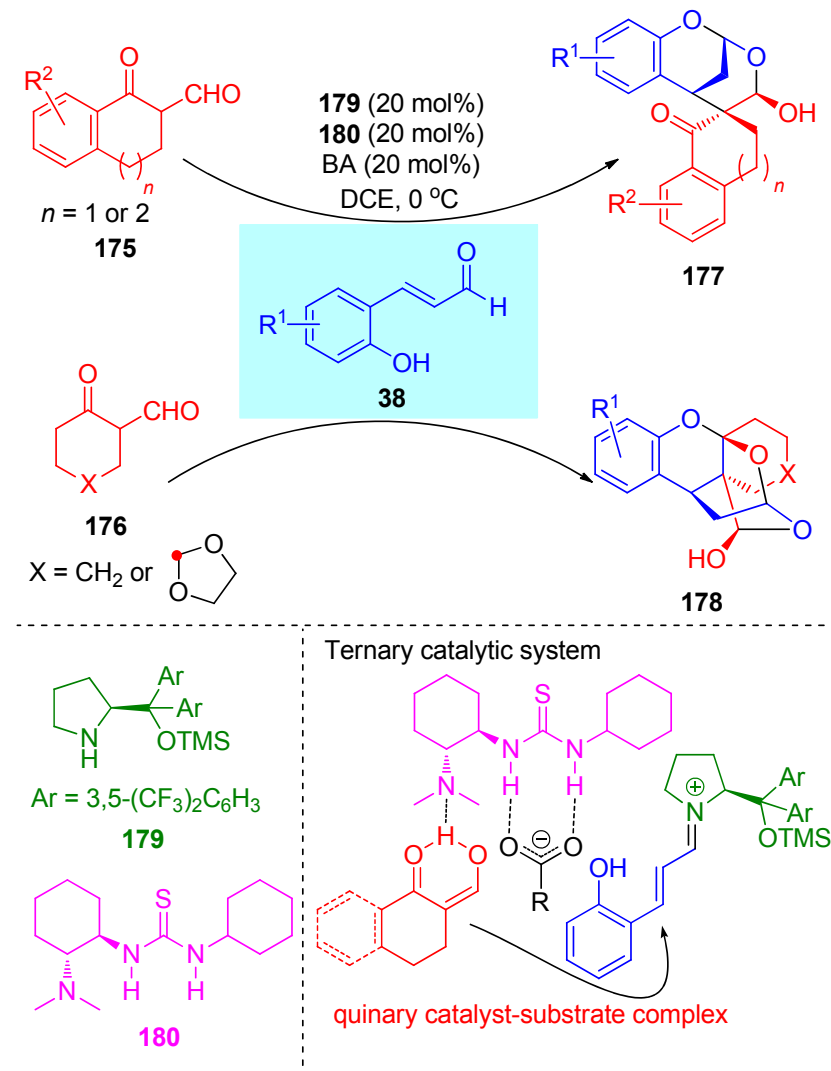

图式 45 底物控制的串联环化反应构建螺环桥环化合物和笼 状桥环化合物

Scheme 45 Substrate-controlled cascade processes for the construction of spiro-bridged and cagelike bridged polyheterocycles

2019 年, Kontham 等 ${ }^{[70]}$ 开发了三氟甲磺酸铁催化的 酚类化合物 181 与 $\alpha, \beta$-不饱和酮 182 参与的 Friedel-
Crafts 烷基化/半缩酮化/内酯化串联反应. 该反应为结 构新渘复杂的色满并内酯骨架桥环化合物 184 的合成提 供了一条行之有效的方法(up to $87 \%$ yield, $>20: 1 d r$ ). 作者阐明，通过调节 $\alpha, \beta$-不饱和酮碳一碳双键在环内和 环外的位置, 可以选择性地合成结构不同的色满桥环化 合物. 当以 183 为底物时, 以中等收率(up to $76 \%$ )得到 色满桥连内酯骨架的多环桥环化合物 185 (Scheme 46).

2019 年，陈应春等 ${ }^{[71]}$ 报道了靛红衍生的 MBH-碳酸 酯 186 与活化的邻乙烯基苯甲醛 187 参与的串联环化反 应, 为手性螺环桥环氧化吲哚的合成提供了新的思路和 方法. 该反应经历 “一锅两步” 过程(Scheme 47). 首先, 在金鸡纳碱衍生物 190 的作用下, 186 与 187 发生 [3+2] 环加成反应生成 188; 随后在氮杂卡宾 191 的作用下, 188 发生分子内的 Stetter 反应; 最终以 $46 \% \sim 94 \%$ 的收 率和高达 $98 \%$ 的对映选择性合成了系列手性螺环桥环 化合物 189. 此外, 作者还尝试了 $188 \mathrm{a}$ 与甲胺参与的还 原胺化反应，以 $45 \%$ 的收率得到了更大环状体系的氮杂 桥环 192, 进一步拓展了该方法在有机合成中的应用 (Scheme 47).

最近, Zhao 课题组 ${ }^{[72]}$ 报道了官能化的查尔酮 193 与 亚胺酯 194 参与的不对称 Mannich/Michael 加成/Aldol 串联反应(Scheme 48). 在金鸡纳碱衍生的叔胺硫嫝和 脯氨酸的共同作用下, 实现了桥环四氢异喹啉的不对称 合成. 值得说明的是，作者通过不同的催化剂组合，实 现了 195 和 196 的高效非对映选择性合成. 总体来讲, 该反应的底物普适性比较广, 均能以中等至优秀的收率 和优秀的立体选择性得到 195 和 196. 但是当 $R^{2}$ 为邻氟
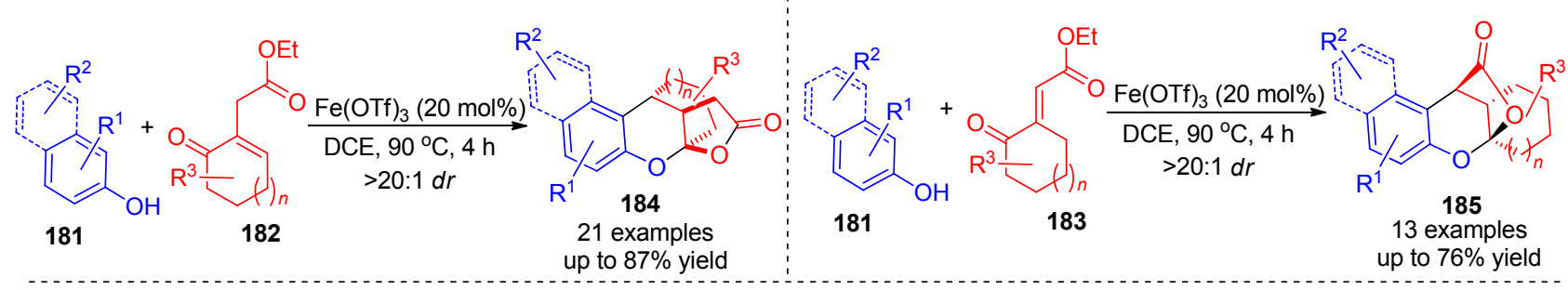

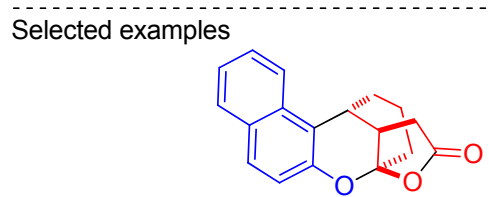

$184 a, 87 \%$ yield

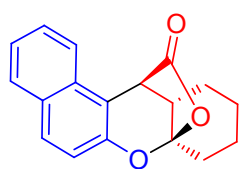

$185 a, 76 \%$ yield

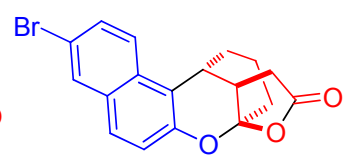

184b, $70 \%$ yield

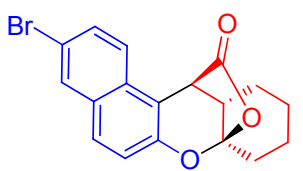

$185 \mathrm{~b}, 63 \%$ yield<smiles>COc1ccc2c(c1)[C@H]1CCC3CC(=O)O[C@]2(O3)C1(C)C</smiles>

184c, $55 \%$ yield<smiles>COc1cc2c(cc1OC)[C@H]1CCCC[C@](C)(O2)O1</smiles>

$185 \mathrm{c}, 58 \%$ yield

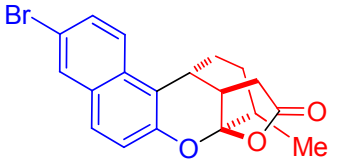

184d, $56 \%$ yield

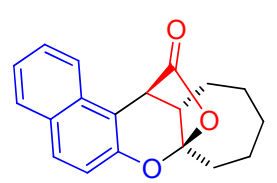

185d, $65 \%$ yield

图式 $46 \mathrm{Fe}$ (III)-催化的 Friedel-Crafts 烷基化/半缩酮化/内酯化串联反应构建桥环色满骨架化合物

Scheme $46 \mathrm{Fe}(\mathrm{III})$-catalyzed Friedel-Crafts alkylation/ hemiketalization/lactonization cascade reactions to access bridged chromans 

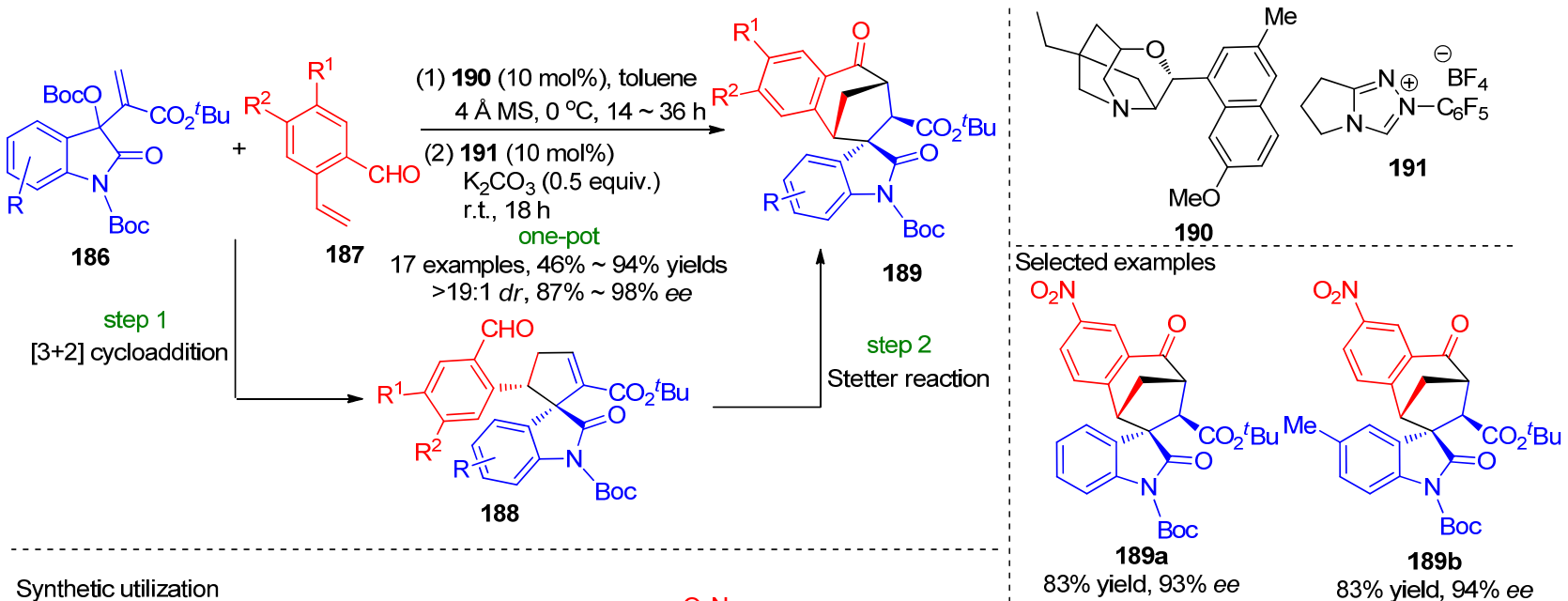

Synthetic utilization

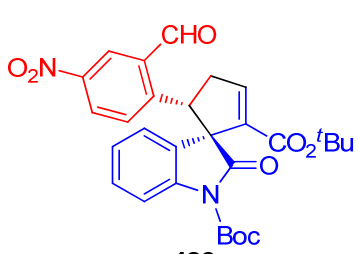

188a

$93 \%$ ee, $15: 1 d r$

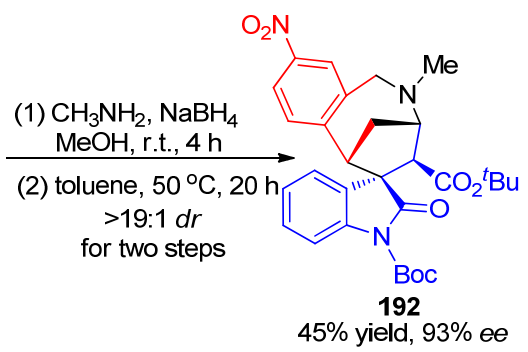

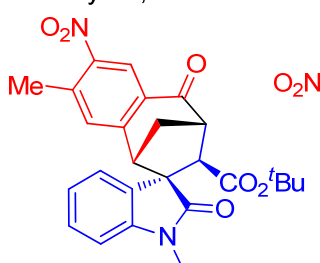

Boc$$
\text { 189c }
$$

$88 \%$ yield, $97 \%$ ee

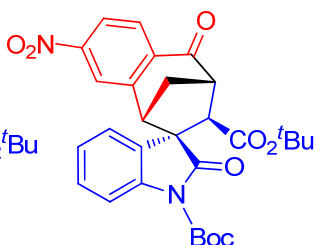

189d

$46 \%$ yield, $98 \%$ ee

图式 $47[3+2]$ 环加成/Stetter 反应串联: 用于构建手性螺环桥环氧化吲哚

Scheme 47 A tandem [3+2] cycloaddition/Stetter reaction to construct chiral spiro-bridged oxindoles

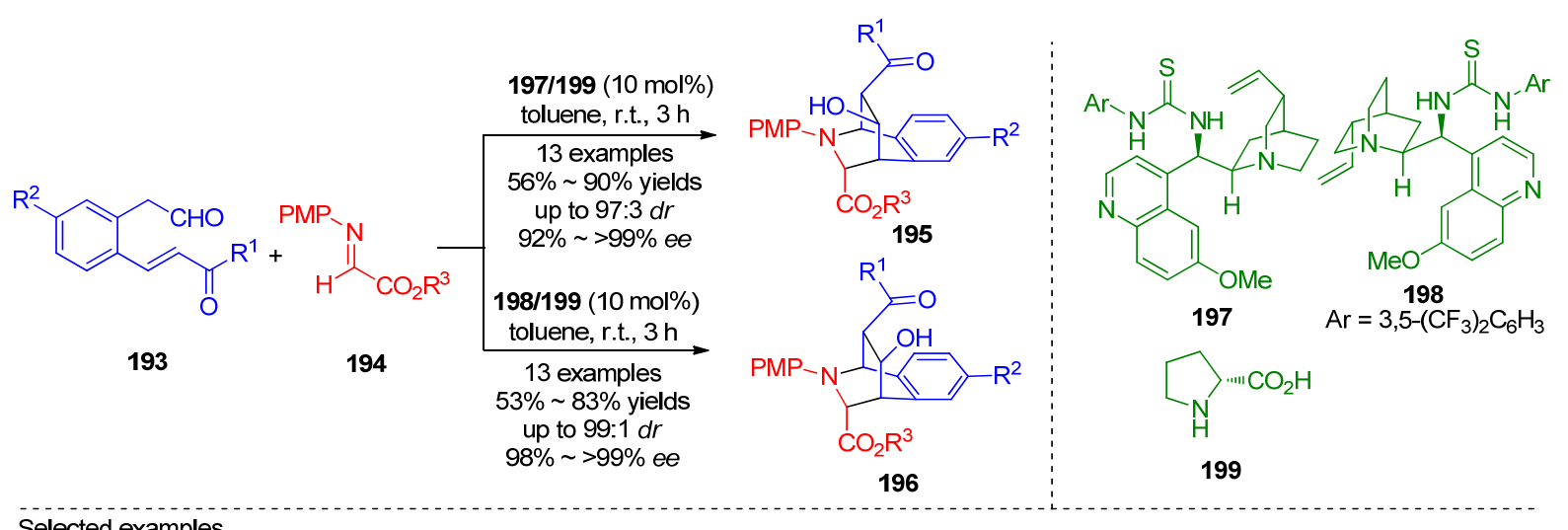

Selected examples

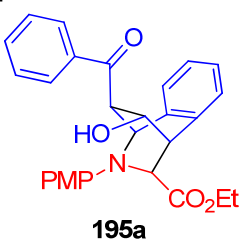

$90 \%, 94: 6 d r,>99 \%$ ee

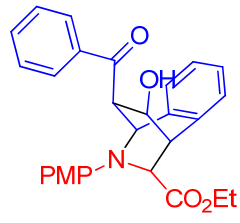

$196 a$

$83 \%, 99: 1 d r, 99 \%$ ee

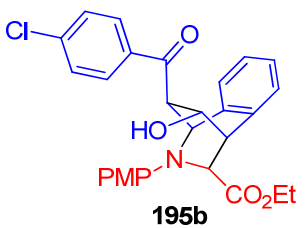

$90 \%, 92 \cdot 8 d r, 99 \%$

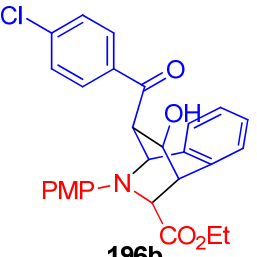

196b ${ }^{\mathrm{CO}_{2} \mathrm{Et}}$

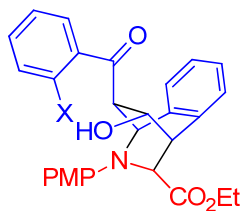

$\mathrm{X}=\mathrm{F}$ or $\mathrm{Cl}, 195 \mathrm{c} / 195$ ND

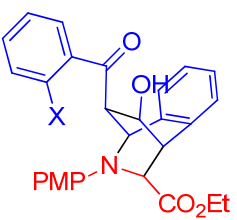

$\mathrm{X}=\mathrm{F}$ or $\mathrm{Cl}, 196 \mathrm{c} / 196 \mathrm{~d}$ ND
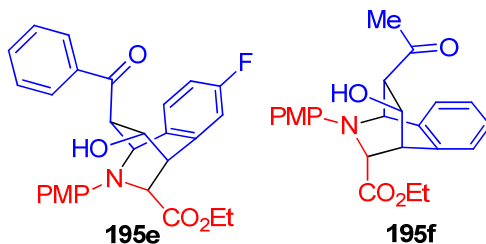

$195 f$

$73 \%, 90: 10 d r$, >99\% ee $56 \%, 86: 14 d r, 99 \%$ ee

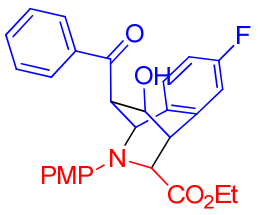

$196 \mathrm{e}$

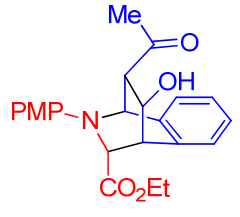

$196 f$

$71 \%, 93: 7 d r, 99 \%$ ee $\quad 53 \%, 90: 10 d r,>99 \%$ ee

图式 48 Mannich/Michael 加成/aldol 串联反应构建桥环四氢异喹啉

Scheme 48 A domino Mannich/Michael addition/aldol reaction for the construction of bridged tetrahydroisoquinones 
或邻氯取代的苯基时, 没有目标产物生成, 作者提出可 能是由于立体位阻和电子效应所致.

2020 年, Lebœuf 课题组 ${ }^{[73]}$ 利用氮杂-Piancatelli 环 化/Michael 加成串联过程实现了桥环四氢异喹啉和桥环 色满骨架 202 的合成(Scheme 49). 该反应经历 “一锅、 两步” 过程, 第一步为路易斯酸催化功能化糠醇衍生物 200 和各种伯胺为或仲胺 201 发生的氮杂-Piancatelli 反 应，生成中间体 $\mathbf{I}$; 当第一步反应结束后，加入 2 equiv. 的三乙胺作为碱, 可以促进第二步 Michael 加成反应的 顺利发生，最终以 $33 \% \sim 93 \%$ 的收率得到目标产物 202. 该反应具有比较广的底物范围, 二级和三级糠醇均能顺 利参与反应, 生成三取代或四取代的桥头碳. 当糠醇 200 上的氨基换为酚羟基时, 反应也能进行, 可以用来 合成色满桥环类化合物.

2020 年, 我们课题组 ${ }^{[74]}$ 以四甲基胍为缚酸剂, 开发
了烯胺酮 203 与 $N$-烷基活化的吡啶盐 204 参与的多组分 环化串联反应，使 $N$-烷基活化吡定盐 204 五个反应位点 完全使用，从而达到吡啶盐反应位点的最大化利用. 该 方法为多桥环并环多取代哌啶 205 的合成提供了快速、 高效、便捷的方法. 通过步骤控制, 我们还实现了喹啉 盐 206 的双功能化和三功能化. 此外, 异喹啉盐 209 也 能成功参与反应, 高效地构筑了具有桥环四氢异喹啉骨 架的产物 210 (Scheme 50). 如 Scheme 51 所示, 这些氮 杂芳烃盐不但具有 “亲电一亲核-亲电”多反应位点，同 时还起着另一分子亲电试剂的作用，通过与双亲核的烯 胺酮发生多组分、“一锅” 串联反应，最终得到具有桥 环/并环复杂结构且具有多个手性中心的氢化吡啶 205a、喹啉 207a/208a 和异喹啉 210a. 该方法最大化地 利用了吡啶盐、喹啉盐和异喹啉的潜在反应位点, 实现 了结构复杂含氮桥环化合物的高效合成. 但是，该方法<smiles>[X]c1cc2ccccc2cc1C([R])(O)c1ccco1</smiles>

200

(1) $\mathrm{Ca}\left(\mathrm{NTf}_{2}\right)_{2}(5 \mathrm{~mol} \%),{ }^{n} \mathrm{Bu}_{4} \mathrm{NPF}_{6}(5 \mathrm{~mol} \%)$

$$
\begin{aligned}
& \mathrm{R}^{3}-\mathrm{NH} \text { toluene/HFIP }(\mathrm{V}: \mathrm{V}=3: 1), 20^{\circ} \mathrm{C}, 9 \sim 17 \mathrm{~h} \\
& \text { (2) } \mathrm{Et}_{3} \mathrm{~N} \text { (2.0 equiv), } 20^{\circ} \mathrm{C}, 5 \mathrm{~min}
\end{aligned}
$$
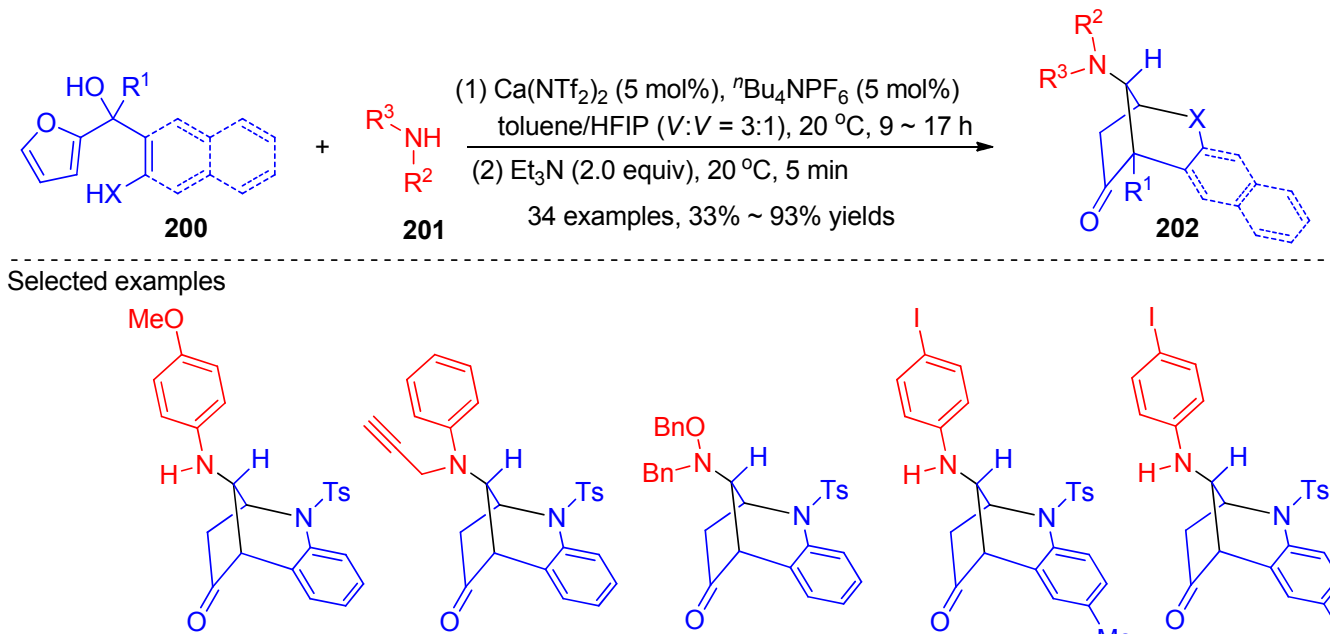

202a, $75 \%$ yield

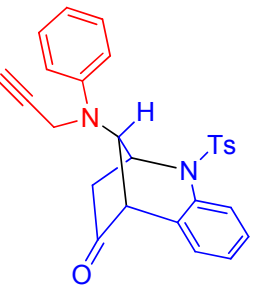

202b, $66 \%$ yield

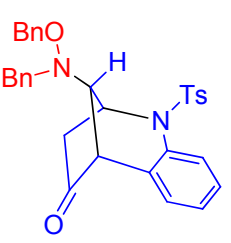

202c, $81 \%$ yield

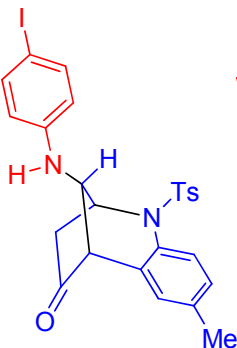

202d, $87 \%$ yield

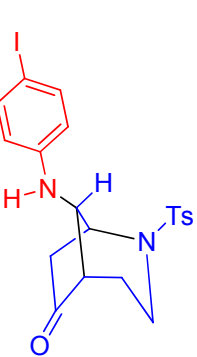

202h, 35\% yield

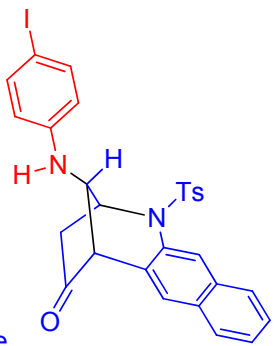

202e, $88 \%$ yield
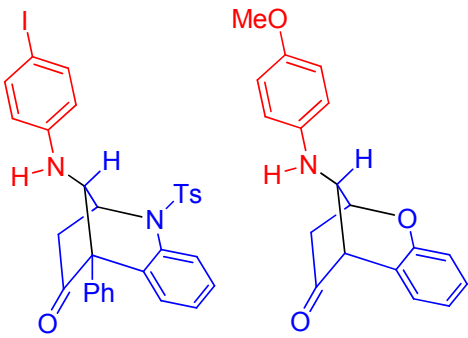

202g, $76 \%$ yield

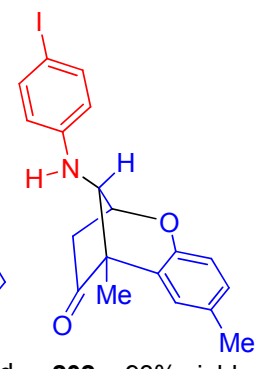

202f, $63 \%$ yield

202g, 93\% yield

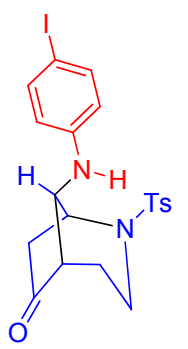

202h', 30\% yield Proposed pathway<smiles>[R]NNc1ccccc1C([R])(O)c1ccco1</smiles>
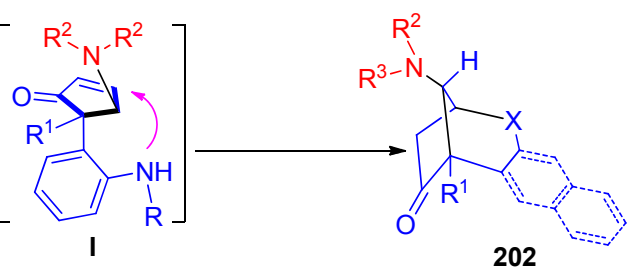

图式 492 -呋喃甲醇和胺参与的氮杂-Piancatelli 环化/Michael 加成串联反应

Scheme 49 Aza-Piancatelli cyclization/Michael addition sequence of 2-furylcarbinols and amines 


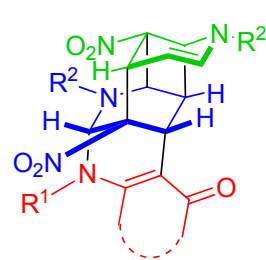

205

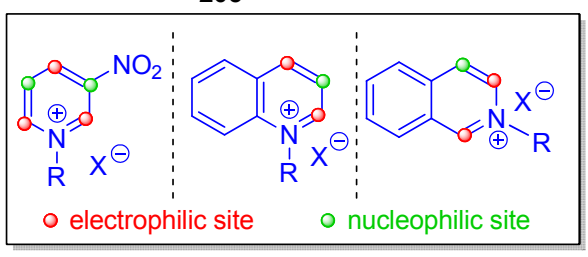

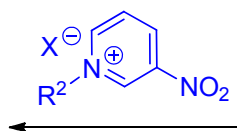

204

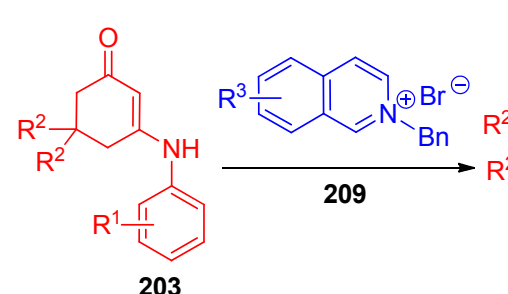

203

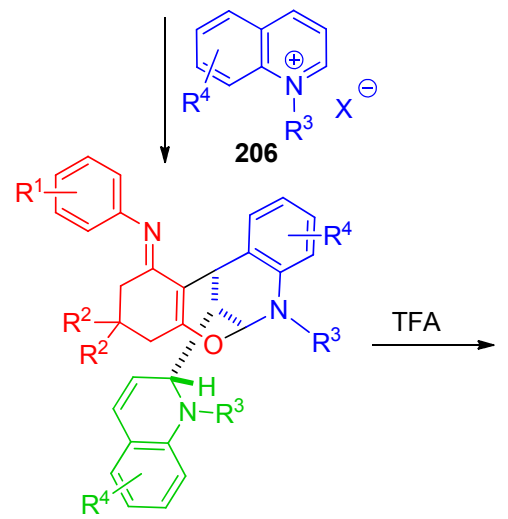

207

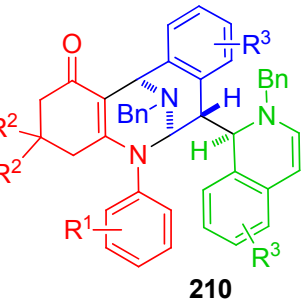

210

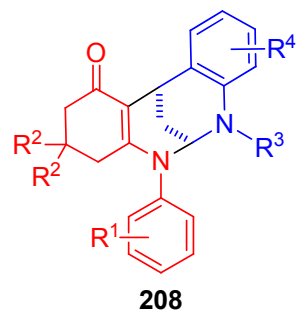

208

图式 $50 \mathrm{~N}$-烷基氮杂芳烃盐反应位点的最大化利用

Scheme 50 Maximization of the reactive sites of $N$-alkyl activated azaarenes

也有弊端. 如需要预先制备 $N$-烷基活化氮杂芳烃盐, 且 $N$-活化基团仅限于烷基取代; 为了使反应高效完成, 还 需要加入过量的碱作为缚酸剂. 因此底物受限, 且原子 和步骤不经济. 为了克服该方法的局限性, 紧接着, 我 们课题组 ${ }^{[75]}$ 通过 $N$-芳基原位活化策略，发展了商业易 得吡啶 211、喹啉 212 和异喹啉 213 分别与芳炔前体 214 和烯胺酮 203 发生的多组分多步串联环化反应, 直接实 现了氮杂芳烃的多官能化, 从而完成了结构复杂桥环化 合物 215、216、217 和 218 的高效非对映选择性合成 (Scheme 52).

基于以上研究，同年，我们课题组 ${ }^{[76]}$ 合成 $N$-查尔酮 吡啶盐 219, 同时通过与双亲核试剂烯胺酮 203 发生 Michael 加成/Michael 加成/氮杂-Mannich 三级串联反 应, 实现了新型吡啶盐的去芳构化, 完成了双桥连氢化 吡啶 220 的高效非对映选择性合成(Scheme 53). 该工作 是查尔酮吡啶盐被首次合成的例子, 查尔酮吡啶盐合成 子的设计合成, 不但在吡啶盐的基础上引入了一个新的 亲电位点, 用于发生多级串联反应，同时引入了一个酮 羰基, 可以进行多种化学转化, 丰富产物的结构类型. 该反应操作简单、经济高效, 并可以构建含有多手性中 心、多官能团的双桥连氢化吡啶.

\section{3 以上两种策略在天然产物全合成中的应用}

由于环加成反应和串联反应具有成环效率高、操作 简便和条件温和等优点, 已逐渐成为合成桥环化合物的
重要手段, 在构筑具有重要生理活性的桥环天然产物方 面也得到广泛的应用. 2017 年, Vincent 课题组 ${ }^{[77]}$ 通过环 加成反应实现了天然产物 vocalgine A (227) 和 bipleiophylline (228)的全合成(Scheme 54). 在初步的尝 试中, 作者发现, 采用 2,3-二羟基苯甲酸甲酯 222 作为 起始原料, 在氧化银的作用下, 222 作为 $\mathrm{C}-\mathrm{C}-\mathrm{O}$ 三原 子合成子参与到反应中, 得到 3-位羟基和 4-位碳关环的 产物 223; 然而, 通过稍微改变 222 的官能团, 得到了截 然不同的反应结果，即：当采用 2,3-二羟基苯甲酸 224 作为反应试剂时, 224 作为 $\mathrm{C}-\mathrm{C}-\mathrm{C}-\mathrm{O}$ 四原子合成子, 与四氢咔唑发生 $[4+2]$ 环加成反应, 得到产物 225. 基于 这一重要发现, 作者通过 224 与 Pleiocarpamine 的甲酸 盐 226 的 [4+2]环加成反应, 以 $21 \%$ 的收率得到了 Vocalgine A (227), 当继续与另一分子 226 反应时, 实现 了极其复杂 Bipleiophylline (228)的全合成.

2019 年, 贾彦兴课题组 ${ }^{[78]}$ 采用类似的氧化 $[3+2]$ 环 加成策略, 以醋酸碘苯(PIDA)为氧化剂, 实现了 2,3-双 取代吲哚 229 与苯酚 230 的 [3+2]环加成反应, 为苯并 呋喃[3,2-b]吲哚啉 231 和苯并呋喃[2,3- $b$ 吲哚啉 232 的 合成提供了新思路和新手段. 随后作者又以此方法作为 关键反应步骤, 通过八步化学反应完成了天然产物 phalarine (241)的全合成(Scheme 55).

2020 年, 韩福社课题组 ${ }^{[79]}$ 首次实现了天然产物 (+)-tronocarpine (258)的不对称全合成(Scheme 56). 首 先, 在辛克宁定衍生的相转移催化剂 245 的作用下, 色 
(a) Dearomative multifunctionalization of pyridinium salt:
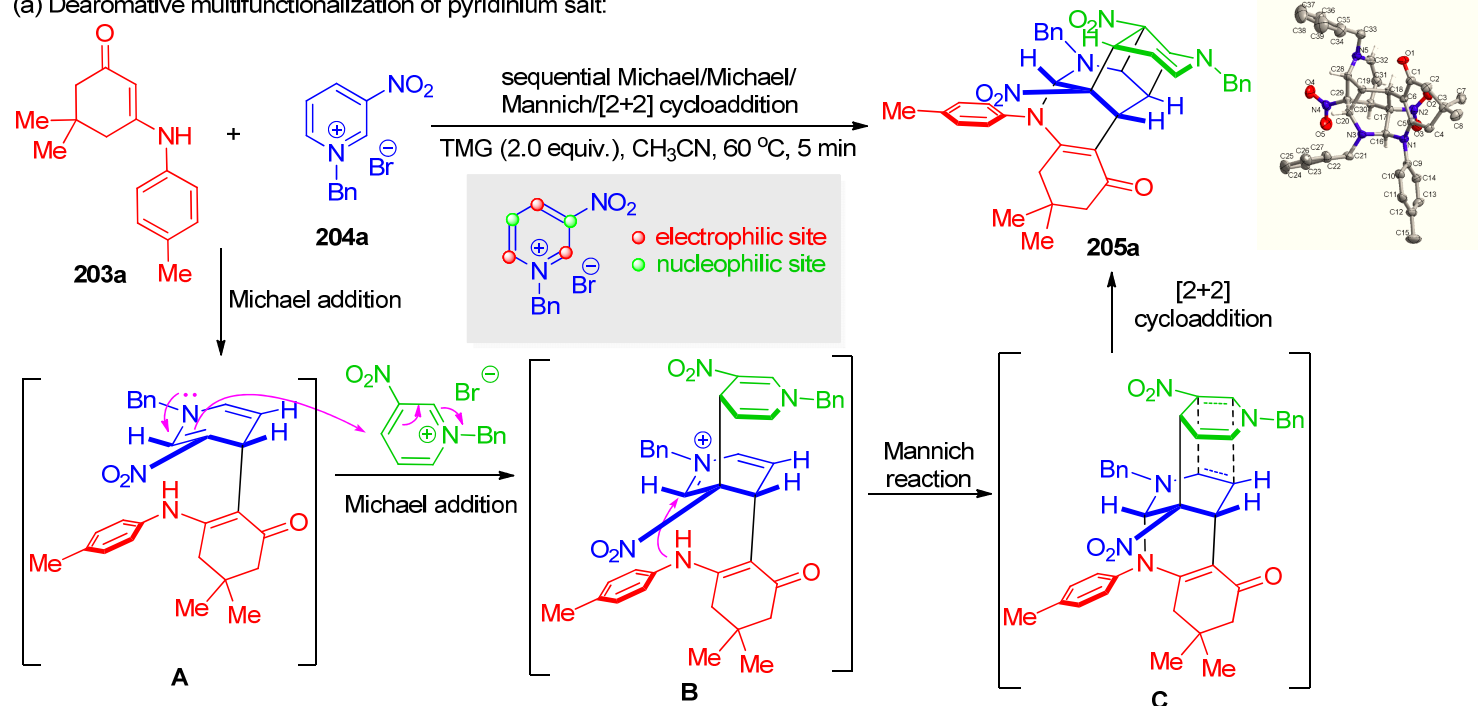

(b) Dearomative tri- and bi-functionalization of quinolinium salt:
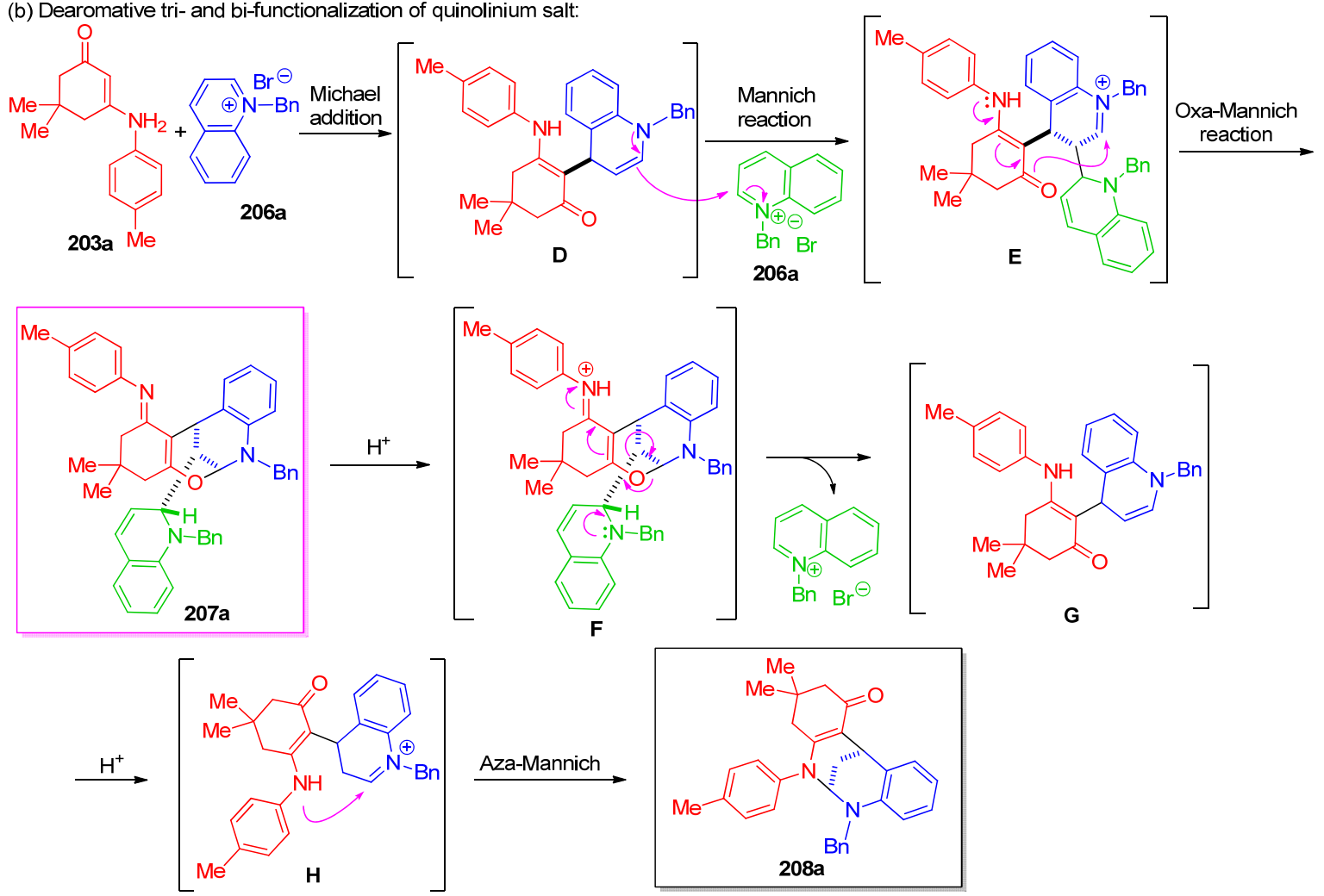

(c) Dearomative trifunctionalization of isoquinolinium salt:

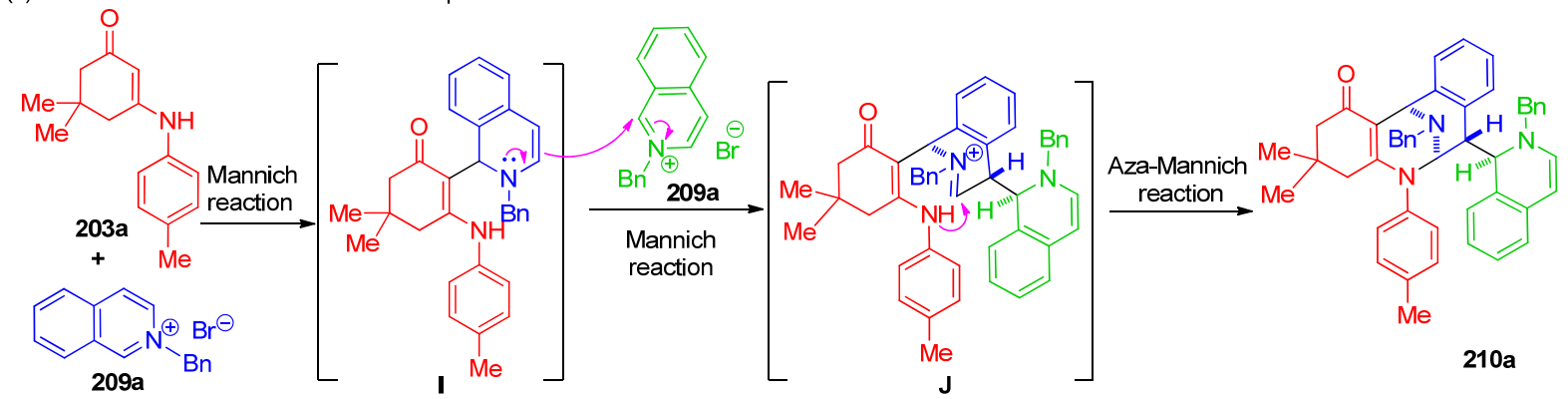

图式 51 反应可能的机理

Scheme 51 Plausible reaction mechanism 


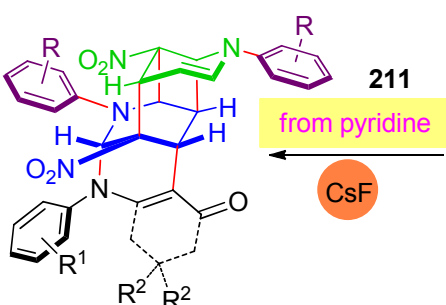

215

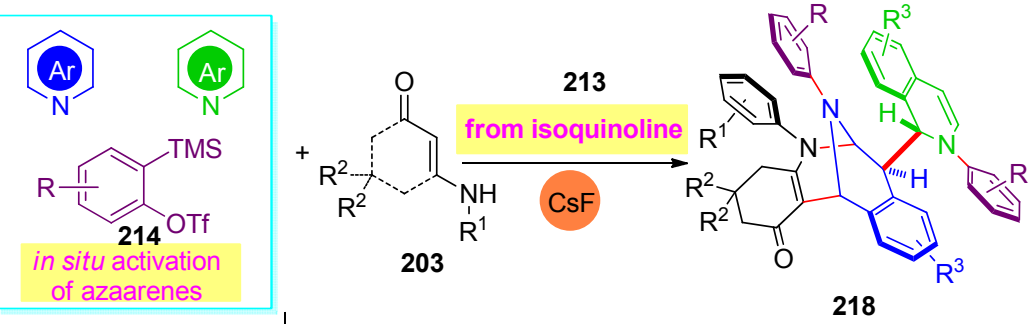

CsF from quinoline

212
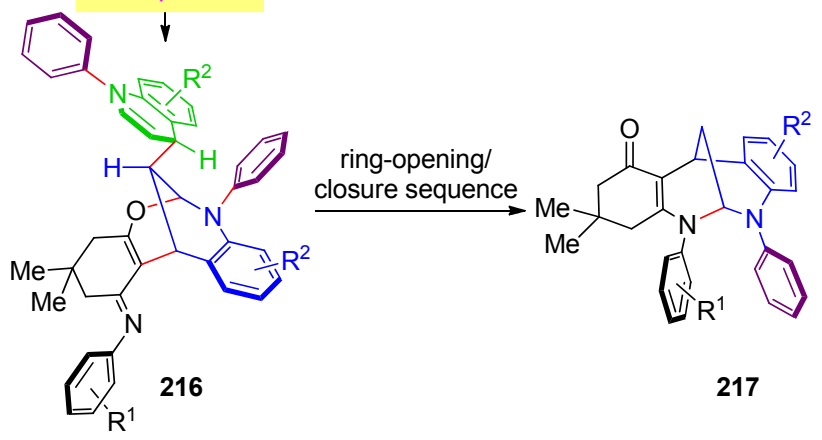

217

图式 52 通过原位活化去芳构化策略实现氮杂芳烃的多官能化

Scheme 52 Multifunctionalization of azaarenes through in situ activation and sequential dearomatization<smiles></smiles>

219<smiles>[R]C1([R])CC(=O)C=C(Nc2cc[R1]cc2)C1</smiles>

203

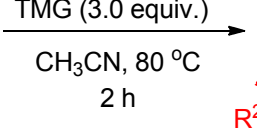

24 examples, $43 \% \sim 89 \%$ yields

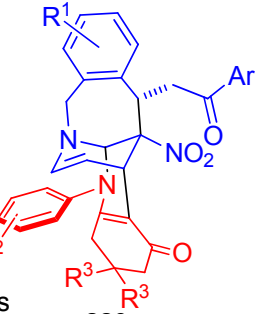

220

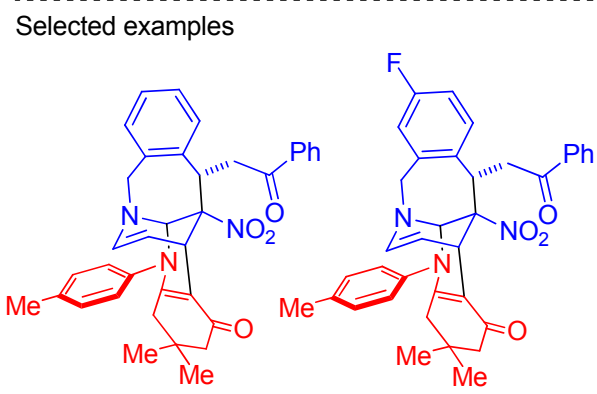

220a, $76 \%$ yield 220b, $46 \%$ yield

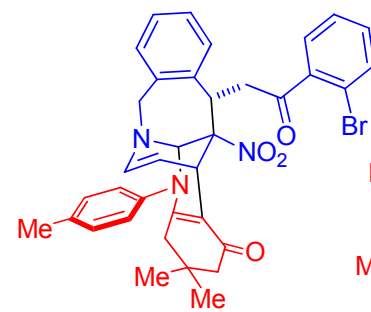

220c, 54\% yield

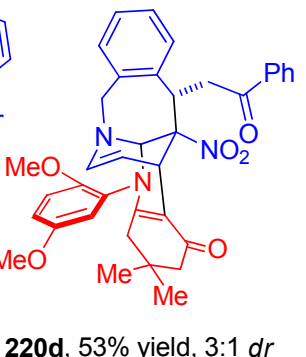

220d, 53\% yield, 3:1 dr Plausible pathway
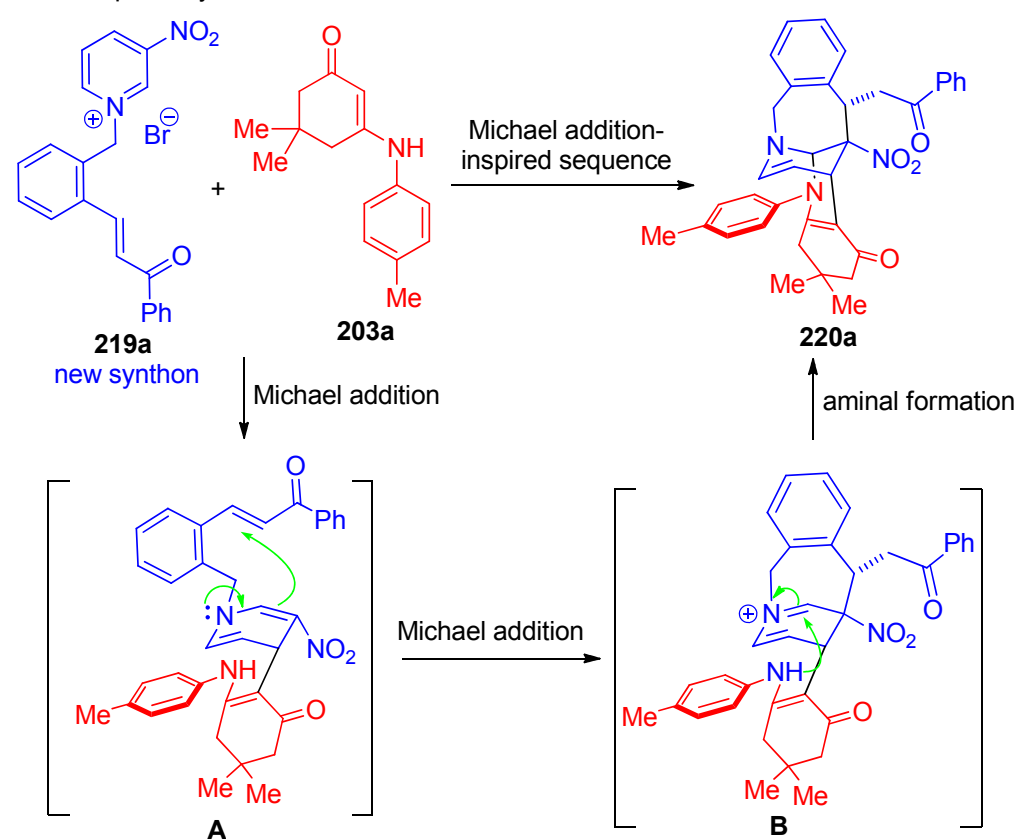

图式 53 新型 $N$-查尔酮吡啶盐及其与烯胺酮的串联环化反应

Scheme 53 New chalcone-based pyridinium salts and their cascade annulations with enaminones 


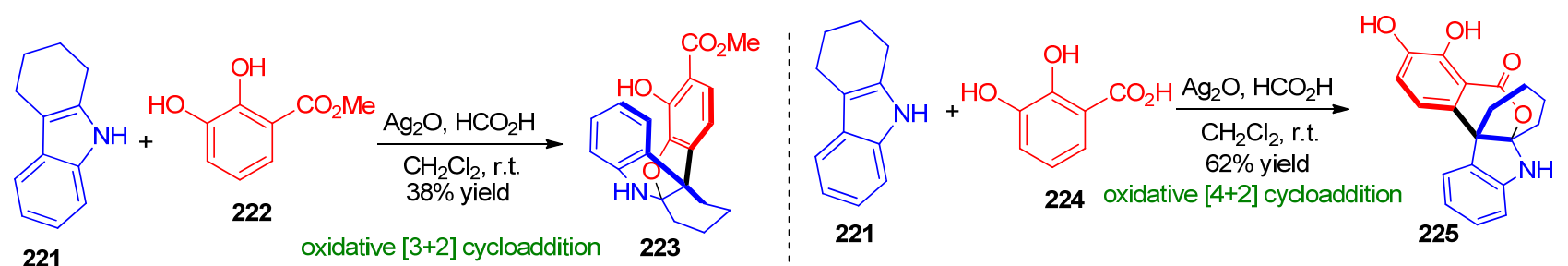

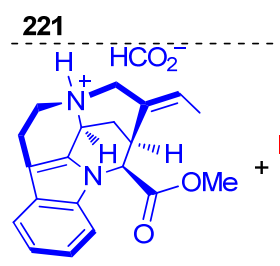

Pleiocarpamine (226) Formate salt oxidative [4+2] cycloaddition

224
Vocalgine A (227)

(Voacanga grandifolia)

Revised structure

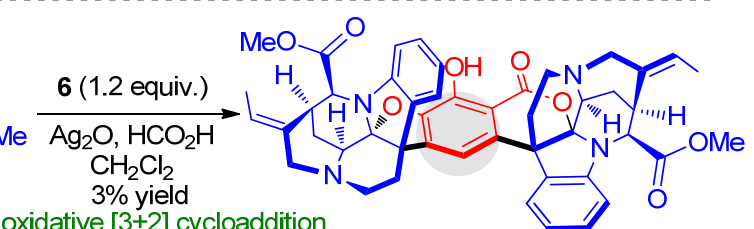

Bipleiophylline (228)

(Alstonia angustifolia)

图式 54 环加成反应在天然产物 Vocalgine A 和 Bipleiophylline 中的应用

Scheme 54 Application of cycloaddition in total synthesis of vocalgine A and bipleiophylline
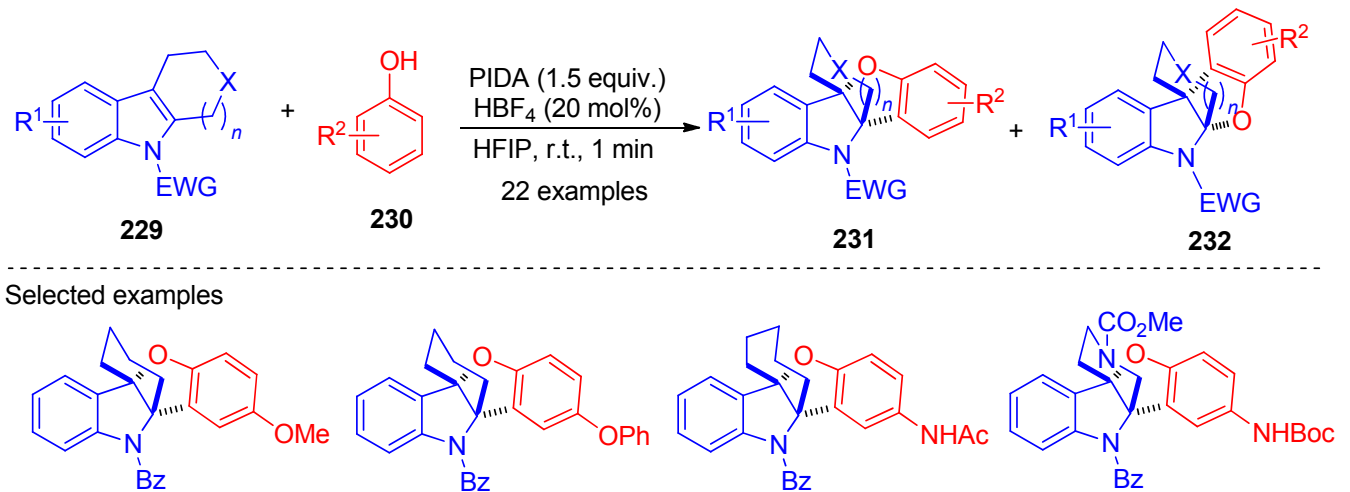

231a, 52\%; 232a, 46\% 231b, 47\%; 232b, n.d. $\quad$ 231c, $59 \%$; 232c, 36\% $231 d, 25 \%$; 232d, n.d.

Synthetic application in the total synthesis of phalarine
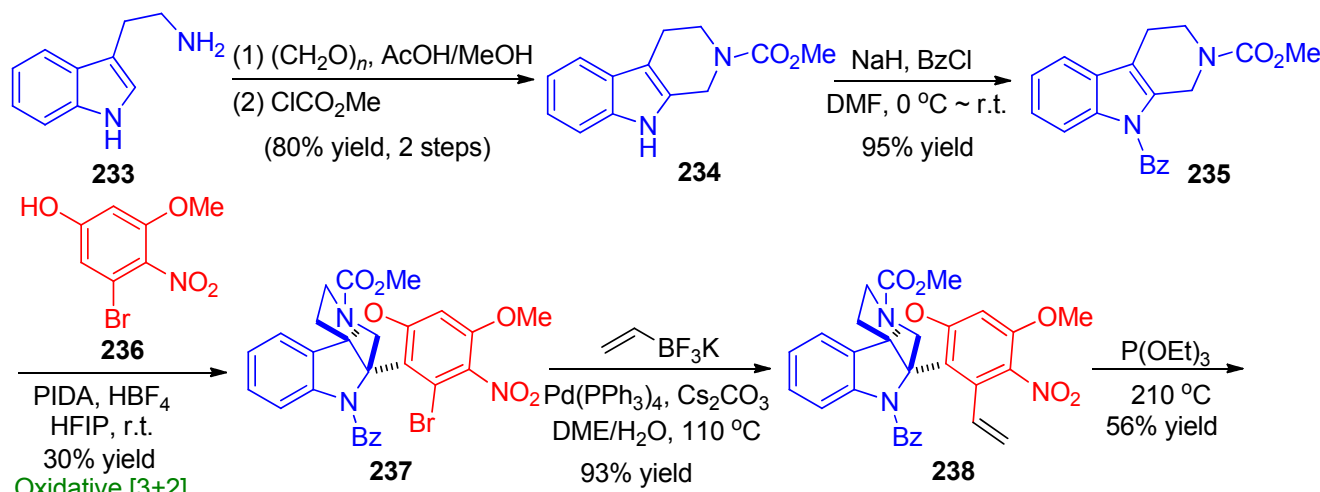

Oxidative

cycloaddition

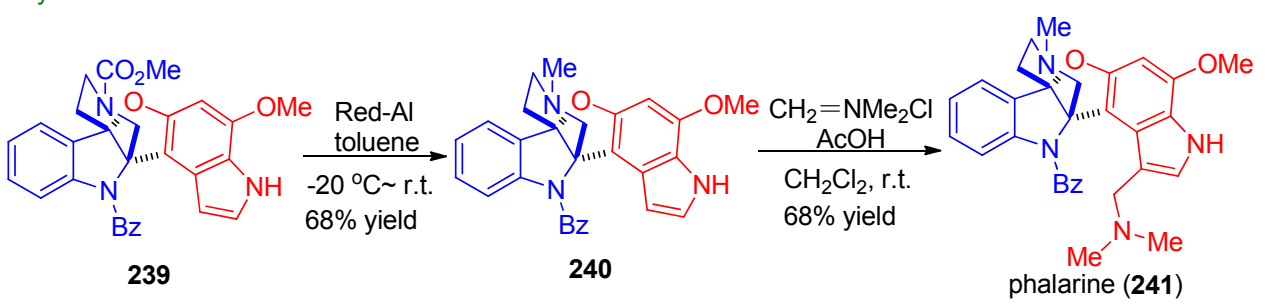

图式 55 取代吲哚与苯酚参与的氧化 $[3+2]$ 环加成反应及其作为关键反应步骤合成 phalarine

Scheme 55 Oxidative [3+2] cycloaddition of substituted indoles with phenols and its application as key step in the total synthesis of phalarine 

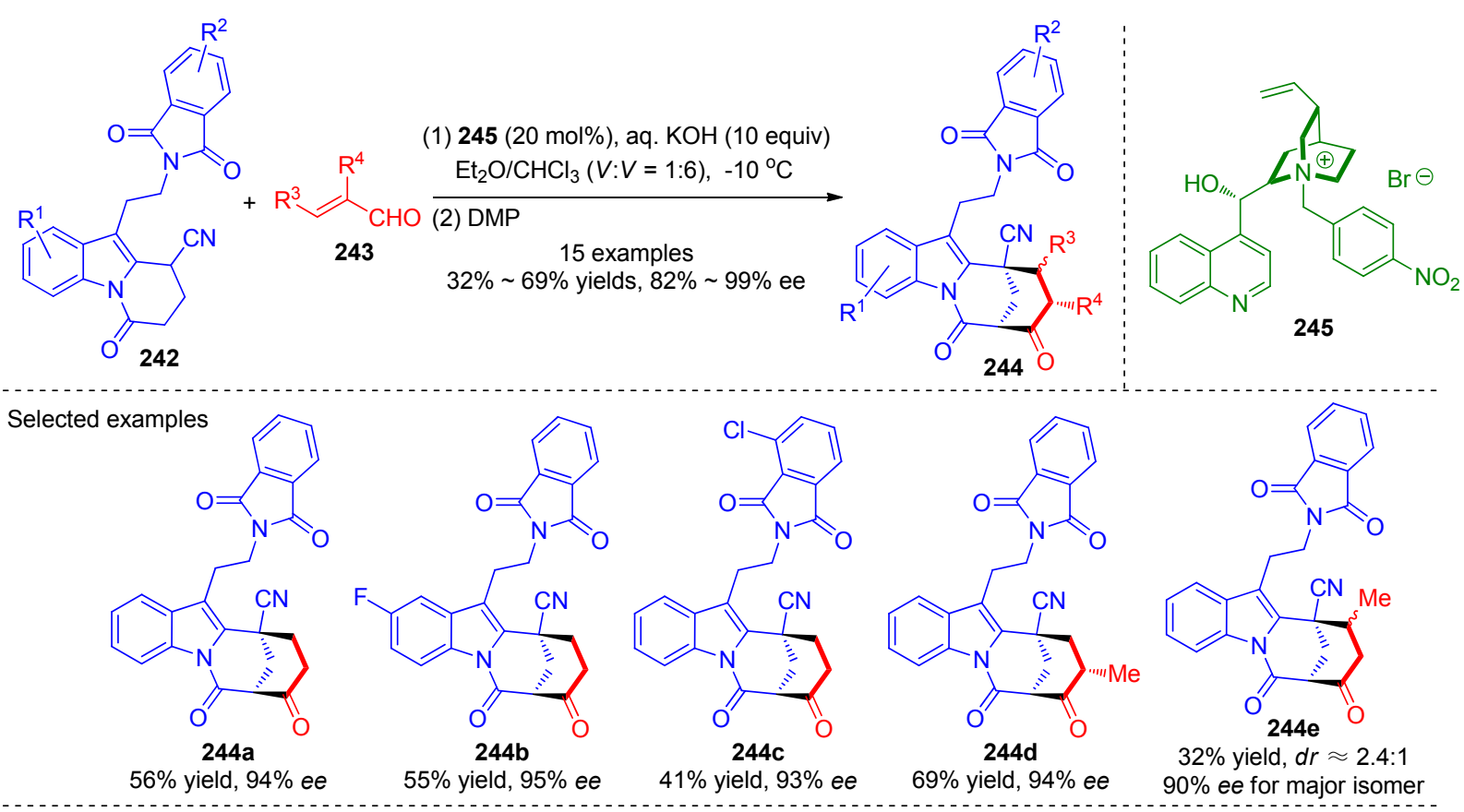

Synthetic application in the total synthesis of tronocarpine

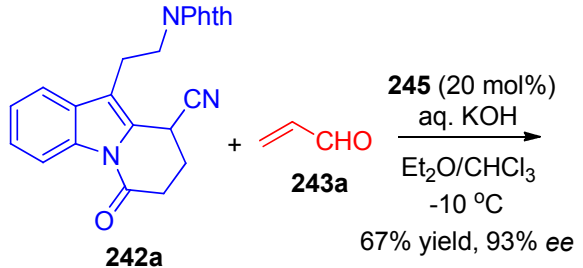<smiles>CC(C)(C)O[C@@H]1C(=O)n2c(c(CCNc3ccccc3)c3ccccc32)[C@@]2(C#N)CC[C@@H](O)[C@H]1C2</smiles>

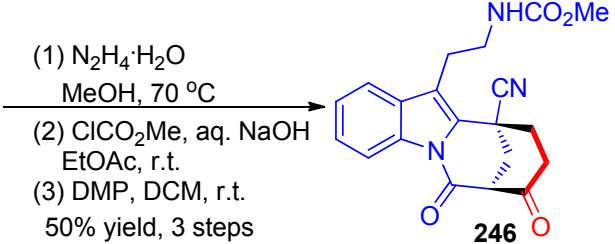

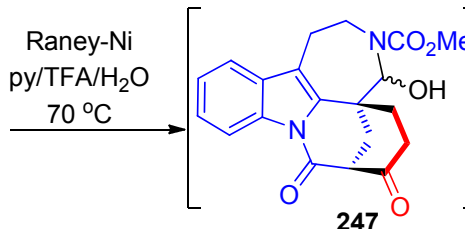

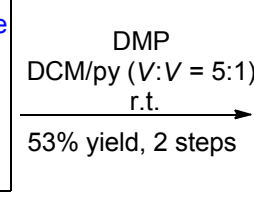

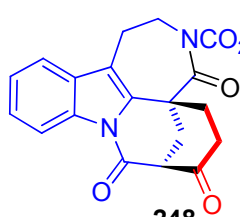

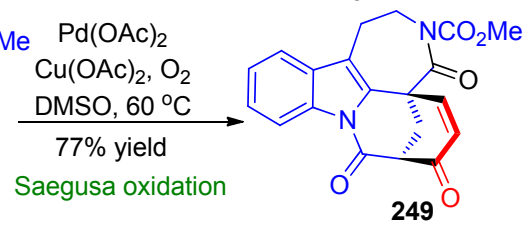

$\mathrm{I}_{2}$, py, DMAP $\mathrm{Pd}\left(\mathrm{PPh}_{3}\right)_{2} \mathrm{Cl}_{2}$ 248 $249^{\circ}$

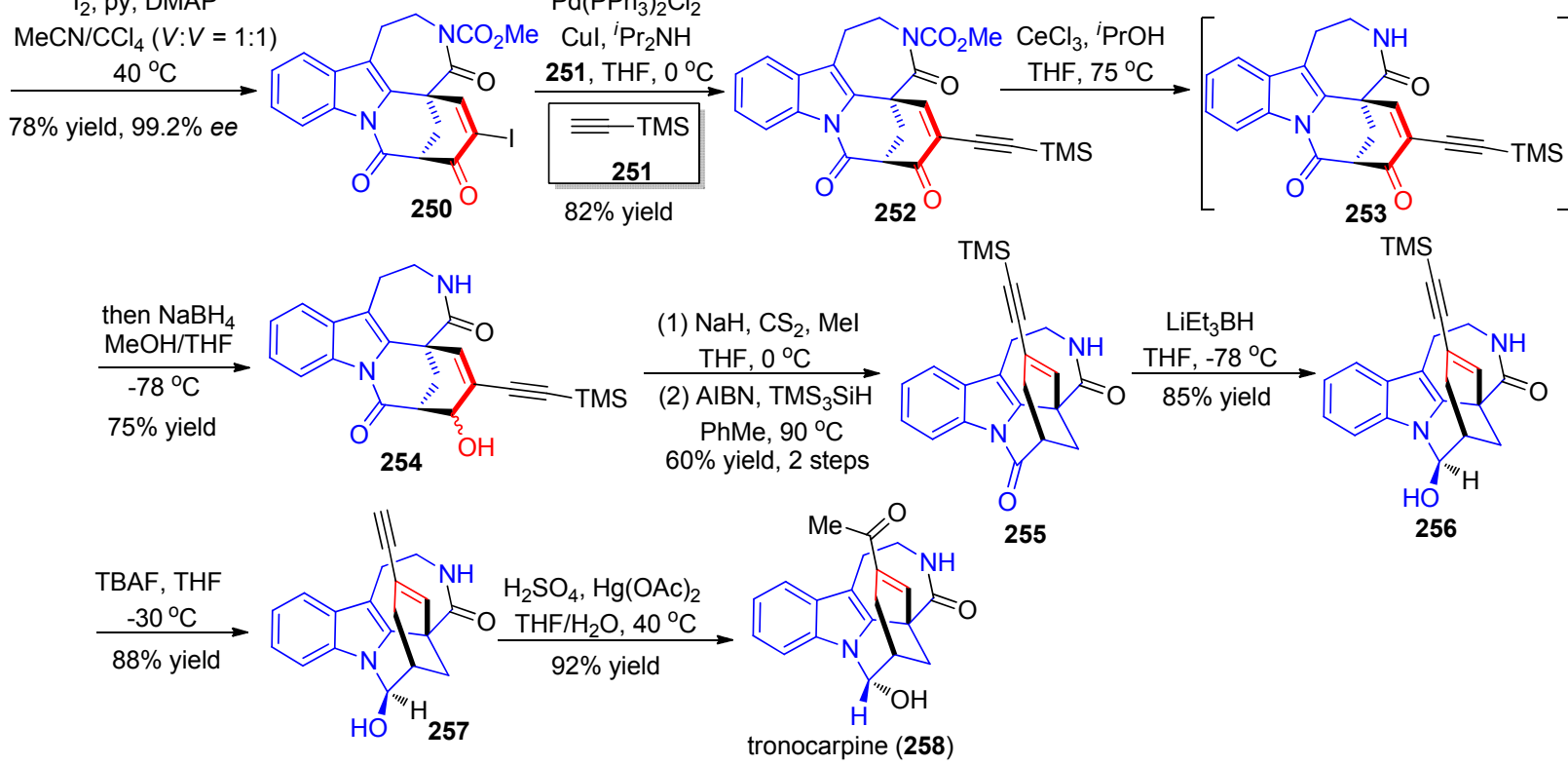

图式 56 不对称 Michael 加成/Aldol 串联反应作为关键步骤合成 $(+)$-tronocarpine

Scheme 56 Asymmetric Michael addition/aldol sequential process as key step to construct $(+)$-tronocarpine 
胺衍生物 242 与丙烯醛 243 发生不对称的 Michael 加成/ Aldol 串联反应，建立了合成 tronocarpine 桥环骨架的通 用方法. 随后, 作者利用发展的不对称串联反应方法学 作为关键合成步骤, 完成了天然产物 $(+)$-tronocarpine (258)的首次不对称全合成. 如 Scheme 56 所示, 作者先 以 242a 和丙烯醛 243a 为起始原料, 通过不对称 Michael 加成/Aldol 串联反应, 完成氮杂 [3.3.1]桥环的构筑. 再 通过还原/半缩醛化/氧化, 实现七元环内酰胺的 248 的 合成. 接下来, 248 通过 Saegusa 氧化、碘代、Sonogashira 反应、还原、水解等多步化学转化, 最终可以得到天然 产物 $(+)$-tronocarpine (258).

2015 年, 祖连锁课题组 ${ }^{[80]}$ 以吲哚醇 259 为原料, 在
酸的作用下，通过发生氮杂频哪醇重排反应，实现了桥 环吲哚啉 260 和假吲哚 261 的高效选择性合成. 如 Scheme 57 (a)所示, R 对反应的选择性影响巨大. 当 R 为 叔丁基酯或氨基、羟基等亲核基团时，得到了桥环产物 260 ; 而当 $\mathrm{R}$ 为乙酯或其他非亲核的烷基时，后续的亲 核加成反应无法进行, 仅仅得到假吲哚 261. 该反应具 有广泛的底物普适性, $N$ 的保护基不仅仅局限于 Boc 基 才，甲酸甲酯或烷基也可以得到不错的反应结果 $(260 \mathrm{e}$, $85 \% ; 260 f, 81 \%$ ). 另外, 3-烯吲哚也可以有效参与反应. 基于此，作者将氮杂频哪醇重排作为关键合成步骤，用 于 minfiensine 的形式全合成(Scheme 58). (a) Boc as the protecting group<smiles>[R]CC1(O)c2cc([R1])ccc2N(C(=O)OCc2ccco2)C12CCCC2</smiles>

259

Selected examples

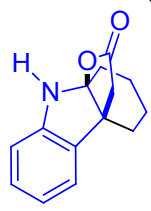

$\mathrm{R}=\mathrm{CO}_{2}{ }^{t} \mathrm{Bu}$ 260a, $97 \%$<smiles>CCOC(=O)CC12CCCCC1CCC2</smiles>

261a, 95\%<smiles>O=C1CC2(CCCC2)c2ccccc2N1</smiles>

260b, $60 \%$<smiles>N#CCC12CCCC(=Nc3ccccc31)C2</smiles>

261b, $98 \%$<smiles>O=C1CCC2(CCCC2)c2cc(I)ccc2N1</smiles>

260<smiles>[R]c1ccc2c(c1)C1(CP)CCCCC1=N2</smiles>

261

(b) other protecting group

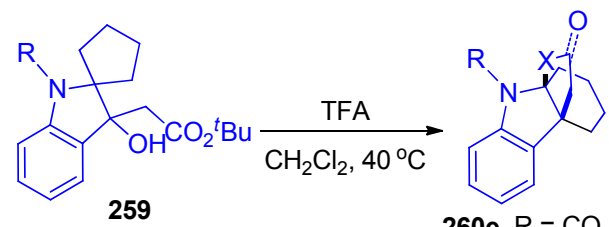

260e, $\mathrm{R}=\mathrm{CO}_{2} \mathrm{Me}, 85 \%$ 260f, $R=M e, 81 \%$

(c) trisubstituted alkenes as substrates

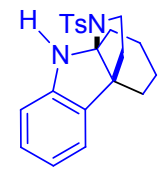

260c, $95 \%$

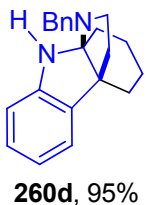<smiles>c1ccc(C23CCCCC2=Nc2ccccc23)cc1</smiles>

261c, $96 \%$<smiles>BrC12CCCC(=Nc3ccccc31)C2</smiles>

261d, $96 \%$

图式 57 氮杂-频哪醇重排构建桥环吲哚啉和假吲哚

Scheme 57 Aza-pinacol rearrangement for the synthesis of bridged indolines and indolenine

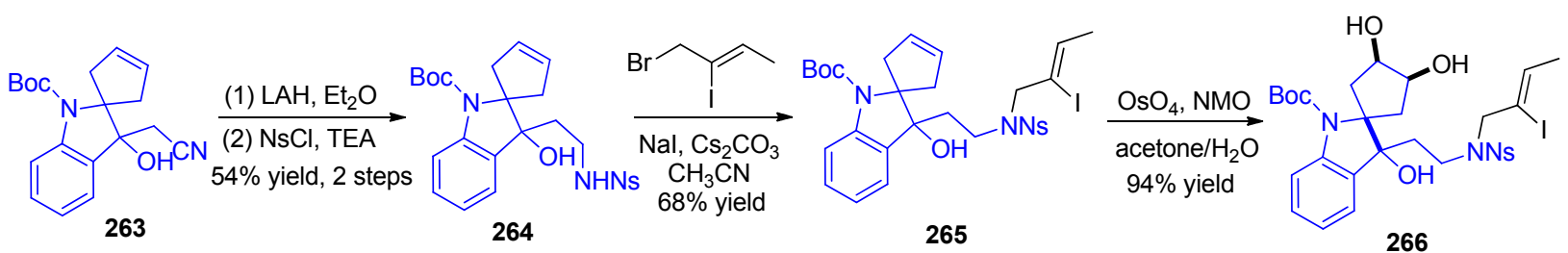

263

264

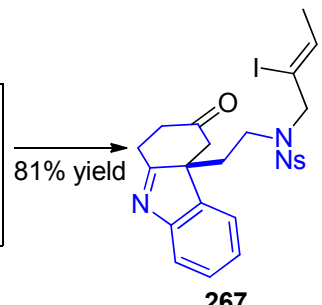

265

266

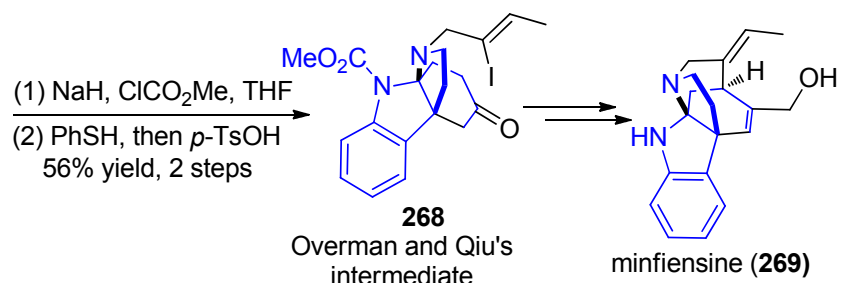

图式 58 氮杂频哪醇重排用于 minfiensine 的形式全合成

Scheme 58 Application of aza-pinacol rearrangement in the formal total synthesis of minfiensine 


\section{4 总结与展望}

桥环化合物在药物化学和有机合成等诸多领域都 具有重要的用途, 吸引了众多有机化学家广泛的研究兴 趣. 目前已发展了通过环加成反应和串联反应两种合成 策略构建桥环化合物的新方法和新手段, 从而成功合成 了系列结构复杂、多样的桥环化合物. 这些方法不但对 深入开展桥环化合物的合成研究具有一定的推动作用, 同时还为高效合成更复杂结构的桥环化合物提供新的 思路和方法, 有助于研究 “结构-性质” 构效关系.

虽然对于桥环化合物的合成已经发展了很多的方 法, 但这一领域的研究仍然有一些局限性, 还有很大的 进步空间. 首先, 很多合成方法主要集中于消旋体的合 成, 而对于手性桥环化合物的合成仍需大力发展, 部分 已发展的不对称合成的例子时常有收率低、立体选择性 和区域选择性不好的缺点. 其次, 反应的成键效率还不 太理想, 有些反应需要多步合成, 反应条件较为苛刻, 且部分例子收率较低. 再次, 有些反应底物类型或官能 团种类受限，尤其是对于串联反应，需要联接特定的官 能团和多重反应位点才能进行, 这无论是对产物的多样 性还是反应类型的多样性都是不利的. 因此, 发展条件 温和、高效高选择性、广谱的合成桥环化合物的方法, 进 一步扩展反应的类型和反应底物范围，仍是今后该领域 一项非常具有研究价值的工作. 另外, 探索这些新方法 和新策略合成的结构新型的桥环化合物在药物化学、材 料科学等方面的应用也是今后努力的方向. 随着化学工 作者在此研究领域的深入开展, 我们相信更多、更广、 更高效、立体选择性更好的反应将被陆续开发出来, 也 将在有机合成、药物化学、生命科学等相关领域得到更 广泛的应用。

\section{References}

[1] (a) Thopate, S. B.; Jadhav, S. B.; Nanubolu, J. B.; Chegondi, R. ACS Catal. 2019, 9, 10012.

(b) Gouse, S.; Reddy, N. R.; Baskaran, S. Org. Lett. 2019, 21, 3822. (c) Liu, Z. G.; Meng, Y. F.; Yuan, P. R.; Wang, Z. S.; Gao, J. M.; Zheng, H. J. Org. Lett. 2020, 22, 520.

[2] Chao, C. H.; Cheng, J. C.; Shen, D. Y.; Wu, T. S. J. Nat. Prod. 2014, 77, 22.

[3] Xu, J.; Wang, M. C.; Sun, X. S.; Ren, Q. H.; Cao, X. R.; Li, S.; Su, G. C.; Tuerhong, M.; Lee, D. H.; Ohizumi, Y.; Bartlam, M.; Guo, Y. Q.J. Nat.Prod. 2016, 79, 2924

[4] (a) Yan, Y. M.; Ai, J.; Zhou, L. L.; Chung, A. C. K.; Li, R.; Nie, J.; Fang, P.; Wang, X. L.; Luo, J.; Hu, Q.; Hou, F. F.; Cheng, Y. X. Org. Lett. 2013, 15, 5488.

(b) Riehl, P. S.; Richardson, A. D.; Sakamoto, T.; Schindler, C. S. Org. Lett. 2020, 22, 290.

[5] (a) Carroll, A. R.; Hyde, E.; Smith, J.; Quinn, R. J.; Guymer, G.; Forster, P. I. J. Org. Chem. 2005, 70, 1096.

(b) Martin, C. L.; Overman, L. E.; Rohde, J. M. J. Am. Chem. Soc. 2008, 130, 7568 .

[6] Bera, S.; Chatterjee, B.; Mondal, D. Eur. J. Org. Chem. 2018, 5337.

[7] (a) Shan, D.; Jia, Y. X. Chin. J. Org. Chem. 2013, 33, 1144 (in Chi- nese).

(单东, 贾彦兴, 有机化学, 2013, 33, 1144.)

(b) Yuan, K.; Jia, Y. X. Chin. J. Org. Chem. 2018, 38, 2386 (in Chinese).

(袁括，贾彦兴，有机化学，2018, 38, 2386.)

[8] (a) Liu, J. Y.; Liu, X.; Wu, J. L.; Li, C. C. Chem 2020, 6, 579. (b) Min, L.; Liu, X.; Li, C. C. Acc. Chem. Res. 2020, 53, 703. (c) Liu, X.; Hu, Y. J.; Fan, J. H.; Zhao, J.; Li, S. P.; Li, C. C. Org. Chem. Front. 2018, 5, 1217.

[9] (a) Mu, W. H.; Cheng, R. J.; Shang, Y. W.; He, R. Z.; Li, D. L.; Fu, M. Chin. J. Org. Chem. 2018, 38, 1327 (in Chinese). (母伟花，程瑞姣，商英伟，贺仁泽，李冬丽，傅冕，有机化学， 2018, 38, 1327.)

(b) Feng, T.; Du, J.; Yan, W. J.; Li, X.; Gao, W. C.; Chang, H. H.; Wei, W. L. Chin. J. Org. Chem. 2019, 39, 1197 (in Chinese) (冯涛，杜佳，间文静，李兴，高文超，常宏宏，魏文珑，有机化 学, 2019, 39, 1197.)

(c) Cai, Q. Chin. J. Chem. 2019, 37, 946

(d) Zhang, Y. C.; Jiang, F.; Shi, F. Acc. Chem. Res. 2020, 53, 425.

[10] (a) O'Hagan, D. Nat. Prod. Rep. 2000, 17, 435.

(b) Cheenpracha, S.; Ritthiwigrom, T.; Laphookhieo, S. J. Nat. Prod. 2013, 76, 723.

[11] Narayan, R.; Bauer, J. O.; Strohmann, C.; Antonchick, A. P.; Waldmann, H. Angew. Chem., Int. Ed. 2013, 52, 12892.

[12] Wang, Z.; Wang, D. C.; Xie, M. S.; Qu, G. R.; Guo, H. M. Org. Lett. 2020, 22, 164

[13] Jia, Z. J.; Shan, G.; Daniliuc, C. G.; Antonchick, A. P.; Waldmann, H. Angew. Chem., Int. Ed. 2018, 57, 14493.

[14] Suga, H.; Yoshiwara, M.; Yamaguchi, T.; Bando, T.; Taguchi, M.; Inaba, A.; Goto, Y.; Kikuchi, A.; Itoh, K.; Toda, Y. Chem. Commun. 2019, 55, 1552.

[15] Kang, Z. H.; Zhang, D.; Hu, W. H. Org. Lett. 2017, 19, 3783.

[16] Leitch, J. A.; Rogova, T.; Duarte, F.; Dixon, D. J. Angew. Chem., Int. Ed. 2020, 59, 4121.

[17] Liu, X. Y.; Yin, Y. L.; Jiang, Z. Y. Chem. Commun. 2019, 55, 11527.

[18] (a) Rao, Y.; Yin, G. D. Org. Biomol. Chem. 2013, 11, 6029. (b) Gao, Y. Q.; Hou, Y.; Zhu, L. M.; Chen, G. Z.; Xu, D. Y.; Zhang, S. Y.; He, Y. P.; Xie, W. Q. RSC Adv. 2019, 9, 29005.

[19] Zhu, Y. S.; Zhou, J.; Jin, S. J.; Dong, H. H.; Guo, J. M.; Bai, X. G.; Wang, Q. L.; Bu, Z. W. Chem. Commun. 2017, 53, 11201.

[20] Zhu, Y. S.; Guo, J.; Jin, S. J.; Guo, J. M.; Bai, X. G.; Wang, Q. L.; Bu, Z. W. Org. Biomol. Chem. 2018, 16, 1751.

[21] Jin, S. J.; Guo, J.; Fang, D. M.; Huang, Y. W.; Wang, Q. L.; Bu, Z. W. Adv. Synth. Catal. 2019, 361, 456

[22] Balha, M.; Pan, S. C. J. Org. Chem. 2018, 83, 14703.

[23] Balha, M.; Soni, C.; Pan, S. C. Eur. J. Org. Chem. 2019, 2552.

[24] Ramachary, D. B.; Anif Pasha, M.; Thirupathi, G. Angew. Chem., Int. Ed. 2017, 56, 12930.

[25] Cui, R. R.; Ye, J. X.; Li, J.; Mo, W. H.; Gao, Y.; Chen, H. J. Org. Lett. 2020, 22, 116.

[26] Buev, E. M.; Stepanov, M. A.; Moshkin, V. S.; Sosnovskikh, V. Y. Org. Lett. 2020, 22, 631.

[27] Fan, W. T.; Li, N. K.; Xu, L. M.; Qiao, C. H.; Wang, X. W. Org. Lett. 2017, 19, 6626.

[28] Guo, J. M.; Bai, X. G.; Wang, Q. L.; Bu, Z. W. J. Org. Chem. 2018 , $83,3679$.

[29] You, Z. H.; Chen, Y. H.; Tang, Y.; Liu, Y. K. Org. Lett. 2018, 20, 6682.

[30] Liu, H. X.; Wang, Y.; Guo, X. Y.; Huo, L. Q.; Xu, Z. F.; Zhang, W. M.; Qiu, S. X.; Yang, B.; Tan, H. B. Org. Lett. 2018, 20, 546.

[31] Guo, J. M.; Miao, H. J.; Zhao, Y.; Bai, X. G.; Zhu, Y. S.; Wang, Q. L.; Bu, Z. W. Chem. Commun. 2019, 55, 5207.

[32] Huo, L. Q.; Dong, C. M.; Wang, M. M.; Lu, X. X.; Zhang, W. G.; Yang, B.; Yuan, Y. F.; Qiu, S. X.; Liu, H. X.; Tan, H. B. Org. Lett. 2020, 22, 934

[33] Zheng, X.; Yang, W. L.; Liu, Y. Z.; Wu, S. X.; Deng, W. P. Adv. Synth. Catal. 2018, 360, 2843.

[34] Gao, R. D.; Xu, Q. L.; Zhang, B.; Gu, Y. T.; Dao, L. X.; You, S. L. 
Chem.-Eur. J. 2016, 22, 11601.

[35] Luo, M. P.; Chen, J. X.; Yu, L. Q.; Wei, W. G. Eur. J. Org. Chem. 2017, 2017, 2652

[36] Wang, W. B.; Bai, X. G.; Jin, S. J.; Guo, J. M.; Zhao, Y.; Miao, H. J.; Zhu, Y. S.; Wang, Q. L.; Bu, Z. W. Org. Lett. 2018, 20, 3451.

[37] (a) Wang, Y.; Li, H. M.; Wang, Y. Q.; Liu, Y.; Foxman, B. M.; Deng, L. J. Am. Chem. Soc. 2007, 129, 6364

(b) Singh, R. P.; Bartelson, K.; Wang, Y.; Su, H.; Lu, X. J.; Deng, L. J. Am. Chem. Soc. 2008, 130, 2422.

(c) Soh, J. Y. T.; Tan, C. H. J. Am. Chem. Soc. 2009, 131, 6904.

(d) Bartelson, K. J.; Singh, R. P.; Foxman, B. M.; Deng, L. Chem. Sci. 2011, 2, 1940.

[38] Shi, L. M.; Dong, W. W.; Tao, H. Y.; Dong, X. Q.; Wang, C. J. Org. Lett. 2017, 19, 4532.

[39] Cole, C. J. F.; Fuentes, L.; Snyder, S. A. Chem. Sci. 2020, 11, 2175.

[40] Saktura, M.; Grzelak, P.; Dybowska, J.; Albrecht, Ł. Org. Lett. 2020, 22, 1813.

[41] Yarlagadda, S.; Sankaram, G. S.; Balasubramanian, S.; Reddy, B. V. S. Org. Lett. 2018, 20, 4195.

[42] Katritzky, A. R.; Dennis, N. Chem. Rev. 1989, 89, 827.

[43] Fu, C. C.; Lora, N.; Kirchhoefer, P. L.; Lee, D. R.; Altenhofer, E.; Barnes, C. L.; Hungerford, N. L.; Krenske, E. H.; Harmata, M. Angew. Chem., Int. Ed. 2017, 56, 14682.

[44] Villar, L.; Uria, U.; Martínez, J. I.; Prieto, L.; Reyes, E.; Carrillo, L.; Vicario, J. L. Angew. Chem., Int. Ed. 2017, 56, 10535.

[45] Lam, H.; Qureshi, Z.; Wegmann, M.; Lautens, M. Angew. Chem., Int. Ed. 2018, 57, 16185.

[46] Xu, C. R.; Wang, K. X.; Li, D. W.; Lin, L. L.; Feng, X. M. Angew. Chem., Int. Ed. 2019, 58, 18438.

[47] Suneja, A.; Loui, H. J.; Schneider, C. Angew. Chem., Int. Ed. 2020, $59,5536$.

[48] Reddy, K. N.; Chary, D. Y.; Sridhar, B.; Reddy, B. V. S. Org. Lett. 2019, $21,8548$.

[49] Feng, J.; Zhou, M.; Lin, X. Z.; Lu, A.; Zhang, X. Y.; Zhao, M. Org. Lett. 2019, 21, 6245.

[50] Cheng, X.; Cao, X.; Zhou, S. J.; Cai, B. G.; He, X. K.; Xuan, J. Adv. Synth. Catal. 2019, 361, 1230.

[51] Pirovano, V.; Brambilla, E.; Moretti, A.; Rizzato, S.; Abbiati, G.; Nava, D.; Rossi, E. J. Org. Chem. 2020, 85, 3265.

[52] Wang, H. K.; Zeng, T. L.; Li, X. H.; Wang, S. M.; Xiao, W. G.; Liu, L. Y.; Chang, W. X.; Li, J. Org. Chem. Front. 2020, 7, 1809.

[53] Li, Q.; Jiang, G. J.; Jiao, L.; Yu, Z. X. Org. Lett. 2010, 12, 1332.

[54] (a) Mei, G. J.; Yuan, H.; Gu, Y. Q.; Chen, W.; Chung, L. W.; Li, C. C. Angew. Chem., Int. Ed. 2014, 53, 11051.

(b) Mei, G. J.; Liu, X.; Qiao, C.; Chen, W.; Li, C. C. Angew. Chem., Int. Ed. 2015, 54, 1754.

[55] Liu, J. Y.; Wu, J. L.; Fan, J. H.; Yan, X.; Mei, G. J.; Li, C. C. J. Am. Chem. Soc. 2018, 140, 5365.

[56] Liu, X.; Liu, J. Y.; Wu, J. L.; Huang, G. C.; Liang, R.; Chung, L. W.; Li, C. C. J. Am. Chem. Soc. 2019, 141, 2872.

[57] Liu, X.; Liu, J. Y.; Zhao, J.; Li, S. P.; Li, C. C. Org. Lett. 2017, 19, 2742.

[58] Xu, J. H.; Zheng, S. C.; Zhang, J. W.; Liu, X. Y.; Tan, B. Angew. Chem., Int. Ed. 2016, 55, 11834.

[59] Hu, B. W.; Zhang, X. Y.; Mo, Y. H.; Li, J. Z.; Lin, L. L.; Liu, X. H.;
Feng, X. M. Org. Lett. 2020, 22, 1034.

[60] Ma, Y. L.; Wang, K. M.; Huang, R.; Lin, J.; Yan, S. J. Green Chem. $\mathbf{2 0 1 7}, 19,3574$.

[61] Guo, S. H.; Liu, Y. F.; Wang, Y. P.; Zhang, X. Y.; Fan, X. S. J. Org. Chem. 2020, 85,8910 .

[62] (a) Zhou, J. Chem.-Asian J. 2010, 5, 422.

(b) Grondal, C.; Jeanty, M.; Enders, D. Nat. Chem. 2010, 2, 167.

(c) Lu, L. Q.; Chen, J. R.; Xiao, W. J. Acc. Chem. Res. 2012, 45, 1278.

(d) Pellissier, H. Adv. Synth. Catal. 2012, 354, 237.

(e) Chen, D. F.; Han, Z. Y.; Zhou, X. L.; Gong, L. Z. Acc. Chem. Res. 2014, 47, 2365.

(f) Volla, C. M. R.; Atodiresei, I.; Rueping, M. Chem. Rev. 2014, 114, 2390.

(g) Wang, Y.; Lu, H.; Xu, P. F. Acc. Chem. Res. 2015, 48, 1832.

[63] Tokimizu, Y.; Oishi, S.; Fujii, N.; Ohno, H. Angew. Chem. Int. Ed. 2015, 54, 7862.

[64] Han, Y. P.; Song, X. R.; Qiu, Y. F.; Li, X. S.; Zhang, H. R.; Zhu, X. Y.; Liu, X. Y.; Liang, Y. M. Org. Lett. 2016, 18, 3866.

[65] Du, J. Y.; Ma, Y. H.; Meng, F. X.; Chen, B. L.; Zhang, S. L.; Li, Q. L.; Gong, S. W.; Wang, D. Q.; Ma, C. L. Org. Lett. 2018, 20, 4371.

[66] Ma, S. S.; Yu, A. M.; Zhang, L.; Meng, X. T. J. Org. Chem. 2018, 83,5410 .

[67] Gurubrahamam, R.; Nagaraju, K.; Chen, K. Chem. Commun. 2018, $54,6048$.

[68] Yang, S. M.; Karanam, P.; Wang, M.; Jang, Y. J.; Yeh, Y. S.; Tseng, P. Y.; Ganapuram, M. R.; Liou, Y. C.; Lin, W. W. Chem. Commun. 2019, 55, 1398.

[69] Wang, C.; Chen, Y. H.; Wu, H. C.; Wang, C.; Liu, Y. K. Org. Lett. 2019, 21, 6750.

[70] Borade, B. R.; Nomula, R.; Gonnade, R. G.; Kontham, R. Org. Lett. 2019, 21, 2629.

[71] Jiang, B.; Xiao, B. X.; Ouyang, Q.; Liang, H. P.; Du, W.; Chen, Y. C. Org. Lett. 2019, 21, 3310.

[72] Jakkampudi, S.; Konda, S.; Arman, H.; Zhao, J. C. G. Adv. Synth. Catal. 2020, 362, 2419.

[73] Wang, S. D.; Guillot, R.; Carpentier, J. F.; Sarazin, Y.; Bour, C.; Gandon, V.; Lebœuf, D. Angew. Chem., Int. Ed. 2020, 59, 1134.

[74] Miao, H. J.; Wang, L. L.; Han, H. B.; Zhao, Y. D.; Wang, Q. L.; Bu, Z. W. Chem. Sci. 2020, 11, 1418.

[75] Bai, X. G.; Miao, H, J.; Zhao, Y.; Wang, Q. L.; Bu, Z. W. Org. Lett. 2020, 22, 5068.

[76] Wang, L. L.; Han, H. B.; Cui, Z. H.; Zhao, J. W.; Bu, Z. W.; Wang, Q. L. Org. Lett. 2020, 22, 873.

[77] Lachkar, D.; Denizot, N.; Bernadat, G.; Ahamada, K.; Beniddir, M. A.; Dumontet, V.; Gallard, J. F.; Guillot, R.; Leblanc, K.; N'nang, E. O.; Turpin, V.; Kouklovsky, C.; Poupon, E.; Evanno, L.; Vincent, G. Nat. Chem. 2017, 9, 793.

[78] Li, L.; Yuan, K.; Jia, Q. L.; Jia, Y. X. Angew. Chem., Int. Ed. 2019, 58,6074 .

[79] Tan, D. X.; Zhou, J.; Liu, C. Y.; Han, F. S. Angew. Chem., Int. Ed. 2020, 59, 3834.

[80] Yu, Y. Y.; Li, G.; Jiang, L.; Zuo, L. S. Angw. Chem., Int. Ed. 2015, $54,12627$. 